MÁRCIO ZAMBOTI FORTES

\title{
PRIORIZAÇÃO DE ALTERNATIVAS DE GERAÇÃO TERMELÉTRICA DISTRIBUÍDA
}

São Paulo 
MÁRCIO ZAMBOTI FORTES

\section{PRIORIZAÇÃO DE ALTERNATIVAS DE GERAÇÃO TERMELÉTRICA DISTRIBUÍDA}

Tese apresentada à Escola Politécnica da Universidade de São Paulo para obtenção do Título de Doutor em Engenharia Elétrica

Área de Concentração:

Sistemas de Potência

Orientador:

Prof. Dr. Marcos Roberto Gouvêa

São Paulo

2007 
Este exemplar foi revisado e alterado em relação à versão original, sob responsabilidade única do autor e com a anuência de seu orientador.

São Paulo, de setembro de 2007.

Assinatura do autor

Assinatura do orientador

FICHA CATALOGRÁFICA

Fortes, Marcio Zamboti

Priorização de alternativas de geração termelétrica distribuí-

da / M.Z. Fortes. -- ed.rev. -- São Paulo, 2007.

$112 \mathrm{p}$.

Tese (Doutorado) - Escola Politécnica da Universidade de São Paulo. Departamento de Engenharia de Energia e Automação Elétricas.

1.Geração de energia elétrica 2.Termoeletricidade 3.Planejamento energético I.Universidade de São Paulo. Escola Politécnica. Departamento de Engenharia de Energia e Automação Elétricas II.t. 


\section{AGRADECIMENTOS}

A Escola Politécnica da USP que proporcionou a oportunidade desta pesquisa, e em especial ao Professor Dr. Marcos Roberto Gouvêa, que orientou e dedicou-se na busca da melhor proposta metodológica.

A Renata minha esposa, que com muito amor me incentivou nestes 5 anos, sacrificando alguns momentos de lazer e compreendendo a ausência para a concretização deste "sonho".

Aos meus pais pais (Agostinho e Vanda) e irmãos (Fábio, Fernando e João Paulo) que me motivaram em todos os momentos da elaboração deste trabalho.

Aos amigos da TIVIT (em especial Bruno, André e Carmen), da USS (Jesivan, Hélio, Evandro, Thomaz, Roberto e Helder), Thiago Farqui, Roberto Schellemberg, Brian Green, Fernando Nuno, Ricardo Aquino, Eduardo Clemente, David, Marco Aurélio Souza, José Thomaz e Carlos Simão.

A todos os colegas da JP Engenharia, AMBEV, Surebeam, USS, TIVIT, Acelétron e IBMEC, que durante estes anos me incentivaram.

Aos colegas do ENERQ que contribuíram nas discussões, debates e procura de dados técnicos.

Aos meus familiares (em especial Milton Zschaber, Carmen, Rogério, Ricardo, e Andréa) pela força e torcida.

A minha avó Maria (que apesar de não estar mais conosco), acompanhou todos os passos deste caminho. 
LISTA DE ABREVIAÇÕES

LISTA DE FIGURAS

LISTA DE TABELAS

RESUMO

ABSTRACT

\section{APRESENTAÇÃO E OBJETIVO}

1.1 Apresentação 15

$\begin{array}{lll}1.2 & \text { Objetivo } & 17\end{array}$

\section{FUNDAMENTAÇÃO CONCEITUAL}

2.1 Considerações Gerais 19

2.2 Conceituação de Geração Distribuída 19

2.3 Programas de Desenvolvimento da Geração Distribuída 20

2.3.1 Fontes Alternativas de Energia Elétrica 20

2.3.2 Conta de Consumo de Combustíveis (CCC) 20

2.3.3 Selo Combustível Social 21

2.3.4 Programa Nacional de Produção e Uso do Biodiesel (PNPB) 22

2.4 Custos Ambientais e Protocolo de Kyoto 22

2.4.1 Custos Operacionais e Ambientais 22

2.4.2 Protocolo de Kyoto 23

2.5 Aspectos Sociais $\quad 25$

2.5.1 Índice de Desenvolvimento Humano - IDH 25

2.5.2 Aspectos Legais da Legislação Tributária 27

2.5.3 Responsabilidade Social 29

2.6 Outros Temas de Interesse 29

2.6.1 Universalização 29

2.6.2 Custos de Geração e Transmissão Elétrica 30

2.6.3 Potenciais de Fontes Primárias 31

2.6.4 Caracterização dos Combustíveis 31

2.6.4.1 Gás Natural 31 


\section{TECNOLOGIA DE GERAÇÃO DISTRIBUIDA}

3.1 Turbina à Gás em Ciclo Combinado 35

3.2 Turbina à Vapor 36

3.3 Geradores com Biodiesel 37

3.4 Motores Dual com Óleo Combustível / Gás Natural 38

4. VIABILIDADE ECONÔMICA DA GERAÇÃO DISTRIBUIDA

4.1 Considerações Gerais 40

4.2 Receita Operacional Liquida (ROL) 40

4.3 Despesa Operacional 43

4.4 Margem e Taxa de Retorno 45

5. VIABILIDADE AMBIENTAL DA GERAÇÃO DISTRIBUIDA

5.1 Considerações Gerais 47

5.2 Padrões de Concentrações de Poluentes Aéreos 47

5.3 Cálculo das Emissões 53

\section{MODELO PROPOSTO}

6.1 Formulação do Problema 54

6.2 Conceitos Básicos e Terminologia 55

6.3 Diretrizes da Solução Proposta 58

6.4 Estrutura do Modelo Proposto 60

6.5 Descrição dos Blocos 62

6.5.1 Caracterização do Caso e das Alternativas 62

6.5.2 Base de Dados 65

6.5.3 Cálculo dos Indicadores 67

6.5.4 Resultados Parciais e Priorização de Alternativas 72

\section{ESTUDO DE CASO}

7.1 Considerações Gerais 73

7.2 Bloco I - Caracterização do Caso e das Alternativas 73 
7.3.1 Informações Técnicas das Máquinas 78

7.3.2 Dados Sócio-Econômicos e Geográficos da Micro Região 78

7.3.3 Caracterização dos Combustíveis 78

7.3.4 Limites de Emissões Ambientais $\quad 79$

7.3.5 Outros Custos e Informações Associadas 79

7.4 Bloco III - Cálculo dos Indicadores 79

$\begin{array}{lll}7.4 .1 & \text { Alternativas } & 79\end{array}$

7.4.1.1 Indicador Econômico E(i,j) 80

7.4.1.2 Indicador Social S(i,j) 81

7.4.1.3 Indicador Ambiental A(i,j) 82

7.5 Resultados Parciais e Priorização de Alternativas 83

7.6 Comentários dos Resultados e Análise de Sensibilidade 88

8. CONCLUSÃO, CONTRIBUIÇÕES E PROSSEGUIMENTO DA PESQUISA

8.1 Conclusão 90

8.2 Contribuições 91

8.3 Temas para Prosseguimento da Pesquisa 92

REFERÊNCIAS BIBLIOGRÁFICAS 99

ANEXOS

ANEXO I - POTENCIALIDADES REGIONAIS DE GERAÇÃO DE ENERGIA COM CANA DE AÇUCAR E ÓLEOS VEGETAIS 98

ANEXO II - LOCALIZAÇÃO DE CITY-GATES E MAPA SISTEMA $\begin{array}{ll}\text { GASODUTOS BRASIL } & 101\end{array}$

ANEXO III - ESTOQUE DE DIESEL E SIMILARES 103

ANEXO IV - EMISSÕES COM GERAÇÃO A TV 105 
ANEXO V - CUSTO DE CONEXÃO DE GERAÇÃO COM O SISTEMA DE DISTRIBUIÇÃO 106

ANEXO VI - ESTUDO DE CASO - MICRO REGIÃO PORTO SEGURO 109 


\section{LISTA DE ABREVIAÇÕES}

ANEEL - Agência Nacional de Energia Elétrica

ANP - Agência Nacional do Petróleo, Gás Natural e Biocombustíveis

BNDES - Banco Nacional de Desenvolvimento Econômico e Social

CCC - Conta de Consumo de Combustíveis

CENBIO - Centro de Referência de Biomassa

CIGRE - International Council on Large Electric Systems

CER - Certificado de Emissões Reduzidas

CHESF - Companhia Hidrelétrica do São Francisco

COFINS - Contribuição para o Financiamento da Seguridade Social

CONAMA- Conselho Nacional do Meio Ambiente

CTE - Central Termelétrica

DOA - Despesa Operacional Anual

EC - Emenda Constitucional

FPE - Fundo de Participação dos Estados

FPM - Fundo de Participação dos Municípios

FUNDEF - Fundo de Manutenção e Desenvolvimento do Ensino Fundamental e de Valorização do Magistério

FUNDEB - Fundo de Manutenção e Desenvolvimento da Educação Básica e de Valorização dos Profissionais de Educação

GD - Geração Distribuída

GEE - - Gases do Efeito Estufa

GN - Gás Natural

GWP - Global Warming Potencial

IBAMA - Instituto Brasileiro do Meio Ambiente e dos Recursos Naturais Renováveis

IBGE - Instituto Brasileiro de Geografia e Estatística

ICMS - Imposto sobre Circulação de Mercadorias e Serviços

IDH - Índice de Desenvolvimento Humano

IPI - Imposto sobre Produtos Industrializados

IPEA - Instituto de Pesquisas Econômicas e Aplicadas

IEEE - Institute of Electrical and Electronics Engineers

IPTU - Imposto sobre a Propriedade Predial e Territorial Urbana 


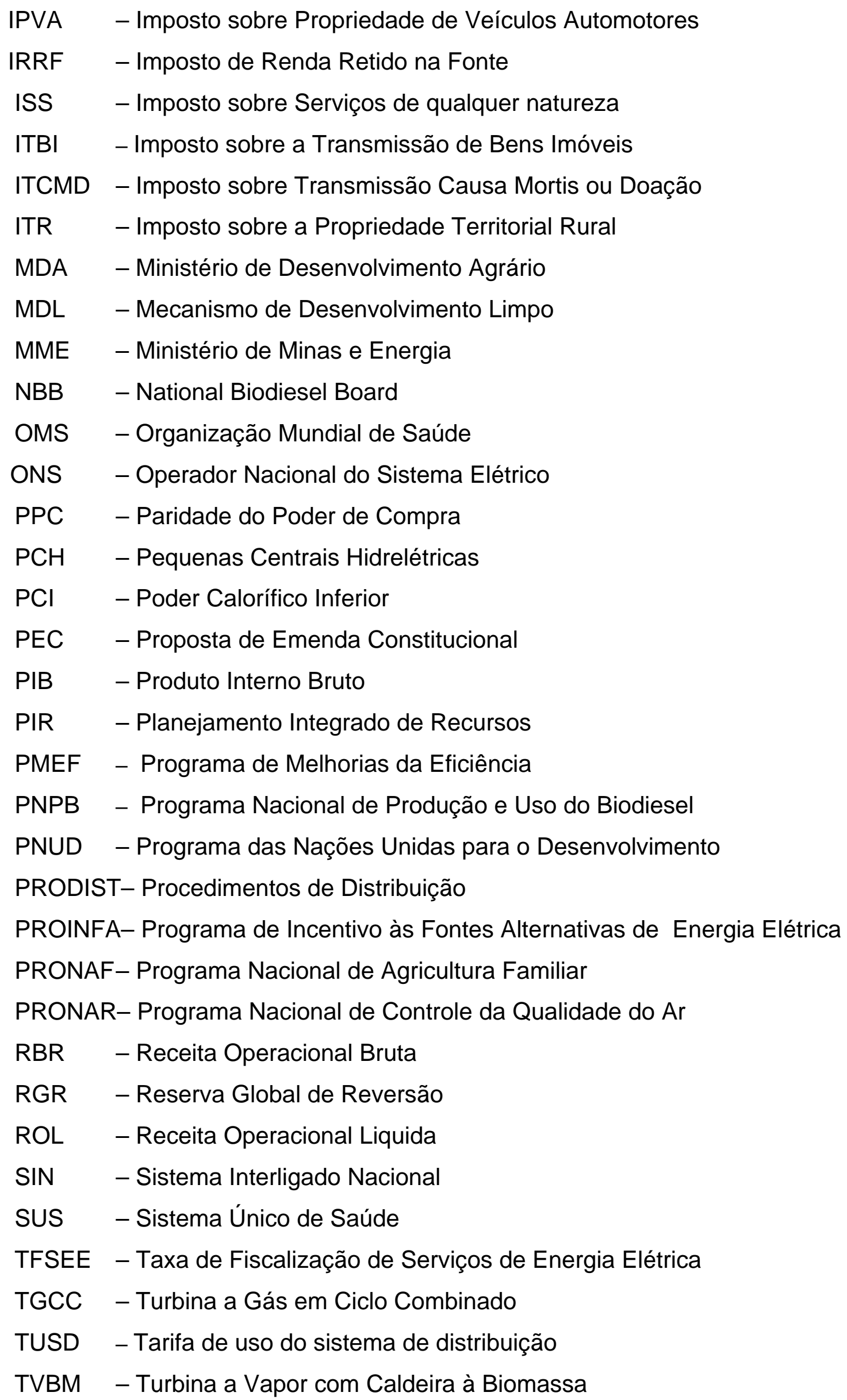


USEPA - U.S. Environmental Protection Agency 


\section{LISTA DE FIGURAS}

Figura 1 - Evolução IDH's de países da América Latina entre 1975-2004 26

Figura 2 - Estrutura da Metodologia em Blocos 60

Figura 3 - Resultados Caso Base 84

Figura 4 - Resultados CE - Caso Econômico 85

Figura 5 - Resultados CS - Caso Social

Figura 6 - Resultados CA - Caso Ambiental 86

Figura 7 - Resultado CES - Caso Econômico Social 86

Figura 8 - Resultados Caso CSA - Caso Social Ambiental 87

Figura 9 - Resultados Caso CEA - Caso Econômico Ambiental 87

Figura 10- Indicadores Globais para as Alternativas 88 


\section{LISTA DE TABELAS}

Tabela 1 - Capacidade Produção de Biodiesel por Estado - Atual e Futura 31

Tabela 2 - Especificação do GN 32

Tabela 3 - Composição do Gás Natural das principais jazidas supridoras da demanda brasileira 33

Tabela 4 - Características Geradores a GN 35

Tabela 5 - Emissões de Poluentes das Misturas 37

Tabela 6 - Controle catalítico das emissões em motores diesel, g/km 39

Tabela 7 - Padrões de qualidade de Ar - OMS adaptada 47

Tabela 8 - Padrões Nacionais de Qualidade Ar segundo CONAMA (adap.) 49

Tabela 9 - Padrões de qualidade do Ar para o Estado de São Paulo 49

Tabela 10- Emissões combustível gasoso 50

Tabela 11- Emissões óleo combustível 50

Tabela 12- Emissões com biomassa 51

Tabela 13- Emissões para Turbina à Gás 51

Tabela 14- Emissões com Motores de Combustão Interna 51

Tabela 15- Padrões emissões brasileiros processos combustão externa 52

Tabela 16- Exemplo de pesos para indicadores 64

Tabela 17- Caracterização dos Cenários $\quad 64$

Tabela 18- Distribuição de pesos para o caso base 76

Tabela 19- Caracterização de Cenários 78

Tabela 20- Caracterização das Alternativas para o caso Porto Seguro 80

Tabela 21- Resultados do Indicador Econômico - Cenário Otimista 81

Tabela 22- Resultados do Indicador Social - Cenário Otimista 82

Tabela 23- Resultados do Indicador Ambiental - Cenário Otimista 83

Tabela 24- Pesos gerais considerados nas simulações do caso 84 


\section{RESUMO}

Os efeitos multidisciplinares presentes em projetos de engenharia, sobretudo naqueles de infra-estrutura, têm alargado as fronteiras de pesquisas para avaliá-los não só do ponto de vista convencional técnico econômico, mas também sob a ótica ambiental e social. Por outro lado, o investidor que tradicionalmente buscava oportunidades apenas considerando o desempenho econômico e financeiro, atualmente é levado a analisar os empreendimentos também no âmbito social e ambiental.

Fundamentado em várias informações disponíveis em bases de dados constituídas por diversas instituições, o modelo desenvolvido nesta pesquisa é uma solução para avaliar o mérito de um empreendimento de geração distribuída de origem térmica, considerando os aspectos econômico, social e ambiental, por meio de indicadores que quantificam, objetivamente, aspectos econômicos como taxa de retorno de capital e margem liquida, bem como fatores sociais como o impacto na educação, na saúde, na renda e no emprego e ainda, verifica o atendimento das restrições ambientais.

A solução apresentada, sem prejuízo da avaliação dos aspectos pragmáticos relativos à viabilidade econômica e respeito à regulamentação ambiental, traz uma forma simples e clara de atribuir um grau de mérito agregado às alternativas de implementação de geração distribuída, considerando a intensidade da responsabilidade social subjetiva do investidor.

A análise de cenários e de sensibilidade diante da variação de parâmetros diversos que o modelo oferece, permite aferir o grau de robustez e de importância da precisão de variáveis específicas.

Embora não esgote o tema, o modelo apresentado contribui para estimular diferentes formas de avaliar e priorizar multidisciplinarmente a implementação um empreendimento de geração distribuída, podendo inclusive, se prestar como indicador de financiamentos privilegiados ou outros incentivos do gênero. 


\begin{abstract}
The multidiscipline effects in engineering projects, mainly in those of infrastructure, have extended the borders of research to not only evaluate them of the conventional point of view, economic and technical, but also environmental and social. On the other hand, the investor who traditionally searched alternatives only considering the economic and financial performance currently is taken to analyze also the social and environmental aspects.
\end{abstract}

Based on some information available in several institutions databases, the model developed in this research is a solution to evaluate the merit of an enterprise of distributed generation of thermal origin, considering the economic, social and environmental aspects, using merit indexes that quantify, directly, economic aspects as capital return tax and operating income eliminates, as well as social factors like the impact in the education, health, income and employment rates and still, it verifies the attendance of the environmental restrictions.

The solution presented, without damage the evaluation of the pragmatic aspects related to economic viability and respect to the ambient regulation, brings a simple and clear form to attribute a merit degree of aggregate to the alternatives to embed distributed generation, considering the intensity of the subjective social responsibility of the investor.

The analysis of sceneries and sensitivity ahead of the diverse parameter variation that the model offers, allows investigating the robustness degree and accuracy importance of specific variable.

Although it does not deplete the subject, the presented model is an important contribution to stimulate a form to evaluate and to prioritize the multidiscipline implementation to a distributed generation enterprise, also being able, to be used as financial index or other incentives of the sort. 


\section{APRESENTAÇÃO E OBJETIVO}

\subsection{Apresentação}

Os efeitos multidisciplinares presentes em projetos de engenharia, sobretudo naqueles de infra-estrutura, tem alargado as fronteiras de pesquisas para avaliá-los não só do ponto de vista convencional técnico econômico, mas também sob a ótica ambiental e social.

Por outro lado, o investidor que tradicionalmente buscava oportunidades apenas considerando o desempenho econômico e financeiro, atualmente é levado a analisar os empreendimentos também no âmbito social e ambiental.

Investir num negócio que apresente bom desempenho quanto aos impactos social e ambiental representa, além dos aspectos éticos, considerável retorno econômicofinanceiro suportado por fatores muitas vezes intangíveis, mas significativos como imagem, facilidade de obtenção de financiamentos privilegiados, aceitação e colaboração da comunidade local e das instituições de modo geral, dentre outros. Multiplicam-se os agentes da sociedade que zelam para que os empresários tenham responsabilidade social em seus investimentos.

A geração de energia elétrica é um exemplo que se enquadra perfeitamente nesse conceito. Embora a evidência desse enquadramento se faça de forma mais explícita nos grandes empreendimentos de geração de energia, as pequenas centrais também podem e devem ser vistas como oportunidades de trazer benefícios além da produção de energia e seu retorno econômico e financeiro. As pequenas centrais podem contribuir para o desenvolvimento regional em aspectos como a educação, a saúde e a renda. 
Há um grande desafio na constituição de modelos de viabilidade que permitam a avaliação de um empreendimento de geração de energia sob os vários impactos que causa no ambiente sócio econômico ao qual é inserido. A dificuldade repousa tanto na carência de ferramental específico, como na complexidade da representação adequada e objetiva dos fatores influentes.

A recente transformação que o setor elétrico brasileiro esta passando, desestatizando o controle operacional das concessionárias de geração e de distribuição de energia elétrica, ao lado da carência de investimentos, sobretudo na expansão da geração, vem criando interessantes oportunidades de investimentos em geração distribuída.

Do exposto, fica estabelecido um quadro onde há uma demanda de modelos de viabilidade de geração distribuída que considere, além dos aspectos convencionais econômicos e financeiros, aqueles que influam na responsabilidade social do empreendimento.

Nesse contexto, esta pesquisa busca propor um modelo de viabilidade de geração distribuída que considere os aspectos econômico, ambiental e social, respeitando e quantificando as visões subjetivas do investidor, que possua interesse em avaliar projetos nos contextos dos programas governamentais de incentivo a produção de energia elétrica.

Longe da pretensão de esgotar esse assunto complexo, é proposto um modelo que analisa e prioriza alternativas de geração, considerando diferentes tecnologias e instalações de geração alocadas em diversos municípios pré-selecionados. O desempenho de cada solução é analisado, considerando parâmetros técnicos da instalação no atendimento da demanda prevista e também parâmetros sócioeconômicos que caracterizam o tecido social onde o empreendimento é inserido. Os aspectos subjetivos são representados por ponderações que o investidor aplica no modelo. As alternativas recebem figuras de mérito que as qualificam, de forma específica e agregada, conforme os aspectos econômico, ambiental e social. 
O resultado deste trabalho representa uma importante contribuição para a pesquisa de modelos de viabilidade de geração distribuída, sob um olhar multidisciplinar.

O trabalho está estruturado em oito capítulos, sendo que o próximo a este, apresenta alguns conceitos e fundamentos que alicerçam a pesquisa.

O terceiro capítulo mostra, sucintamente, as tecnologias de geração distribuída de energia abordadas neste trabalho, com suas principais características necessárias para o estudo de viabilidade.

O capítulo quarto e o quinto abordam, respectivamente, aspectos econômicos e ambientais da viabilidade de geração distribuída de energia elétrica.

O sexto capítulo trata da proposta de solução, especificando o modelo de viabilidade e o sétimo apresenta estudo de caso.

Finalmente, o oitavo traz a conclusão, a contribuição desse trabalho e temas que, embora identificados no transcorrer do trabalho não foram desenvolvidos e se apresentam como possíveis assuntos para o prosseguimento desta linha de pesquisa.

\subsection{Objetivo}

O objetivo deste trabalho é propor uma metodologia para avaliação de alternativas de implementação de geração distribuída constituída por centrais termelétricas, considerando aspectos sociais, ambientais, tecnológicos e econômicos, bem como, características regionais, fontes de combustíveis fosseis e renováveis disponíveis e ainda, aspectos tecnológicos dos equipamentos de geração, como: Turbinas à Gás, Turbinas à Vapor, Motores Diesel/Gás Natural e Geradores com Biodiesel.

Devido ao caráter probabilístico das condições de contorno que cercam empreendimentos dessa natureza, o modelo deve considerar incertezas na previsão de variáveis sujeita a fatores intangíveis como preço de venda da energia, custo de insumos primários e de mercado de energia e de demanda. 
O modelo deve dedicar especial atenção à quantificação do impacto social vis-à-vis ao papel auxiliar no desenvolvimento regional do negócio de geração de energia, em consonância com os atuais conceitos de consciência social de empreendimentos de qualquer natureza. Desta forma, o modelo a ser proposto deve contemplar instrumentos para promover e incentivar a projetos de Geração Distribuída que resultem em benefícios sociais. 


\section{FUNDAMENTAÇÃO CONCEITUAL}

\subsection{Considerações Gerais}

Este capítulo situa o tema tratado neste trabalho no ambiente tecnológico, econômico, ambiental e social que abriga as instalações de pequeno porte de geração de energia elétrica.

Assim são apresentados conceitos abrangendo assuntos relacionados com 0 impacto socioeconômico e ambiental da instalação de uma geração de energia elétrica, de forma a fundamentar a proposição de modelo de avaliação de alternativas de implementação de geração distribuída, considerando aspectos sociais e ambientais vis-à-vis a viabilidade econômica.

Tais assuntos abordam Programas de Apoio a Geração Distribuída, Custos Ambientais, Protocolo de Kyoto, Índice de Desenvolvimento Humano, Aspectos Sociais da Legislação Tributária, Biodiesel, dentre outros.

\subsection{Conceituação de Geração Distribuída}

Existem muitas definições para Geração Distribuída (GD), segundo a International Council on Large Electric Systems (CIGRE), geração distribuída é a geração que não é planejada de modo centralizado, nem despachada de forma centralizada, não havendo portanto um órgão que comande a operação das unidades de GD. De acordo com o Institute of Electrical and Electronics Engineers (IEEE), geração descentralizada é uma central de geração pequena o suficiente para estar conectada à rede de distribuição e próxima do consumidor.

A Agência Nacional de Energia Elétrica (ANEEL) conceitua GD conforme documento Procedimentos da Distribuição - PRODIST [3], como: “... produção de energia elétrica proveniente de empreendimentos de agentes concessionários, permissionários ou autorizados conectados diretamente no sistema elétrico de 
distribuição do comprador, exceto as usinas hidrelétricas maiores que $30 \mathrm{MW}$ e termelétricas com eficiência energética menor que 75\%. Os empreendimentos termelétricos que utilizem biomassa ou resíduos de processo não estão limitados ao percentual de eficiência. Incluem-se ainda na Geração Distribuída as usinas hidrelétricas menores que $1 \mathrm{MW}$ e termelétricas menores que $5 \mathrm{MW}$, que estão dispensadas de concessão, permissão ou autorização. A Geração Distribuída não é despachada centralizadamente pelo Operador Nacional do Sistema Elétrico (ONS)".

Nesta pesquisa consideramos GD unidades menores que $30 \mathrm{MW}$, que podem ou não ser conectadas a rede de distribuição da concessionária, atendendo a consumidores exclusivos, regiões isoladas ou gerando para o sistema interligado.

\subsection{Programas de Desenvolvimento da Geração Distribuída}

\subsubsection{FONTES ALTERNATIVAS DE ENERGIA ELÉTRICA}

Em abril de 2002, foi criado o Programa de Incentivo às Fontes Alternativas de Energia Elétrica (PROINFA), através da Lei $n^{\circ} 10.438$ e depois revisado pela Lei $n^{\circ}$ 10.762 em novembro de 2003, pela qual o Banco Nacional de Desenvolvimento Econômico e Social (BNDES) incentiva com financiamento de até $70 \%$ do valor total de projetos de geração de energia elétrica a partir de fontes renováveis (excluindo bens e serviços importados e aquisição de terrenos) como: Biomassa, Eólicas e Pequenas Centrais Hidrelétricas ( $\left.\mathrm{PCH}^{\prime} \mathrm{s}\right)$, com o valor de compra de energia garantido para o pagamento do empréstimo. Este programa coordenado pelo Ministério das Minas e Energia (MME), estabelece a contratação de $3.300 \mathrm{MW}$ de energia no Sistema Interligado Nacional (SIN).

\subsubsection{CONTA DE CONSUMO DE COMBUSTÍVEIS (CCC)}

A Conta de Consumo de Combustíveis (CCC) é um fundo recolhido dos todos consumidores de energia elétrica do país para subsidiar os custos devidos à geração de energia baseada em combustíveis fósseis, tanto no sistema interligado quanto no sistema isolado. As distribuidoras de energia recolhem mensalmente as 
cotas que lhes cabem e repassam esses valores para a tarifa de energia elétrica. Estes recursos são administrados pela Eletrobrás.

Esse incentivo, que vigora até 2022, pode beneficiar a geração por fonte renovável no sistema isolado, que substitui termelétricas que utilizem combustível derivado do petróleo. Em 2002, a CCC somou um valor da ordem de R\$ 2,8 bilhões [2].

\subsubsection{SELO COMBUSTÍVEL SOCIAL}

O Selo Combustível Social é um componente de identificação concedido pelo Ministério do Desenvolvimento Agrário (MDA) aos produtores de biodiesel que promoverem a inclusão social e o desenvolvimento regional por meio de geração de emprego e renda para os agricultores familiares enquadrados nos critérios do Programa Nacional de Agricultura Familiar (PRONAF).

Para obter o selo deve-se seguir a Instruções Normativas Nos 1 e 2 do Ministério de Desenvolvimento Agrário, datadas de 05 de julho e 30 de novembro de 2005, respectivamente.

Por meio desse Selo, o produtor de biodiesel tem acesso a alíquotas de PIS/Pasep e Contribuição para o Financiamento da Seguridade Social (COFINS) com coeficientes de redução diferenciados, bem como melhores condições de financiamentos junto ao BNDES e suas Instituições Financeiras Credenciadas que possuam condições especiais de financiamento para projetos com esse Selo. $O$ produtor de biodiesel também poderá usar o Selo para fins de promoção comercial de sua empresa.

O Selo é concedido para os produtores de biodiesel que comprarem matéria-prima da agricultura familiar em percentual mínimo de 50\% região Nordeste e Semi-árido; $10 \%$ na região Norte e Centro Oeste e 30\% região Sudeste e Sul e ainda fizerem contratos negociados com os agricultores familiares, constando: prazo contratual, valor de compra e critérios de reajuste do preço contratado; condições de entrega da matéria-prima; salvaguardas de cada parte e identificação e concordância de uma representação dos agricultores que participam das negociações. Os produtores de 
Biodiesel que desejarem o Selo também deverão assegurar assistência e capacitação técnica aos agricultores familiares. Um exemplo é o da empresa Caramuru Alimentos S/A, certificada pelo Ministério de Desenvolvimento Agrário (MDA) em julho deste ano.

\subsubsection{PROGRAMA NACIONAL DE PRODUÇÃO E USO DO BIODIESEL (PNPB)}

Em dezembro de 2003, foi lançado por meio do Decreto $\mathrm{n}^{\circ} 10.093$, o Programa Nacional de Produção e Uso do Biodiesel (PNPB), que incentiva a implantação da produção e uso desse combustível de forma sustentável, com enfoque na inclusão social e no desenvolvimento regional, via geração de emprego e renda. Esse programa também visa reduzir a importação de óleo diesel.

Em janeiro de 2005, foi publicada a Lei 11.097 que dispõe sobre a introdução do Biodiesel na matriz energética brasileira, estabelecendo um percentual de $5 \%$ de adição do Biodiesel ao Diesel a partir de 2013. Com base nesta legislação vários trabalhos de Pesquisa e Desenvolvimento foram iniciados como podem ser vistos em [6], mas sem metodologia para avaliação efetiva de projetos com foco social, econômico e ambiental.

\subsection{Custos Ambientais e Protocolo de Kyoto}

\subsubsection{CUSTOS OPERACIONAIS E AMBIENTAIS}

Há várias informações na literatura sobre custos operacionais e custos atribuídos às emissões, que podem ser obtidos por informativos técnicos de plantas de médio porte em ciclo combinado [12] ou até pequenas plantas em ciclo combinado [11].

Em Negri [35] é apresentado um modelo especifico para avaliação de inserção de Centrais Termelétricas (CTE's) avaliando emissão e dispersão de $\mathrm{NO}_{\mathrm{x}}$. Pode-se encontrar várias informações referentes a custos operacionais de CTE's genéricas por meio de projetos básicos [45] e avaliações de sistemas específicos como sistemas de biogás [11]. 
Com relação aos aspectos ambientais, a publicação [30] faz uma análise especifica das variáveis ambientais em projetos de Geração, com destaque para uma avaliação dos riscos envolvidos em um projeto de Geração Eólica.

\subsubsection{PROTOCOLO DE KYOTO}

O Protocolo de Kyoto que abrange alguns gases de efeito estufa (GEE) como: Dióxido de Carbono $\left(\mathrm{CO}_{2}\right)$, Metano $\left(\mathrm{CH}_{4}\right)$, Óxido Nitroso $\left(\mathrm{N}_{2} \mathrm{O}\right)$, HidroFluor Carbonos (HFC's), PerFluor Carbonos (PFC's) e Hexafluoreto de Enxofre (SF6), apresenta em seu artigo 12, o conceito de Mecanismo de Desenvolvimento Limpo (MDL), para que os países não inclusos no Anexo I desse protocolo, possam auxiliar os países que estão no Anexo a atingirem seus compromissos de redução de GEE's. A idéia do MDL consiste em que cada tonelada de $\mathrm{CO}_{2}$ deixada de ser emitida ou retirada da atmosfera por um pais em desenvolvimento, poderá ser negociada no mercado mundial, criando um novo atrativo para redução das emissões globais. Com o Protocolo de Kyoto o aspecto ambiental ganhou destaque e com a criação do MDL, procurou-se uma forma de inserir os países em desenvolvimento em mercado novo e de grande potencial, já que as empresas que não conseguirem, ou não desejarem, reduzir suas emissões, poderão comprar Certificados de Emissões Reduzidas (CER) de paises em desenvolvimento e utilizá-los para cumprir suas metas acordadas em Kyoto. Por sua vez, os paises em desenvolvimento, deverão utilizar o MDL para promover o desenvolvimento sustentável. Dentro deste tema, diversos estudos estão sendo elaborados, como em [37] que apresenta um histórico deste mecanismo e suas perspectivas. Campos [13] apresenta estudos de casos para reflorestamento e em [14] estudos de CTE`s acopladas a PCH`s. Em [43] encontra-se um estudo avaliando-se alguns CTE`s com respeito a emissões com diversos tipos de combustíveis e o custo do $\mathrm{CO}_{2}$ evitado estimado e em [46] apresenta-se um trabalho similar com expansão de análise com energia nuclear.

Em [42] é apresentado um estudo do mercado de carbono no mundo, com projeções de negócios com esta "nova moeda ambiental". E em [21], destaca-se a crescente oportunidade da utilização de créditos de carbono de novos projetos. 
Cabe ressaltar que outros mecanismos de flexibilização foram incluídos no Protocolo, mas que não podem ser utilizados no Brasil, pois são específicos dos paises relacionados no Anexo I. Estes mecanismos são: Comércio de Emissões entre paises do Anexo I e a Implementação Conjunta que permite a transferências de créditos do país em que o projeto está sendo implementado para o pais emissor do CER quando houver participação deste ultimo pais, no que recebeu o projeto.

Existem projetos de sucesso funcionando no Brasil, utilizando créditos de carbono em seus negócios como o da Companhia Energética Santa Elisa de Sertãozinho, que estima obter 660.000 CER's no período entre 2003-2009, alcançando em torno de US\$ 3,3 milhões, com geração de energia a partir de bagaço de cana em sua CTE, além do projeto Nova Gerar, em Nova Iguaçu (RJ) e a Veja em Salvador (BA), que se utilizam de resíduos urbanos para geração de energia, entre outros [26].

Outro projeto em destaque é o Projeto Bandeirantes, que foi implantado com vistas à reduzir o metano gerado na decomposição dos resíduos orgânicos depositados no Aterro Bandeirantes, em São Paulo. O Aterro Bandeirantes é o maior de sua categoria no Brasil, recebendo diariamente cerca de 7.000 toneladas de resíduos sólidos, que devido a sua alta carga orgânica têm um enorme potencial de geração de metano.

Cada crédito de carbono equivale a uma tonelada de dióxido de carbono equivalente. Essa medida internacional foi criada com o objetivo de medir o potencial de aquecimento global (GWP - Global Warming Potencial) de cada um dos seis gases causadores do efeito estufa. Por exemplo, o metano possui um GWP de 21, pois seu potencial causador do efeito estufa é 21 vezes mais poderoso que o $\mathrm{CO}_{2}$. Portanto, uma tonelada de metano reduzida corresponde a 21 CRE's. Em países como a China e a Índia, utiliza-se na indústria de refrigeração, o gás HFC 23 que possui um GWP de 11.700, ou seja, muito mais poderoso que o $\mathrm{CO}_{2}$ e que o $\mathrm{CH}_{4}$. O preço de mercado da tonelada de carbono evitado tem sido bastante volátil. Segundo Jockyman [26], os negócios no Brasil em 2003 envolvendo CER's ficaram entre US\$ 3 a US\$ 6 por tonelada e em janeiro de 2007 foi negociado a $€ 16,25$ [52]. 
Em setembro de 2007 deverá ocorrer o primeiro leilão de créditos de carbono no Brasil.

Segundo Magalhães Sobrinho [31], as emissões evitadas para um sistema de cogeração com ciclo combinado com gás natural na indústria de papel e celulose podem atingir 0,023 ton $\mathrm{CO}_{2}$ evitado/MWh. Em projetos utilizando biomassa com cana de açúcar obtêm-se 0,4 ton $\mathrm{CO}_{2}$ evitado/MWh segundo Coelho [19] e com óleo de palma em substituição ao Óleo Diesel, pode-se obter segundo Araújo [4] 0,6 ton $\mathrm{CO}_{2}$ evitado/MWh.

\subsection{Aspectos Sociais}

\section{5.1 IDH - ÍNDICE DE DESENVOLVIMENTO HUMANO}

Até o aparecimento do conceito de Desenvolvimento Humano, o indicador utilizado para medir o desenvolvimento de um município, região ou país baseava-se apenas no calculo do PIB per capita.

O Índice de Desenvolvimento Humano (IDH) foi criado em 1990 pelos economistas Mahbud ul Hag e Amartya Sen que receberam prêmio Nobel por este trabalho. A concepção do IDH apresenta, além da característica renda, avaliada pelo PIB real per capita utilizando a metodologia conhecida como paridade do poder de compra PPC entre os países, considera também a longevidade da população, medida pela esperança de vida ao nascer e condições de saúde, e ainda, o grau de maturidade educacional, avaliado pela taxa de alfabetização dos adultos e uma avaliação combinada da taxa de matricula nos três níveis de ensino.

O Programa das Nações Unidas para o desenvolvimento (PNUD ou UNDP) calcula anualmente o IDH, fundamentando-se em relatórios sobre o Desenvolvimento Humano realizados por um grupo de trabalho constituído por especialistas independentes que avaliam a renda per capita, a longevidade, o nível de educação e também outros fatores como liberdade e dignidade. 
$\mathrm{O}$ IDH é indicador numérico entre zero e a unidade, onde zero corresponde ao menor nível e a unidade ao maior, classificando-se como elevado nível de desenvolvimento as comunidades com IDH maior do que 0,8, médio para valores entre 0,511 e 0,79 e baixo valores abaixo de 0,5, aproximadamente.

No Brasil a avaliação do IDH é elaborada pelo PNUD, em conjunto como IPEA (Instituto de Pesquisas Econômicas e Aplicadas) e a Fundação João Pinheiro, resultando em valores que evoluem de 0,679 em 1980 a 0,792 em 2004, que o coloca, atualmente, na $69^{\mathrm{a}}$ posição mundial entre 177 países avaliados, conforme apresentado na Figura 1 onde estão os IDH's de paises da América Latina para o período 1975 a 2004.

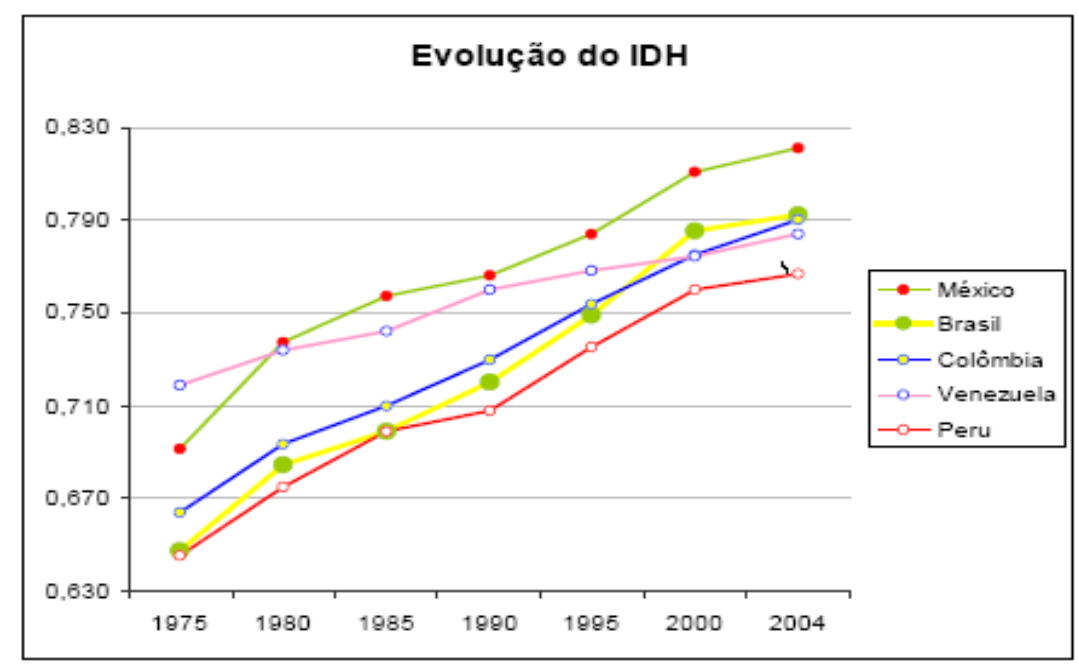

Figura 1 - Evolução IDH’s de países da América Latina entre 1975-2004 [40]

O nível de desenvolvimento humano de municípios é aferido considerando os mesmos fatores previstos no IDH : educação, longevidade e renda, além de outros indicadores entendidos como mais adequados para avaliar as condições de núcleos sociais menores. Em educação considera-se: taxa de alfabetização de pessoas acima de 15 anos de idade (com peso dois) e a taxa bruta de freqüência à escola (com peso um). Na dimensão longevidade, somente a dimensão esperança de vida ao nascer e na dimensão renda o critério é renda mensal per capita. 


\subsubsection{ASPECTOS SOCIAIS DA LEGISLAÇÃO TRIBUTÁRIA}

A aplicação dos recursos municipais nas áreas de saúde e educação é regulamentada pelo Conselho Nacional de Saúde através da Resolução No 322 de 8/05/2003 e do Ministério da Educação com a aprovação da Proposta de Emenda Constitucional (PEC) 536/1997 em 06/12/2006, que cria o Fundo de Manutenção e Desenvolvimento da Educação Básica e de Valorização dos Profissionais de Educação (Fundeb).

Para os aspectos relacionados á saúde, o Sistema Único de Saúde (SUS) criado pela Constituição Federal de 1988 e regulamentado pelas Leis n 8080/90 (Lei Orgânica da Saúde) e n 8142/90, diz que: "A União é o principal financiador da saúde publica no país e que o município é o principal responsável pela saúde pública da população". Em 2006, foi criado o "Pacto pela Saúde", em que o gestor municipal passa assumir imediata e paulatinamente a plenitude da gestão das ações e serviços de saúde oferecidos em seu território. O município que não possui todos os serviços de saúde, negocia com outras cidades de sua região ou com o Estado de forma a atender integralmente à saúde de sua população. Através desse "pacto" os Estados e Municípios recebem os recursos federais por meio de cinco blocos de financiamento, a saber: Atenção Básica, Atenção de Média e Alta Complexidade, Vigilância em Saúde, Assistência Farmacêutica e Gestão do SUS.

Os recursos destinados à saúde são definidos pela Emenda Constitucional (EC) $n^{\circ}$ 30 de 09/2000, que estabelece que os gastos da União devam ser iguais ao do ano anterior, corrigidos pela variação nominal do PIB.

Os Estados devem garantir 12\% de suas receitas para o financiamento da saúde, sabendo-se que as receitas do Estado são: Impostos (ICMS, IPVA e ITCMD), Transferências da União (cota-parte do FPE, cota-parte do IPI - Exportação e transferências da Lei Complementar n 87/96 - Lei Kandir), IRRF e outras receitas (dívida ativa de impostos e multas, juros de mora e correção monetária de impostos), dos quais são reduzidas as Transferências Constitucionais e Legais aos Municípios (25\% do ICMS, 50\% do IPVA e 25\% IPI - Exportação). 
Aos municípios cabe aplicar $15 \%$ de suas receitas para o SUS, sendo que as receitas do município são: Impostos Municipais (ISS, IPTU e ITBI), Transferências da União (cota-parte do FPM, cota-parte do ITR e transferências da Lei Complementar n 87/96 - Lei Kandir), IRRF, Transferências do Estado (cota-parte do ICMS, cota-parte do IPVA e cota-parte do IPI - Exportação) e outras receitas (dívida ativa de impostos e multas, juros de mora e correção monetária de impostos).

Para os aspectos relacionados à educação o Fundef foi substituído pelo Fundeb, que têm por objetivo a universalização do atendimento à educação básica, baseando-se na redistribuição eqüitativa de recursos entre o estado e seus municípios.

O Fundeb prevê a manutenção das fontes de recursos do Fundef, com um aumento de alíquota de $15 \%$ para $20 \%$, baseado na transferência dos principais impostos e transferências dos estados e municípios como: FPE, FMP, ICMS, IPI - Exportação e transferências da Lei Complementar no 87/96. Serão acrescidas novas fontes como: IPVA, ITCMD e cota-parte municipal do ITR, ficando fora os impostos municipais: IPTU, ISS e ITBI.

A Implementação do Fundeb será progressiva, atendendo a uma escala como descrita a seguir: $1^{0}$ ano $-16,66 \%$ de (FPE+FMP+ICMS+IPI-E) + 6,66\% (IPVA+ITCMD+cota-parte ITR), $2^{\circ}$ ano - 18,33\% de (FPE+FMP+ICMS+IPI-E) + 13,33\% (IPVA+ITCMD+cota-parte ITR) e $3^{\circ}$ ano - 20\% de (FPE+FMP+ICMS+IPI-E) + 20\% (IPVA+ITCMD+cota-parte ITR). Cabe salientar que a legislação obriga ao uso destes recursos conforme descrito, mas, podem existir outras prioridades que desviem este fundo para aplicações em ações definidas pelos gestores dos recursos.

Do exposto, conclui-se que alocação de uma central de geração de energia elétrica em um município propicia o aumento dos recursos destinados à saúde e à educação, por meio dos repasses legais que incidem sobre a receita de venda da energia. 


\subsubsection{RESPONSABILIDADE SOCIAL}

A avaliação da Responsabilidade Social pode ser considerada como item complementar na avaliação de projetos de geração distribuída, através da importância relativa entre o retorno econômico e o benefício social que representa.

Atividades a serem desenvolvidas pela implantação da central termelétrica como: atendimento aos requisitos ambientais legais, reciclagem de resíduos, treinamento do corpo técnico, apoio à criação de novas escolas publicas locais e apoio à criação de novos postos de atendimentos do sistema de saúde local são alguns dos aspectos da responsabilidade social. Um exemplo de responsabilidade social e aplicação do MDL em uma atividade empresarial é o projeto da PEUGEOT na Fazenda São Nicolau no Mato Grosso, onde o projeto intitulado "Poço de Carbono" objetiva fixar 300 toneladas de carbono por hectare em 100 anos, em um projeto de reflorestamento de 1.200 hectares [39].

Existem várias formulações conceituais para Responsabilidade Social (RS), e uma das que se destaca é do Instituto ETHOS, "Responsabilidade social é a forma de gestão que se define pela relação ética e transparente da empresa com todos os públicos com os quais ela se relaciona e pelo estabelecimento de metas empresariais compatíveis com o desenvolvimento sustentável da sociedade, preservando recursos ambientais e culturais para as gerações futuras, respeitando a diversidade e promovendo a redução das desigualdades sociais" . [25].

\subsection{OUTROS TEMAS DE INTERESSE}

\subsubsection{UNIVERSALIZAÇÃO}

A Universalização do Fornecimento de Energia Elétrica conforme Lei no 10.438 de abril de 2002 tem motivado a publicação de trabalhos sobre o impacto social da energia elétrica em comunidades isoladas em [50] e a situação atual da quantidade de domicílios sem atendimento de energia elétrica em [20]. Segundo [18] a Universalização é motivador para o desenvolvimento de metodologias considerando 
aspectos sociais, colaborado por Macedo [29], que apresenta uma avaliação inclusive da demanda reprimida em localidades isoladas.

A implantação de GD em sistemas isolados ou com demanda reprimida, impacta diretamente no desenvolvimento regional considerando os aspectos econômicos e sociais envolvidos.

\subsubsection{CUSTOS DE GERAÇÃO E TRANSMISSÃO DE ENERGIA}

Existem trabalhos de avaliação de custos de referência para projetos de cogeração, alguns estudos específicos de avaliação de projetos de CTE`s com foco em definir o preço de venda da energia, como o caso de estudo com resíduos de Serraria, apresentado em [24] e análises econômico financeiras para CTE's à Gás Natural (GN), como explorado em [44].

Outros trabalhos apresentam dados específicos sobre desempenho, rendimento e disponibilidade de CTE`s como em [27].

Trabalhos envolvendo avaliação dos custos da eletricidade gerada com biogás de suinocultura como apresentado em [47], ou estudo de custos para conexão de novas unidades de geração em sistemas isolados [8], [9], também fazem parte da literatura técnica pesquisada.

Existem trabalhos com estudos em foco ambiental, social e econômico, mas com avaliações da rede de alimentação como em [10] e no apoio a escolha do projeto mais adequado para sustentar e promover o desenvolvimento de uma região.

Udaeta aborda, em sua publicação [51], o conceito Planejamento Integrado de Recursos (PIR), que considera a conservação de energia como recurso energético, focando em usos finais da energia e avaliando custos e benefícios envolvidos com a escolha e com foco na adequação ambiental. 


\subsubsection{POTENCIAIS DE FONTES PRIMÁRIAS}

Os potenciais regionais de algumas oleaginosas como o dendê, estão apresentados em [17] e os de geração com Biodiesel e seus impactos sociais regionais são abordados por Bose em [10], incluindo 80 usinas de bioóleo em funcionamento ou em fase final de montagem [7].

O potencial de geração de energia elétrica a partir de cana-de-açúcar e óleos vegetais nas diversas meso regiões brasileiras, conforme publicação de Coelho [17] estão apresentadas no Anexo I.

As capacidades de produção de bioóleo por Estado (atual e futura) estão apresentadas na Tabela 1 [7].

Tabela 1 - Capacidade Produção de Bioóleo por Estado - Atual e Futura

\begin{tabular}{|c|c|c|c|}
\hline ESTADO & $N^{\circ}$ USINAS & $\begin{array}{c}\text { PRODUÇÃO } \\
\text { ATUAL (litros ano } \\
\times 10^{6} \text { ) outubro } \\
2006\end{array}$ & $\begin{array}{c}\text { PRODUÇÃO } \\
\text { FUTURA (litros } \\
\text { ano x } 10^{6} \text { ) } \\
\text { previsão para dez. } \\
2007\end{array}$ \\
\hline MATO GROSSO & 16 & 21 & 813 \\
\hline BAHIA & 7 & 24 & 467 \\
\hline RIO GRANDEDO SUL & 5 & 0 & 382 \\
\hline GOIAS & 6 & 0 & 448,4 \\
\hline SÂO PAULO & 12 & 55 & 405,8 \\
\hline MINAS GERAIS & 10 & 16,8 & 266,8 \\
\hline PARANÁ & 8 & 9 & 205 \\
\hline CEARA & 6 & 0 & 177 \\
\hline MARANHÃO & 2 & 0 & 153 \\
\hline TOCANTINS & 2 & 0 & 128,7 \\
\hline MATOGROSSODO SUL & 3 & 0 & 113,5 \\
\hline SANTA CATARINA & 2 & 0 & 100 \\
\hline PERNANBUCO & 2 & 0 & 60 \\
\hline RIO DE JANEIRO & 1 & 48 & 48 \\
\hline PIAUI & 1 & 45 & 45 \\
\hline PARAIB A & 1 & 0 & 40 \\
\hline PARA & 1 & 24 & 24 \\
\hline ALAGOAS & 1 & 0 & 3 \\
\hline
\end{tabular}

\subsubsection{CARACTERIZAÇÃO DOS COMBUSTÍVEIS}

\subsubsection{Gás Natural}

Os equipamentos escolhidos devem ser analisados para utilização do GN especificado pela Agencia Nacional do Petróleo, Gás Natural e Biocombustiveis 
(ANP) para distribuição no Brasil conforme Portaria No 41 de 15/4/1998, apresentado na Tabela 2 [1].

Considera-se que no GN existem diferenças nas características de sua composição dependente da fonte. Observa-se na Tabela 3 a comparação entre as principais fontes brasileiras [1].

Para instalação das unidades geradoras termelétricas com $G N$, é necessário um mapeamento dos locais onde o energético está disponível, bem como, uma caracterização de sua demanda.

Tabela 2 - Especificação do GN

\begin{tabular}{|c|c|c|}
\hline Características $^{(1)}$ & Unidade & Valores \\
\hline Poder Calorífico Superior (PCS) & $\mathrm{Kcal} / \mathrm{m}^{3}$ & $8.800-10.200$ \\
\hline Densidade relativa ao ar & & $0,55-0,69$ \\
\hline Teor máximo de gás sulfídrico $\left(\mathrm{H}_{2} \mathrm{~S}\right)$ & $\mathrm{mg} / \mathrm{m}^{3}$ & 20 \\
\hline $\begin{array}{c}\text { Teor máximo de enxofre }\left(\mathrm{H}_{2} \mathrm{~S} \text { e enxofre }\right. \\
\text { mercaptidico })\end{array}$ & $\mathrm{mg} / \mathrm{m}^{3}$ & 80 \\
\hline Teor máximo de dióxido de carbono $\left(\mathrm{CO}_{2}\right)^{(2)}$ & $\%$ volume & 2 \\
\hline Teor máximo de inertes ${ }^{(3)}$ & $\%$ volume & 4 \\
\hline Teor máximo de oxigênio & $\%$ volume & 0,5 \\
\hline Ponto máximo de orvalho de água, 1 atm ${ }^{(4)}$ & ${ }^{\circ} \mathrm{C}$ & -45 \\
\hline $\begin{array}{l}\text { NotaS: } \\
\text { (1) Limites especificados são valores referidos a } 20^{\circ} \mathrm{C} \text { e } 101,33 \mathrm{kPa}(1 \\
\text { (2) Para as regiões Norte e Nordeste, admite-se o valor de } 3,5 \\
\text { (3) Para as regiões Norte e Nordeste, admite-se o valor de } 6,0 \\
\text { (4) Para as regiões Norte e Nordeste, admite-se o valor de }-39\end{array}$ & exceto onde ind & Fonte: [1] \\
\hline
\end{tabular}

Em [22] apresentam-se várias informações atualizadas sobre o sistema de Gasodutos brasileiro e dados correlatos. São considerados pontos de conexão, aqueles posicionados próximos a city - gates. No Anexo II apresenta-se o atual 
status do sistema de distribuição brasileiro e a localização dos city - gates no território nacional.

Tabela 3 - Composição do Gás Natural das principais jazidas supridoras da demanda brasileira

\begin{tabular}{|c|r|r|r|r|}
\hline Componentes & \multicolumn{1}{|c|}{ Campos } & \multicolumn{1}{|c|}{ Guamaré } & \multicolumn{1}{|c|}{ Bahia } & Bolívia \\
\hline Metano & 89,44 & 83,48 & 88,56 & 90,74 \\
\hline Etano & 6,7 & 11 & 9,17 & 6,06 \\
\hline Propano & 2,26 & 0,41 & 0,42 & 1,21 \\
\hline Butano e superiores & 0,46 & 0 & 0 & 0,02 \\
\hline $\mathrm{H}_{2} \mathrm{~S}$ & Traços & Traços & Traços & Traços \\
\hline $\mathrm{CO}_{2}$ & 0,34 & 1,95 & 0,65 & 0,52 \\
\hline $\mathrm{N}_{2}$ & 0,8 & 3,16 & 1,2 & 1,45 \\
\hline Densidade $\left(\mathrm{ar}^{2}\right)$ & 0,623 & 0,644 & 0,615 & 0,607 \\
\hline P.C.I $\left(\mathrm{kcal} / \mathrm{m}^{3}\right)$ & 9.608 & 9.207 & 9.375 & 9.264 \\
\hline
\end{tabular}

\subsubsection{2 Óleo Diesel}

O Óleo Diesel pode ser qualificado com relação a sua quantidade de enxofre como: Tipo A (A-1 e A-2 - automotivo ou motores diesel de pequeno porte), Tipo B (máximo de 0,35\% de enxofre), Tipo D (máximo de 0,5\% de enxofre), Tipo S-500 (utilizado em grandes metrópoles a partir de 2005, com 0,05\% de enxofre) e Marítimo (características especificas para ponto de fulgor).

A instalação de unidades geradoras utilizando óleo diesel deve considerar a localização e a capacidade dos estoques nas micro regiões e custos de transporte. Os estoques estão indicados em tabelas especificas no Anexo III. 


\subsubsection{Biomassa}

A preocupação crescente por redução dos GEE apresenta, como alternativa de interesse para a geração de energia elétrica, a utilização de resíduos agrícolas e urbanos. Há várias publicações que analisam a viabilidade da aplicação de biomassa oriunda de vários resíduos agrícolas como: bagaço de cana, casca de arroz, milho, coco da Bahia, casca da castanha do caju, soja, trigo, óleo de palma, resíduos de madeireiras entre outros. O CENBIO em [18], apresenta estudo comparando centrais térmicas operando com diversos combustíveis renováveis alternativos. Nessa pesquisa estão avaliados os potenciais de geração de energia elétrica com aproveitamento do bagaço de cana-de-açúcar e bioóleos, utilizando dados referentes ao desempenho de equipamentos de processamento e geração com biomassa obtidos de [41].

Na tecnologia Turbina à Vapor com Caldeira à Biomassa (TVBM) as emissões acontecem principalmente na queima do bagaço na caldeira a vapor. Coelho [15], apresenta tabelas comparativas das emissões geradas nesta tecnologia. Estas informações estão apresentadas no Anexo IV. 


\section{TECNOLOGIA DE GERAÇÃO DISTRIBUÍDA}

\subsection{Turbina à Gás em Ciclo Combinado}

A Tecnologia Turbinas a Gás em ciclo combinado (TGCC) é uma solução energética que utiliza combustíveis fósseis, que conta com uma turbina a vapor como equipamento complementar. O vapor residual da Turbina a Gás é direcionado a uma caldeira de recuperação e depois a uma turbina a vapor ou para processos de produção que utilizam vapor d'água. Uma alternativa desta tecnologia é a Turbina a Gás com Injeção de Vapor - STIG, que surgiu no inicio da década de 80, com a entrada no mercado das turbinas aeroderivativas e consiste em re-injetar o vapor da própria turbina a gás, ou seja, aquele resultante na entrada da caldeira de recuperação para proporcionar geração complementar de eletricidade no próprio gerador principal, reduzindo a emissão de óxido de nitrogênio.

A Tabela a seguir apresenta exemplos de parâmetros típicos de instalações com essa tecnologia.

Tabela 4 - Características Geradores a GN

\begin{tabular}{|c|c|c|c|c|c|c|}
\hline Modelo & $\begin{array}{l}\text { Potência } \\
\text { Máxima } \\
(\mathrm{kW})^{(1)}\end{array}$ & $\begin{array}{l}\text { Consumo } \\
\text { (BTU/kWh) }\end{array}$ & $\begin{array}{c}\text { Rotação } \\
\text { (rpm) }\end{array}$ & $\begin{array}{l}\text { Vazão } \\
\text { gases } \\
\text { (kg/s) }\end{array}$ & $\begin{array}{c}\text { Temp. } \\
\text { Gases } \\
\left({ }^{\circ} \mathrm{C}\right)\end{array}$ & $\begin{array}{c}\text { Eficiência } \\
\text { (\%) }\end{array}$ \\
\hline GE5 & 5500 & 11110 & 16630 & 19,6 & 574 & 30,7 \\
\hline GE10 & 13735 & 9776 & 7900 & 47,4 & 493 & 34,9 \\
\hline LM1600 & 13735 & 9776 & 7900 & 47,4 & 493 & 34,9 \\
\hline LM2000 & 18000 & 9389 & 3600 & 65,4 & 470 & 36,4 \\
\hline \multicolumn{7}{|c|}{ (1) Condições de Operação : ISO, temperatura ambiente $15^{\circ} \mathrm{C}$, umidade relativa do ar $60 \%$, sob } \\
\hline
\end{tabular}




\subsection{Turbina à Vapor}

Há dois tipos básicos de turbinas a vapor: as sem condensação ou de contrapressão e as de condensação. Nas turbinas de condensação, extrai-se vapor à pressão desejada durante a fase de expansão, enquanto o restante continua expandindo-se até a condensação, gerando energia adicional. Neste caso, a relação potência / calor é conseqüentemente mais alta, mas o ciclo global tem eficiência menor. As turbinas de condensação são escolhidas nas aplicações de geração de energia elétrica por sua alta produtividade e flexibilidade.

De modo geral, as turbinas a vapor são especialmente adequadas para instalações de médio/grande porte e têm uma eficiência térmica relativamente baixa, porém com a vantagem de possuir alta disponibilidade.

A baixa eficiência térmica de uma instalação caldeira/turbina a vapor torna economicamente desaconselhável o uso de combustíveis de alto custo, como o gás natural. Desta forma, são mais usadas com carvão ou óleos pesados e em alguns casos biomassa, particularmente com bagaço de cana-de-açúcar. Nessa aplicação, é importante ressaltar que a produção do insumo primário ocorre apenas durante a safra, quando se obtém o bagaço e também $40 \%$ de palha com 15\% de umidade.

A título de ilustração, a produtividade típica de uma instalação de geração de energia elétrica a partir de cana-de-açúcar, utilizando uma caldeira que opera a 80 bar a $480^{\circ} \mathrm{C}$ é de $126 \mathrm{kWh} /$ ton cana [17].

\subsection{Geradores com Biodiesel}

A alternativa de geração de energia com óleos vegetais, se deve principalmente ao fato de que o valor do óleo diesel é substancialmente elevado quando atende a comunidades menores e isoladas.

Conforme estudos da empresa americana National Biodiesel Board (NBB), são cultivadas no Brasil 40 das 50 espécies oleaginosas capazes de produzir Biodiesel, 
dentre as quais estão: óleo de dendê, de mamona, de oiticica que é originado de amêndoas de pequi, de copaíba, de babaçu, de licuri (coquilho) e até mesmo os óleos de milho, algodão, girassol e soja. Particularmente, estudos demonstram que a produtividade da mamona está entre 1200-2000 kg/hectare/safra e que o grão de mamona apresenta 45\% de óleo extraível [36]. Ressalta-se que a produção típica do bioóleo de mamona ou de dendê é $4 \mathrm{~kg} / \mathrm{kWh}$ e que está em desenvolvimento um reator para melhorar a eficiência do óleo vegetal utilizado, fazendo com que passe a ter uma viscosidade similar a do óleo diesel.

O bioóleo (B-100) não gera poluentes durante sua produção industrial, não é tóxico nem explosivo e tão pouco inflamável, além de ser biodegradável e não conter enxofre. Estudos apresentados em [36], ilustrados na Tabela 5, mostram as emissões de poluentes em misturas de biodiesel (B-5). Neste trabalho, as avaliações consideram o uso da mistura B-5.

Tabela 5 - Emissões de Poluentes das Misturas

\begin{tabular}{|c|c|c|c|c|c|}
\hline \multirow{2}{*}{ Poluente } & \multirow{2}{*}{$\begin{array}{l}\text { Redução/ } \\
\text { Aumento }\end{array}$} & B100 & B20 & $\mathrm{B} 10$ & B5 \\
\hline & & \multicolumn{4}{|c|}{ Percentual (\%) } \\
\hline \multirow{2}{*}{$\begin{array}{l}\text { Gases de } \\
\text { Efeito Estufa }\end{array}$} & & & & & \\
\hline & $\mathrm{R}$ & 78 & 15 & 7,15 & 3,75 \\
\hline Enxofre & $\mathrm{R}$ & 98 & 19 & 9,5 & 4,95 \\
\hline $\begin{array}{l}\text { Material } \\
\text { Particulado }\end{array}$ & $\mathrm{R}$ & 50 & 10 & 5 & 2,5 \\
\hline $\mathrm{No}_{x}$ & $\bar{A}$ & $13^{\star}$ & $2,5^{\star \star}$ & $1,3^{\star \star}$ & $0,65^{\star *}$ \\
\hline
\end{tabular}

* USEPA (United States Environmental Protection Agency)

Fonte : [36]

** Caso o incremento seja linear

A utilização do bioóleo como energético traz um alto índice de geração de empregos por capital investido e a valorização do trabalhador rural, tendo grande impacto social e econômico pela fixação do homem no campo, por ser um cultivo de longo ciclo. 
Para o Brasil em especial, o biodiesel tem uma vantagem adicional que é a redução das importações de diesel e a possibilidade de comercialização de certificados de redução de emissões de gases de efeito estufa.

\subsection{Motores Dual com Óleo Combustível / Gás Natural}

Existe no mercado equipamentos de geração a diesel/gás natural com potência entre 7 e 16500 kW. Em alguns casos, máquinas podem ser repotenciadas para aumento de suas capacidades com duplo combustível, como na Usina Termelétrica de Camaçari da Companhia Hidrelétrica do São Francisco (CHESF), onde máquinas de 58,5 MW utilizando Óleo Diesel Tipo D foram repotenciadas para 70 MW com o combustível original e com a opção de GN.

A grande diferença na construção dos motores bicombustiveis em relação aos convencionais está no projeto das câmaras de combustão e de aquecimento, do turbo compressor e nos cuidados especiais com os materiais utilizados para evitar ataque corrosivo (óxido de enxofre).

Esta opção é a indicada para operação de motores com combustíveis de elevado número de cetano, em especial o Óleo Diesel e outros óleos combustíveis, mas podem, quando adequadamente projetados, operar com misturas que incluem o gás natural. As misturas poderão combinar proporções de 5\% a 95\% e utilizar ciclo combinado para aproveitamento dos gases de escape, quando possível. É desejável que o conteúdo de enxofre no combustível seja menor do que 0,05 \% e o de aromáticos menor do que 35\%, para limitar as emissões de particulados à nível adequado. Em alguns casos devem ser utilizados filtros, para remoção de particulados, com substrato de bloco cerâmico de corderita celular, com regeneração por sistemas passivos (catalisadores e aditivos). Lora [28] apresenta os benefícios do uso de filtros catalisadores, que estão reproduzidos na Tabela 6, a título de exemplo. 


\begin{tabular}{|c|c|c|c|c|}
\hline Caso & HC & Co & NO $_{\mathbf{x}}$ & Particulados \\
\hline Sem catalisador & 0,149 & 0,627 & 0,559 & 0,142 \\
\hline Com catalisador & 0,031 & 0,099 & 0,491 & 0,068 \\
\hline
\end{tabular}

Tabela 6 - Controle catalítico das emissões em motores diesel, g/km

Fonte: [28] 


\section{VIABILIDADE ECONÔMICA DA GERAÇÃO DISTRIBUÍDA}

\subsection{Considerações Gerais}

Fundamentalmente os fatores que influem na viabilidade econômica de uma instalação de geração distribuída são a receita operacional líquida (ROL) e a despesa prevista que resultam na margem (lucro) e na taxa de retorno de capital esperados.

A receita operacional líquida num determinado período, advém da venda de energia, adicionada a eventuais outras receitas, descontados os tributos.

A despesa operacional num determinado período, em geral um ano civil, é fundamentalmente a soma da amortização dos investimentos realizados $\left(\mathrm{C}_{\text {amor }}\right)$ aos custos de manutenção e de operação ( $\mathrm{C}_{\mathrm{O \& M}}$ ) acrescida de eventuais multas contratuais $\left(\mathrm{C}_{\mathrm{mul}}\right)$ e ônus advindos de emissões de $\mathrm{CO}_{2}$ não contemplada nos limites regulamentados. Nas centrais geradoras consideradas neste trabalho o custo do insumo primário é a parcela mais importante do custo de operação e manutenção.

Nos itens subseqüentes são apresentados os conceitos dos parâmetros citados, utilizados no modelo proposto.

\subsection{Receita Operacional Líquida (ROL)}

A Receita Operacional Líquida Anual é formalmente a receita operacional bruta RBR, originada dos contratos de venda de energia e de demanda, e inclui o resultado advindo da captura de eventuais créditos de carbono, descontada a soma dos custos de Operação (incluindo combustíveis) e dos tributos TRB, ou seja:

$$
R O L=R B R-D O A-T R B+C K Y
$$

Onde : 
A) $R B R=\left(E a \cdot C_{\text {ene }}\right)+\left(D_{\max } \cdot C_{\text {dem }}\right)$

com : Ea é a energia produzida e vendida pela central

$D_{\max }$ é a demanda máxima fornecida pela central

$C_{\text {ene }}$ é o preço da energia vendida pela central em $R \$ / M W h$

$\mathrm{C}_{\text {dem }}$ é o preço da demanda vendida pela central em $\mathrm{R} \$ / \mathrm{MW}$.ano

B) TRB é a soma dos encargos e tributos devidos pelo exercício da atividade de geração de energia, a saber:

$$
T R B=p_{\text {imp }} \cdot R B R+p_{\text {TUSD }} \cdot P_{\text {nom }}
$$

Onde $p_{\text {imp }}$ e $p_{\text {TUSD }}$ São resultantes da aplicação dos tributos abaixo relacionados e $P_{\text {nom }}$ é a potencia nominal de geração da instalação.

a) ISS - É um imposto municipal, para prestação habitual e remunerada, por empresa ou profissional autônomo, de serviços constantes na lista de serviços instituída pelo município, com base no Decreto Lei 406/68 e Lei Complementar 56/87. A base de cálculo é o valor da operação (caracterizado como serviço de transporte e transmissão intramunicipal de energia), com alíquotas variáveis entre municípios.

b) COFINS - É uma contribuição destinada a União, tendo como base o faturamento mensal, considerando receita bruta de vendas de mercadoria, mercadoria/serviços e serviços de qualquer natureza. Alíquota de 3\% (três por cento).

c) PIS - Contribuição para o Programa de Integridade Social - É também uma contribuição destinada a União, considerando o faturamento do mês, entendido da mesma forma do COFINS, com alíquota de 0,65\% (sessenta e cinco centésimos por cento).

d) TFSEE - Taxa de Fiscalização de Serviços de Energia Elétrica - É uma taxa destinada a ANEEL, por todos aqueles que produzem (incluindo autoprodutores e produtores independentes), transmitem, distribuem e comercializam Energia Elétrica. Com base definida pela Lei $n^{\circ} 9427$, de 26/12/1996 e alíquota de 0,5\% (cinco décimos por cento) do valor unitário 
do Beneficio Anual decorrente da exploração da atividade de geração, sendo que o valor devido é deduzido das quotas de Reserva Global de Reversão (RGR).

e) RGR - É uma quota anual fixada pela ANEEL, devida por concessionárias e permissionárias do serviço publico de energia elétrica às Centrais Elétricas Brasileira S. ${ }^{a}$. A base de cálculo é o investimento reversível projetado no Programa de Melhorias da Eficiência (PMEF) e, na falta deste, informações prestadas pelas concessionárias e permissionárias em cada exercício. Esta alíquota é de 2,5\% (dois e meio por cento), limitado a $3 \%$ (três por cento) da receita anual, além da dedução da TFSEE já citada.

f) CPMF - Contribuição Provisória sobre Movimentação Financeira - É uma Contribuição de Competência da União, relacionando-se a movimentação ou transmissão de créditos e direitos de natureza financeira. Tem como base uma alíquota de $0,38 \%$ (trinta e oito centésimos por cento) e será considerada para efeito de despesas sobre a receita anual do empreendimento.

g) IRPJ - Imposto de Renda Pessoa Jurídica - É um Imposto de competência da União, incide sobre o lucro real que é a base de cálculo segundo registros contábeis e fiscais efetuados sistematicamente de acordo com leis comerciais e fiscais. O IRPJ é calculado mediante a aplicação da alíquota de 15\% (quinze por cento) sobre a base de cálculo. Sobre a parcela da base de cálculo anual que exceder a $R \$ 240,000,00$ (duzentos e quarenta mil reais ) será devido adicional à alíquota de $10 \%$ (dez por cento).

h) Contribuição Social sobre o Lucro Liquido - É uma Contribuição de competência da União, é aplicada nas mesmas normas do IRPJ, mantendo alíquotas previstas na legislação. Para 2007 é prevista uma alíquota de 9\% no sistema de lucro real no formato de apuração por Lucro Real.

i) Tarifa de uso do sistema de distribuição (TUSD) - É uma tarifa cobrada pela distribuidora local pela utilização de suas instalações para transmitir a energia gerada para o sistema consumidor. Essa tarifa é regulada pela ANEEL e é cobrada em função da potência instalada (kW/mês) 
Atualmente, em caráter temporário, a TUSD de pequenas unidades geradoras com fontes renováveis é $50 \%$ da tarifa paga por um consumidor que tenha uma carga de mesma intensidade. Essa prática deve ser revisada após o resultado de estudos que estão sendo conduzidos nesse sentido.

C) CKY é a receita advinda da venda de certificados de captura de carbono segundo o Protocolo de Kyoto, calculado por :

$$
C K Y=p_{k y o} \cdot C_{k y o}
$$

onde: $p_{\text {kyo }}$ - é a quantidade de toneladas de carbono evitada, em função da tecnologia adotada;

$\mathrm{C}_{\text {kyo }}$ - preço de mercado da tonelada de carbono evitada.

\subsection{Despesa Operacional}

A Despesa Operacional Anual é formalmente a soma da amortização dos investimentos realizados em geração e conexão ( $\left.\mathrm{C}_{\text {amor }}\right)$, dos custos de manutenção e de operação ( $\left.\mathrm{C}_{\mathrm{O} \& \mathrm{M}}\right)$, de eventuais multas contratuais e ainda do custo atribuído às emissões de $\mathrm{CO}_{2}$, ou seja:

$$
D O A=C_{\text {amor }}+C_{O \& M}+C_{m u l}+C_{C O 2}
$$

Onde :

A) $\quad C_{\text {amor }}=C G e_{\text {amor }}+C C x_{\text {amor }}$

Onde $\mathrm{CGe}_{\text {amor }}$ é o custo de amortização das instalações de geração e CCXamor é o custo de amortização das instalações de conexão e :

$$
C G e_{\text {amor }}=\left[C G_{i n s t}+C_{o b c}+J D C\right] \cdot f_{a c}
$$

onde: 
$\mathrm{CG}_{\text {instal }}$ é o custo de instalação das unidades geradoras, incluindo terreno, projeto e montagem. Esse custo é obtido por meio do custo das máquinas e da subestação elevadora de conexão à rede, fornecidos pelo fabricante e porcentuais típicos que representam as demais parcelas.

C $_{\text {obc }}$ é o custo da construção civil

JDC é o juros durante o período de construção

$f_{a c}$ é o de atualização de capital dado por $\left.f_{a c}=\frac{j u r}{\left[1-(1+j u r)^{-n v i d a}\right.}\right]$, onde jur é a taxa de atualização do capital e n $_{\text {vida }}$ é o período de amortização da instalação.

e, $\quad C C x_{\text {amor }}=C C x_{\text {instal }} \cdot f_{a c}$

onde:

CCXinstal - é o custo de instalação da conexão da subestação elevadora da central, da linha que transporta a energia até o ponto de conexão da rede elétrica e da subestação de conexão, quando for o caso. Assume-se que a tensão da linha é a mesma da rede elétrica que recebe a energia gerada pela central.

O custo da linha é calculado a partir do custo dos postes ou das torres de transmissão, conforme seja uma linha de distribuição de média tensão ou linha de transmissão para alta tensão e do custo dos cabos obtidos pela determinação do cabo de secção econômica, conforme apresentado no Anexo V .

B) $C_{O \& M}=C_{c o b}+C_{f i x o O \& M}+C_{\text {var } O \& M}$

onde:

Ccob é o custo do combustível consumido durante um ano, em R\$;

Cfixo independentemente da produção, durante um ano, em R\$/MVA $A_{\text {instal. ano; }}$

Cvaro\&m é o custo de operação e manutenção que é gasto em função da produção, exceto o custo de combustível, em $\mathrm{R} \$ / \mathrm{MWh}$, durante um ano;

C) $C_{\text {mul }}$ é o eventual custo de multas contratuais advindas de períodos de não fornecimento decorrente de manutenção preventiva ou corretiva. Esse custo é proporcional ao produto da demanda contratada pela diferença entre a 
quantidade de horas contratadas por ano (confiabilidade contratada) e a quantidade de horas esperada de operação, ou seja:

$$
C_{m u l}=k_{\text {mul }} \cdot(8760-\text { horas_disponiveis).Demanda_Contratada }
$$

D) $\mathrm{C}_{\mathrm{co2}}$ é o produto das toneladas de $\mathrm{CO}_{2}$ emitidas anualmente pelo custo da emissão específica.

\subsection{Margem e Taxa de Retorno}

A Margem Anual (M) é conceituada neste trabalho como sendo a diferença da Receita Operacional Liquida Anual e a Despesa Operacional Anual, do mesmo ano.

Toda decisão de investimento usualmente realiza uma análise de viabilidade econômica para avaliar alternativas, que determina a atratividade de um investimento. Existem vários métodos para estudos de atratividade, dentre os quais se pode citar: Valor Presente Liquido (VPL), Valor Anual Uniforme (VAL), Taxa Interna de Retorno (TIR) e Tempo de Retorno de Capital (TRC).

A técnica utilizada nesta análise econômica baseia-se na formação de fluxo de caixa das receitas e das despesas de uma alternativa ao longo do período de estudo, que também é considerado como o de amortização. Essa técnica é a Taxa Interna de Retorno (TIR) que consiste determinação da taxa de remuneração que torna o valor presente do fluxo de caixa da ROL (receita) igual ao valor presente da DOA (despesa).

O período de amortização é considerado como suficiente para a depreciação das instalações. Depreciação é conceitualmente, o tempo que bens ativos imobilizados em uso vão perdendo sua eficiência funcional devido a desgastes, deterioração física, ou perda de utilidade ao uso por ação da natureza ou obsolescência (Artigo 138, $\S 2^{\circ}$, da Lei $\left.n^{\circ} 6.406 / 76\right)$. A depreciação não é obrigatória perante o Imposto de Renda, mas é uma prática adotada para tornar o lucro/prejuízo de uma instalação 
mais próximo da realidade. Adota-se neste trabalho os critérios consolidados no Regulamento do Imposto de Renda em seus artigos 248 e 256, para máquinas e equipamentos em $10 \%$ ao ano.

Existem outras regulamentações para depreciação a saber: 5\% para produção térmica conforme Decreto $\mathrm{n}^{\circ} 82.962$ de 20 de dezembro de 1978 ou taxas entre 2$20 \%$ conforme Resolução ANEEL $n^{\circ}$ 2, de 24 de dezembro de 1997, que foi alterada pela Resolução n ${ }^{\circ}$ 002, de 24 de dezembro de 1997, com taxas diferentes por tipo de equipamento como: Gerador $-3,3 \%$ ao ano, Equipamentos de ciclo térmico $4,5 \%$, caldeiras $-5 \%$, transformadores $-3,3 \%$, entre outros.

Tolmasquim em [49] apresenta para estudos com térmicas à gás, carvão,nuclear e biomassa da cana-de-açúcar a taxa de $5 \%$ e para geração com $\mathrm{PCH}^{\prime}$ s e hidrelétricas a taxa de 3,3\%. Balestieri em [5] utiliza também o valor de $5 \%$ em suas análises com centrais de cogeração e Santos [45] considera vida útil de centrais termelétricas de 25 anos com TIR de $10 \%$ ao ano. 


\section{VIABILIDADE AMBIENTAL DE GERAÇÃO DISTRIBUÍDA}

\subsection{Considerações Gerais}

A poluição aérea causada pela geração termelétrica tratada neste trabalho é o principal fator limitante para a análise ambiental de uma alternativa no modelo de viabilidade proposto. Assim, o mérito das alternativas, quanto à questão ambiental é avaliado por meio das emissões de poluentes que lhes é atribuída diante dos padrões regulamentados.

Os principais elementos efluentes poluidores emitidos pela geração termelétrica são $\mathrm{CO}, \mathrm{SO}_{2}, \mathrm{NO}_{2}$ e materiais particulados, cujos limites estão regulamentados. Além desses, o $\mathrm{CO}_{2}$ também é um agente poluente cujo limite tolerável não é estabelecido na regulamentação, mas traz prejuízos ao meio ambiente.

A seguir apresentam-se as regulamentações pertinentes que estabelecem limites de poluentes emitidos pela geração termelétrica.

\subsection{Padrões de Concentrações de Poluentes Aéreos}

A Organização Mundial da Saúde (OMS) publicou, em 2000, padrões de concentração de gases para determinar o nível recomendado de qualidade do ar. A Tabela 7 apresenta um extrato destes dados.

Tabela 7 - Padrões de qualidade de Ar - OMS adaptada

\begin{tabular}{|c|c|c|c|}
\hline Poluente & Padrões em $\mu \mathrm{g} / \mathrm{m}^{3}$ & $\begin{array}{c}\text { Concentração } \\
\text { Natural no Ar } \\
\text { Limpo em } \\
\mu \mathrm{g} / \mathrm{m}^{3}\end{array}$ & $\begin{array}{c}\text { Valor Médio } \\
\text { Anual nas } \\
\text { Cidades em } \\
\mu \mathrm{g} / \mathrm{m}^{3}\end{array}$ \\
\hline \multirow{2}{*}{ NOx } & 1 hora: 200 & $1-9$ & $20-90$ \\
\cline { 2 - 2 } SOx & 1 ano: 40 & & $20-40$ \\
\cline { 2 - 2 } & 1 hora: 125 & & $200-400$ \\
\hline Ozônio & 8 horas: 120 & $40-70$ & $300-40$ \\
\hline
\end{tabular}


Uma primeira tentativa nacional de controle sobre emissões de poluentes aéreos aconteceu em 1976, com a Portaria no 231 de 27/04/1976, na qual foram estabelecidos níveis de concentração máximos permitidos através de padrões de emissão, com o objetivo de proteger a população e criar metas para planejamentos regionais de controle de poluição do ar.

Em 1989, institui-se o PRONAR - Programa Nacional de Controle da Qualidade do Ar, a partir da Resolução do Conselho Nacional do Meio Ambiente - CONAMA em sua Resolução no 5 [32], que objetivou utilizar vários instrumentos para limitar os níveis de poluentes por fonte. Em 1990, o CONAMA em sua Resolução no 3 [33], estabeleceu os padrões nacionais de qualidade do ar, com base na Portaria Normativa $n^{\circ} 348$ do Instituto Brasileiro do Meio Ambiente e dos Recursos Naturais Renováveis (IBAMA). Segundo a mesma, por padrões de qualidade do ar são: "concentrações de poluentes atmosféricos que, quando ultrapassados, poderão afetar a saúde, a segurança e o bem-estar da população, bem como, ocasionar danos à flora e à fauna, aos materiais e ao meio ambiente em geral."

Esta resolução inclui normas relativas a padrões primários e secundários. Os chamados padrões primários são aqueles definidos como as concentrações de poluentes que, ultrapassadas, poderão afetar a saúde da população. Os secundários constituem as concentrações dos poluentes abaixo das quais prevê o mínimo efeito adverso ao bem-estar da população, assim como, dano à fauna, flora, materiais e meio ambiente em geral.

A Tabela 8 apresenta os padrões nacionais de qualidade do ar. Em particular, o Estado de São Paulo possui por Decreto um padrão de Qualidade do $\mathrm{Ar}$ apresentado na Tabela 9 [28].

Os limites de emissões adotados no Brasil são maiores dos que adotados por outros países, como os da Comunidade Européia e Japão, destacando-se que no Brasil não existe limite de emissão para $\mathrm{NO}_{x}$.

O modelo da pesquisa considera alguns valores limites, visto que existem legislações estaduais com estas referências. 
Tabela 8 - Padrões Nacionais de Qualidade do Ar segundo CONAMA (adaptado)

\begin{tabular}{|c|c|c|c|}
\hline POLUENTE & PADRÃO & $\begin{array}{c}\text { TEMPO DE } \\
\text { AMOSTRAGEM }\end{array}$ & $\begin{array}{c}\text { CONCENTRAÇÃO } \\
\mu \mathrm{g} / \mathrm{m}^{3}\end{array}$ \\
\hline \multirow{4}{*}{$\begin{array}{l}\text { PARTICULAS } \\
\text { TOTAIS }\end{array}$} & \multirow{2}{*}{ PRIMÁRIO } & ANUAL (1) & 80 \\
\hline & & $24 \mathrm{~h}(2)$ & 240 \\
\hline & \multirow{2}{*}{ SECUNDARIO } & ANUAL (1) & 50 \\
\hline & & $24 \mathrm{~h}(2)$ & 150 \\
\hline \multirow{4}{*}{$\begin{array}{l}\text { DIÓXIDO DE } \\
\text { ENXOFRE }\end{array}$} & \multirow{2}{*}{ PRIMÁRIO } & ANUAL (3) & 80 \\
\hline & & $24 \mathrm{~h}(2)$ & 365 \\
\hline & \multirow{2}{*}{ SECUNDARIO } & ANUAL (3) & 40 \\
\hline & & $24 \mathrm{~h}(2)$ & 100 \\
\hline \multirow{2}{*}{$\mathrm{CO}$} & \multirow{2}{*}{ PRIM. E SEC. } & $8 \mathrm{~h} \mathrm{(2)}$ & 10.000 \\
\hline & & $1 \mathrm{~h}(2)$ & 40.000 \\
\hline OZÔNIO & PRIM. E SEC. & $1 \mathrm{~h}(2)$ & 160 \\
\hline \multirow{4}{*}{$\mathrm{NO}_{2}$} & \multirow{2}{*}{ PRIMÁRIO } & ANUAL (3) & 100 \\
\hline & & $1 \mathrm{~h}(2)$ & 320 \\
\hline & \multirow{2}{*}{ SECUNDARIO } & ANUAL (3) & 100 \\
\hline & & $1 \mathrm{~h}(2)$ & 190 \\
\hline \multirow{4}{*}{ FUMAÇA } & \multirow{2}{*}{ PRIMÁRIO } & ANUAL (3) & 60 \\
\hline & & $24 \mathrm{~h}(1)$ & 150 \\
\hline & \multirow{2}{*}{ SECUNDARIO } & ANUAL (3) & 40 \\
\hline & & $24 \mathrm{~h}(1)$ & 100 \\
\hline \multirow{4}{*}{$\begin{array}{l}\text { PARTICULAS } \\
\text { INALÁVEIS }\end{array}$} & \multirow{2}{*}{ PRIMÁRIO } & ANUAL (3) & 50 \\
\hline & & $24 \mathrm{~h}(1)$ & 150 \\
\hline & \multirow{2}{*}{ SECUNDARIO } & ANUAL (3) & 50 \\
\hline & & $24 \mathrm{~h}(1)$ & 150 \\
\hline
\end{tabular}

(2) Média Geométrica Anual. (3) Média Aritmética Anual.

Tabela 9 - Padrões de qualidade do Ar para o Estado de São Paulo (Decreto Estadual no 8.468, de 08/09/1976)

\begin{tabular}{|c|c|c|}
\hline Poluente & Tempo de Amostragem & Padrão $\mu \mathrm{g} / \mathrm{m}^{3}$ \\
\hline \multirow{2}{*}{$\begin{array}{c}\text { Particulas Totais em } \\
\text { Suspensão }\end{array}$} & 24 horas & 240 \\
\hline & Anual(2) & 80 \\
\hline \multirow{2}{*}{ Dióxido de Enxofre } & 24 horas (1) & 365 \\
\hline & Anual (3) & 80 \\
\hline \multirow{2}{*}{ Monoxido de Carbono } & 1 hora (1) & 40.000 \\
\hline & 8 horas (1) & 10.000 \\
\hline $\begin{array}{l}\text { Oxidantes Fotoquimicos } \\
\text { (como ozônio) }\end{array}$ & 1 hora (1) & 160 \\
\hline
\end{tabular}

O Estado do Paraná através da Resolução no 041/2002, apresenta legislação especifica, incluindo os óxidos de nitrogênio. Os padrões foram subdivididos em 
função do combustível, tecnologia e potência e alguns limites estão nas Tabelas 10, $11,12,13$ e 14.

Tabela 10 - Emissões combustível gasoso

\begin{tabular}{|c|c|c|c|c|c|c|}
\hline Potência (MW) & MP - Total & $\begin{array}{c}\mathrm{CO} \\
\left(\mathrm{mg} / \mathrm{Nm}^{3}\right)\end{array}$ & $\begin{array}{c}\mathrm{NO}_{\mathrm{x}} \\
\left(\mathrm{mg} / \mathrm{Nm}^{3}\right)\end{array}$ & $\mathrm{SO} \times$ & \multicolumn{2}{|c|}{ Automonitoramento - Amostragem } \\
\cline { 6 - 7 } & $\mathrm{NA}$ & 500 & $\mathrm{NA}$ & $\mathrm{NA}$ & $\mathrm{CO}, \mathrm{O}_{2}$ & Semestral \\
\hline$<10$ & $\mathrm{NA}$ & 100 & $\mathrm{NA}$ & $\mathrm{NA}$ & $\mathrm{CO}, \mathrm{O}_{2}$ & Semestral \\
\hline Entre 10-50 & $\mathrm{NA}$ & 100 & 320 & $\mathrm{NA}$ & $\mathrm{CO}, \mathrm{NO}_{\mathrm{x}} \mathrm{e} \mathrm{O}_{2}$ & Semestral \\
\hline Entre $50-100$ & $\mathrm{NA}$ & 100 & 200 & $\mathrm{NA}$ & $\mathrm{CO}, \mathrm{NO}_{\mathrm{x}} \mathrm{e} \mathrm{O}_{2}$ & Continuo \\
\hline$>100$ & \multicolumn{7}{l}{} \\
\hline
\end{tabular}

Tabela 11 - Emissões óleo combustível

\begin{tabular}{|c|c|c|c|c|c|c|}
\hline \multirow{2}{*}{ Potência (MW) } & \multirow{2}{*}{$\begin{array}{l}\text { MP - Total } \\
\left(\mathrm{mg} / \mathrm{Nm}^{3}\right) \\
\end{array}$} & \multirow{2}{*}{$\begin{array}{c}\mathrm{CO} \\
\left(\mathrm{mg} / \mathrm{Nm}^{3}\right)\end{array}$} & \multirow{2}{*}{$\begin{array}{c}\mathrm{NO}_{\mathrm{x}} \\
\left(\mathrm{mg} / \mathrm{Nm}^{3}\right) \\
\end{array}$} & \multirow{2}{*}{$\begin{array}{c}\mathrm{SO}_{\mathrm{x}} \\
\left(\mathrm{mg} / \mathrm{Nm}^{3}\right) \\
\end{array}$} & \multicolumn{2}{|c|}{ Automonitoramento - Amostragem } \\
\hline & & & & & Parâmetros & Frequência \\
\hline$<10$ & NA & 500 & NA & NA & $\mathrm{CO}, \mathrm{O}_{2}$ & Semestral \\
\hline Entre $10-50$ & 250 & 250 & 820 & 1700 & $\begin{array}{l}\text { MP-total, } \mathrm{CO} \\
\mathrm{NO}_{x}, \mathrm{SO}_{\mathrm{x}} \mathrm{e} \mathrm{O}_{2}\end{array}$ & Semestral \\
\hline Entre $50-100$ & 100 & 250 & 620 & 1700 & $\begin{array}{l}\text { MP-total, CO, } \\
\mathrm{NO}_{x}, \mathrm{SO}_{\mathrm{x}} \text { e } \mathrm{O}_{2}\end{array}$ & Semestral \\
\hline$>100$ & 75 & 175 & 400 & 400 & $\begin{array}{l}\text { MP-total, } \mathrm{CO} \\
\mathrm{NO}_{x}, \mathrm{SO}_{\mathrm{x}} \text { e } \mathrm{O}_{2}\end{array}$ & Continuo \\
\hline & \begin{tabular}{|c|} 
MP- \\
inorgânico \\
Classe I,II e \\
III
\end{tabular} & & & & MP-inorgânico & Semestral \\
\hline \multicolumn{7}{|c|}{ NA : Não aplicável } \\
\hline \multicolumn{7}{|c|}{$\begin{array}{l}\text { * Artigo 61: Classe I: } 0,2 \mathrm{mg} / \mathrm{Nm}^{3} \text {, Classe II: } 1,0 \mathrm{mg} / \mathrm{Nm}^{3} \text { e Classe III: } 5,0 \mathrm{mg} / \mathrm{Nm}^{3} \\
\text { Condicão referencial de oxiaênio }: 3 \%\end{array}$} \\
\hline
\end{tabular}


Tabela 12 - Emissões com biomassa

\begin{tabular}{|c|c|c|c|c|c|c|}
\hline \multirow{2}{*}{ Potência (MW) } & \multirow{2}{*}{$\begin{array}{l}\text { MP - Total } \\
\left(\mathrm{mg} / \mathrm{Nm}^{3}\right)\end{array}$} & \multirow{2}{*}{$\begin{array}{c}\mathrm{CO} \\
\left(\mathrm{mg} / \mathrm{Nm}^{3}\right)\end{array}$} & \multirow{2}{*}{$\begin{array}{c}\mathrm{NO}_{\mathrm{x}} \\
\left(\mathrm{mg} / \mathrm{Nm}^{3}\right)\end{array}$} & \multirow{2}{*}{$\mathrm{SO}_{\mathrm{x}}$} & \multicolumn{2}{|c|}{ Automonitoramento - Amostragem } \\
\hline & & & & & Parâmetros & Frequência \\
\hline$<10$ & NA & 1000 & NA & NA & $\mathrm{CO}, \mathrm{O}_{2}$ & Semestral \\
\hline Entre $10-50$ & 400 & 1000 & 500 & NA & $\begin{array}{c}\text { MP-total, CO, } \\
\mathrm{NO}_{x} \mathrm{e} \mathrm{O}_{2}\end{array}$ & Semestral \\
\hline Entre 50-100 & 200 & 500 & 500 & NA & $\begin{array}{c}\text { MP-total, CO, } \\
\mathrm{NO}_{\mathrm{x}} \text { e } \mathrm{O}_{2}\end{array}$ & Semestral \\
\hline$>100$ & 100 & 250 & 400 & NA & $\begin{array}{c}\text { MP-total, CO, } \\
\mathrm{NO}_{\mathrm{x}} \mathrm{e} \mathrm{O}_{2}\end{array}$ & Continuo \\
\hline \multicolumn{7}{|c|}{ NA : Não aplicável } \\
\hline & & & & & & \\
\hline
\end{tabular}

Tabela 13 - Emissões para Turbina à Gás

\begin{tabular}{|c|c|c|c|c|c|c|}
\hline \multirow{2}{*}{ Potência (MW) } & \multirow{2}{*}{ MP - Total } & \multirow{2}{*}{$\begin{array}{c}\mathrm{CO} \\
\left(\mathrm{mg} / \mathrm{Nm}^{3}\right)\end{array}$} & \multirow{2}{*}{$\begin{array}{c}\mathrm{NO}_{\mathrm{x}} \\
\left(\mathrm{mg} / \mathrm{Nm}^{3}\right)\end{array}$} & \multirow{2}{*}{$\mathrm{SO}_{\mathrm{x}}$} & \multicolumn{2}{|c|}{ Automonitoramento - Amostragem } \\
\hline & & & & & Parâmetros & Frequência \\
\hline$<10$ & NA & 100 & 350 & NA & $\mathrm{CO}, \mathrm{NO}_{\mathrm{x}} \mathrm{e} \mathrm{O}_{2}$ & Semestral \\
\hline Entre $10-100$ & NA & 100 & 300 & NA & $\mathrm{CO}, \mathrm{NO}_{\mathrm{x}} \mathrm{e} \mathrm{O}_{2}$ & Semestral \\
\hline$>100$ & NA & 100 & $\begin{array}{l}125^{1)} \\
165^{2)}\end{array}$ & NA & $\mathrm{CO}, \mathrm{NO}_{\mathrm{x}} \mathrm{e} \mathrm{O}_{2}$ & Continuo \\
\hline \multicolumn{7}{|c|}{ NA : Não aplicável } \\
\hline \multicolumn{7}{|c|}{ Combustivel : ${ }^{1)}$ Gás Natural ${ }^{2)}$ Óleo Diesel } \\
\hline
\end{tabular}

Tabela 14 - Emissões com Motores de Combustão Interna

\begin{tabular}{|c|c|c|c|c|c|c|}
\hline \multirow{2}{*}{$\begin{array}{l}\text { Potência } \\
\text { (MW) }\end{array}$} & \multirow{2}{*}{$\begin{array}{l}\text { MP - Total } \\
\left(\mathrm{mg} / \mathrm{Nm}^{3}\right)\end{array}$} & \multirow{2}{*}{$\begin{array}{c}\mathrm{CO} \\
\left(\mathrm{mg} / \mathrm{Nm}^{3}\right)\end{array}$} & \multirow{2}{*}{$\mathrm{NO}_{\mathrm{x}}\left(\mathrm{mg} / \mathrm{Nm}^{3}\right)$} & \multirow{2}{*}{$\mathrm{SO}_{\mathrm{x}}$} & \multicolumn{2}{|c|}{$\begin{array}{c}\text { Automonitoramento - } \\
\text { Amostragem }\end{array}$} \\
\hline & & & & & Parâmetros & Frequência \\
\hline$<3$ & 130 (Diesel) & 650 & $\begin{array}{c}500 \text { (ciclo Otto } 4 \\
\text { tempos) } 800 \\
\text { (ciclo Otto } 2 \\
\text { tempos) } 4000 \\
\text { (Diesel) }\end{array}$ & NA & $\begin{array}{c}\text { MP-total, } \\
\mathrm{CO}, \mathrm{NO}_{\mathrm{x}} \mathrm{e} \\
\mathrm{O}_{2}\end{array}$ & Semestral \\
\hline$>3$ & 130 (Diesel) & 650 & $\begin{array}{c}500 \text { (ciclo Otto } 4 \\
\text { tempos) } 800 \\
\text { (ciclo Otto } 2 \\
\text { tempos) } 2000 \\
\text { (Diesel) }\end{array}$ & NA & $\begin{array}{c}\text { MP-total, } \\
\mathrm{CO}, \mathrm{NO}_{\mathrm{x}} \mathrm{e} \\
\mathrm{O}_{2}\end{array}$ & Semestral \\
\hline \multicolumn{7}{|c|}{ NA : Não aplicável } \\
\hline \multicolumn{7}{|c|}{ Não aplicável em instalações para geração em emergência } \\
\hline
\end{tabular}


Os fatores de emissão podem ser utilizados para avaliação das quantidades emitidas de poluentes. A emissão especifica de uma fonte de poluentes é limitada por padrões, considerando o nível atual de desenvolvimento tecnológico. Desta forma, o CONAMA, através da Resolução no 8 [34], estabelece padrões de emissões para processos de combustão externa em fontes novas fixas de poluição com potencias nominais totais em nível nacional. Estes limites estão apresentados na Tabela 15 e consideram uma classificação de áreas por critérios de criticidade para prevenir deterioração significativa da qualidade do Ar, segundo classes estabelecidos na Resolução no 5 como:

Classe I - Nível de poluição o mais próximo do verificado sem intervenção antropogênica (provocadas pela ação do homem), como em Áreas de Preservação, lazer e turismo, parques nacionais e estaduais, reservas e estações ecológicas, estâncias hidrominerais e hidrotermais.

Classe II - Limitado por padrão secundário de qualidade (níveis desejados de concentração de poluentes).

Classe III - Limitado por padrão primário de qualidade (níveis máximos toleráveis de poluentes atmosféricos, e se ultrapassados, podem afetar a saúde).

Tabela 15 - Padrões de emissão brasileiros para processos de combustão externa conforme Resolução CONAMA nº 8/1990

\begin{tabular}{|c|c|c|c|c|c|}
\hline \multirow{2}{*}{\multicolumn{2}{|c|}{ AREAS/CLASSE }} & \multirow[t]{2}{*}{ POTÊNCIA } & \multirow[t]{2}{*}{ PARÂMETRO } & \multicolumn{2}{|c|}{$\begin{array}{c}\text { PADRÃO g/MILHÃO } \\
\text { de kcal }\end{array}$} \\
\hline & & & & ÓLEO & CARVÃO \\
\hline \multirow{2}{*}{\multicolumn{2}{|c|}{ I }} & \multirow{2}{*}{$<70 \mathrm{MW}$} & PART. TOTAL & 120 & \\
\hline & & & $\mathrm{SO}_{2}$ & 2000 & \\
\hline \multirow{4}{*}{\multicolumn{2}{|c|}{ II $\quad$ e III }} & \multirow{2}{*}{$<70 \mathrm{MW}$} & PART. TOTAL & 350 & 1500 \\
\hline & & & $\mathrm{SO}_{2}$ & 5000 & 5000 \\
\hline & & \multirow{2}{*}{$>70 \mathrm{MW}$} & PART. TOTAL & 120 & 800 \\
\hline & & & $\mathrm{SO}_{2}$ & 2000 & 2000 \\
\hline
\end{tabular}




\subsection{Cálculo de Emissões}

O confronto entre as emissões fornecidas pelos fabricantes de geradores com os limites admissíveis estabelece o critério de aceitação ou rejeição de uma alternativa de geração. Assim, os limites que eliminam alternativas de geração pelo critério ambiental são:

- emissão de CO superior a $10.000 \mu \mathrm{g} / \mathrm{m}^{3}$ para um período de 8 horas em média anual ou $40.000 \mu \mathrm{g} / \mathrm{m}^{3}$ em 1 hora por uma vez ano, segundo Conama [32];

- emissão de $\mathrm{NO}_{2}$ superior a $100 \mu \mathrm{g} / \mathrm{m}^{3}$ em média aritmética anual ou $320 \mu \mathrm{g} / \mathrm{m}^{3}$ para padrão primário e $190 \mu \mathrm{g} / \mathrm{m}^{3}$ em padrão secundário para períodos de 1 hora em média geométrica anual, segundo Conama [32];

- emissão de $\mathrm{SO}_{2}$ superior a $80 \mu \mathrm{g} / \mathrm{m}^{3}$ para padrão primário e $40 \mu \mathrm{g} / \mathrm{m}^{3}$ em padrão secundário para média aritmética anual e $365 \mu \mathrm{g} / \mathrm{m}^{3}$ em para padrão primário e $100 \mu \mathrm{g} / \mathrm{m}^{3}$ em padrão secundário para média geométrica anual, segundo Conama [32];

- emissão de Particulados Totais (MP) superior a $80 \mu \mathrm{g} / \mathrm{m}^{3}$ para padrão primário e $50 \mu \mathrm{g} / \mathrm{m}^{3}$ em padrão secundário para não ser excedido mais que uma vez ao ano e $240 \mu \mathrm{g} / \mathrm{m}^{3}$ em para padrão primário e $150 \mu \mathrm{g} / \mathrm{m}^{3}$ em padrão secundário para média geométrica anual em um período de 24 horas, segundo Conama [32];

Existem outros limitantes relativos a poluentes que não são considerados porque não se caracterizam como rejeitos dos equipamentos de geração de energia elétrica em estudo neste trabalho.

Uma vez aceita, a alternativa pode ser avaliada sob o aspecto ambiental, pela proporção de emissões de poluentes que provoca diante do limite regulamentado. 


\section{MODELO PROPOSTO}

\subsection{Formulação do Problema}

Considerando a possibilidade de ocorrência de diferentes cenários que envolvam parâmetros probabilísticos, tais como projeções de carga e de preço da energia, o objetivo desta tese é propor uma metodologia para avaliação de alternativas sob aspectos sociais, econômicos e ambientais, para instalação de uma Geração Distribuída (GD) de energia elétrica em micro regiões, definidas conforme conceito do Instituto Brasileiro de Geografia e Estatística (IBGE). Desta forma, a metodologia proposta se presta a atender os interesses de várias modalidades de agentes, quer seja do Poder Público quer seja de investidores privados.

A proposição de alternativas de GD se limita, nesta pesquisa, às seguintes soluções tecnológicas: Geração Distribuída com Turbinas à Gás em Ciclo Combinado, com Turbinas à Vapor com Biomassa, com Centrais de Geração com Motores Diesel e/ou Motores à Gás Natural e com Centrais de Geração com Biodiesel. Não obstante, a metodologia proposta deve ser adequada à expansão para outras tecnologias com a inclusão de informações e considerações específicas.

A caracterização da alternativa deve consistir na pré-seleção de uma ou mais microregiões candidatas e na proposta de utilização de módulos de geração também préselecionados pelo usuário. Os cenários, por sua vez, devem ser definidos por valores que determinados parâmetros podem assumir e correspondentes probabilidades de ocorrência.

A avaliação das alternativas deve ser realizada através de indicadores que quantificam o mérito de cada uma, quanto aos aspectos considerados e por processo de hierarquização segundo critérios estabelecidos pelo usuário. Assim, um projeto que tenha alto retorno econômico, mas que não apresenta impacto social positivo pode ser preterido por outro, que embora apresente resultados econômicos apenas razoáveis, ofereça vantajosos impactos sociais e ambientais. 
Os indicadores devem ser definidos com base em dados e informações técnicas e socioeconômicas, pré-organizadas em adequadas bases de dados.

Os resultados devem consistir de uma relação de alternativas priorizadas conforme o mérito dos indicadores que lhes caracterizam.

\title{
6.2 Conceitos Básicos e Terminologia
}

Os termos e conceitos utilizados neste trabalho são :

\begin{abstract}
Alternativa
Consiste em definir os dados gerais e o módulo gerador a ser implementado em um município pré-estabelecido pertencente a um caso.

\section{Caso}

É o conjunto das alternativas possíveis, aplicadas em uma micro-região, para atender a uma determinada carga, segundo cenários pré-estabelecidos.
\end{abstract}

\section{Carga}

A carga é definida por um conjunto seqüencial de diagramas diários válidos para todos os dias da semana e para cada um dos períodos seqüenciais, onde o primeiro começa no ano de início de operação e o último termina no ano horizonte do estudo. Os diagramas apresentam 3 patamares - leve, médio e pesado. A cada um dos períodos estão associados o preço a ser pago pela energia $(\mathrm{R} \$ / \mathrm{kwh})$, a confiabilidade exigida (em horas/ano sem serviço), e a multa de não atendimento do nível de confiabilidade acordado.

\section{Cenário}

Consiste em um conjunto de parâmetros que apresentam 4 valores, conforme sejam as expectativas pessimista, média e otimista. Esses atributos são: custo do insumo primário, o preço de venda de energia, fator multiplicativo das curvas de carga (incerteza da carga) e o atraso (em anos) da operação comercial da geração devido aspectos ambientais. A cada valor desses 
parâmetros está associada uma probabilidade de ocorrência, como por exemplo: $20 \%$ de probabilidade de ocorrência do cenário otimista, $70 \%$ o médio e $10 \%$ o pessimista. Os valores dos parâmetros em cada cenário são expressos em porcentagem do valor de referencia correspondente ao cenário médio assim, por exemplo, o preço de venda de energia pode ser $120 \%$ do valor de referencia no cenário otimista.

\section{Despesas}

Despesas são gastos associados ao consumo de bens e serviços relacionados à produção de energia elétrica.

\section{Distritos}

São as unidades administrativas dos Municípios, pertencentes a uma micro região.

\section{Esperança de Vida}

Idade média em que ocorre óbito num determinado município.

\section{Indicador Econômico}

É a diferença entre a receita e a despesa anuais associadas a uma alternativa(i) operando em um cenário(j), expresso de forma normalizada.

\section{Indicador Ambiental}

Exprime o mérito ambiental da operação de uma determinada geração distribuída em um determinado município que corresponde a uma alternativa (i) em um cenário (j).

\section{Indicador Social}

Exprime o mérito social da instalação de uma determinada geração distribuída em um determinado município que corresponde a uma alternativa (i),em um cenário(j). 


\section{Índice de Gini}

Mede o grau de desigualdade da distribuição de renda domiciliar per capita em uma comunidade, variando de 0 , quando não há desigualdade (a renda de todos os indivíduos tem o mesmo valor), a 1, quando a desigualdade é máxima (apenas um indivíduo detém toda a renda da comunidade).

\section{Intensidade de Pobreza}

Porcentual da população economicamente ativa com renda domiciliar menor do que um valor adotado como sendo a linha de pobreza, usualmente metade ou um quarto do salário mínimo ( $R$ \$ 151,00 em agosto de 2000, data do levantamento atualmente disponível em [23] ).

\section{Micro Região}

Região geográfica continua definida pela divisão administrativa do território nacional estabelecida pelo IBGE.

\section{Modo de Operação}

O modo de operação caracteriza o ciclo operativo do módulo gerador, se em período de ponta ou continuamente, quando sua produção é contratada no mercado regulado ou por um consumidor livre, ou seja, quando o módulo gerador não opera no mercado livre spot.

\section{Módulo gerador}

Unidade capaz de transformar um insumo primário em energia elétrica, utilizando uma determinada tecnologia, caracterizado por: Tipo de Tecnologia, Potência e Fabricante.

\section{Municípios}

São as unidades de menor hierarquia dentro da organização políticoadministrativa do Brasil, criadas através de leis ordinárias das Assembléias Legislativas de cada Unidade da Federação e sancionadas pelo Governador. 


\section{Receita}

Receita é o ingresso de recursos sob a forma de bens ou direitos auferido por uma instalação de geração composta por um ou mais módulos.

\section{Benefício Social}

Considera-se empresa socialmente responsável aquela que conhece os interesses das diferentes partes (acionistas, funcionários, prestadores de serviço, fornecedores, consumidores, comunidade e governo) e incorpora-os ao planejamento de suas atividades, atendendo às demandas de todos e não apenas dos acionistas ou proprietários. Neste texto, a intensidade de benefício social associada a uma alternativa é expressa pela porcentagem que o indicador social representa diante da figura que quantifica o mérito econômico, ambiental e social de uma alternativa.

\section{Tributos}

Valor monetário pago, obrigatoriamente, pelos contribuintes (pessoas físicas ou jurídicas) ao Estado (União, Estados, Distrito Federal ou Municípios) quando praticam fatos geradores previstos pelas leis tributárias. Os tributos se classificam em quatro categorias: impostos, taxas, empréstimos compulsórios e contribuições, sendo que esta ultima é dividida em contribuições de melhoria e contribuições sociais.

\subsection{Diretrizes da Solução Proposta}

A solução proposta para o problema formulado anteriormente consiste em desenvolver uma metodologia em que a cada alternativa são associados indicadores econômico, social e ambiental, que a qualifica quanto ao seu desempenho em cada um dos cenários, avaliando o seu mérito esperado. Esses indicadores são ponderados e agregados em uma só figura de mérito que permite a priorização das alternativas.

Os indicadores são calculados a partir de dados e informações da micro-região, da carga e do módulo de geração de cada alternativa e ainda, pelos de alguns dados 
gerais e de fatores de ponderação aos indicadores, que são atribuídos pelo usuário, expressando o valor relativo e subjetivo entre os aspectos econômico, social e ambiental.

Como resultado adicional é atribuído um "Certificado Beneficio Social" às alternativas que apresentarem componente social importante, diante dos demais aspectos.

Oportunidades de receitas oriundas do Mecanismo de Desenvolvimento Limpo e Créditos de Carbono (Protocolo de Kyoto) também integram o modelo proposto por meio de suas vantagens econômicas inseridas no contexto do indicador econômico. Assim, quantifica-se a quantidade de dióxido de carbono a ser removida ou a quantidade de gases do efeito estufa que deixará de ser lançada na atmosfera com a efetivação de uma alternativa de geração.

Os indicadores são calculados a partir de elementos de bases de dados, previamente preparadas e uma seqüência de procedimentos, fundamentados em análises técnicas, econômicas, sociais e regulatórias, considerando critérios tecnológicos, ambientais e regionais que podem ser limitadores a solução em estudo.

As bases de dados pré-estabelecidas são estruturadas e obtidas de informações técnicas de fabricantes, literatura especializada, informações geográficas, dados sócio-econômicos de referência regional e expectativas de comercialização dentro do modelo de expansão sugerido para o Setor Elétrico.

Os indicadores são calculados para cada um dos anos do período de estudo, a seguir são normalizados e transformados em uma figura de mérito que representa toda a serie temporal do período. A transformação é realizada, via de regra, por uma média dos valores anuais dos indicadores, afetados de um fator que privilegia os valores próximos da data presente em detrimento dos valores futuros.

Para comercialização da energia produzida são consideradas as alternativas de venda no ambiente regulado e no mercado livre. 


\subsection{Estrutura do Modelo Proposto}

O modelo proposto consiste na execução de procedimentos, que utilizam de dados informados pelo usuário ou extraídos de bases de dados pré-estabelecida, cuja estrutura básica pode ser expressa através de blocos, conforme o diagrama da Figura 2.

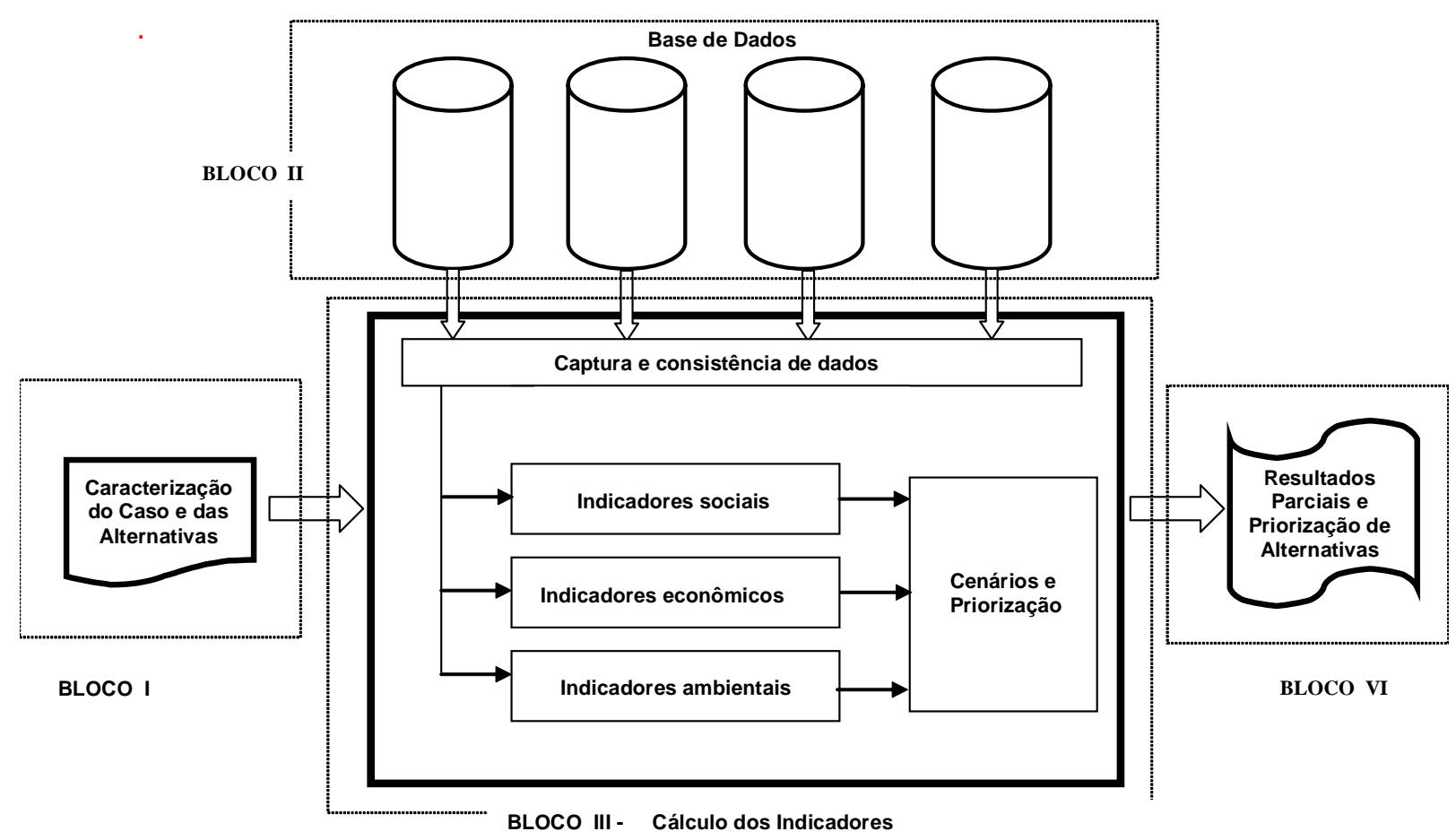

Figura 2 - Estrutura da Metodologia em Blocos

A descrição sucinta de cada bloco é apresentada a seguir:

- Bloco I - Caracterização do Caso e das Alternativas - O caso é caracterizado neste bloco, através da identificação da micro-região a ser estudada e dos módulos de geração a serem considerados, e também da descrição dos cenários, da carga a ser atendida e outros dados gerais, como ponderações de indicadores, tipo de comercialização prevista, dados para cálculo da conexão, parâmetros técnicos e econômicos . 
A identificação da micro-região é realizada de acordo com a terminologia e conceituação estabelecida pelo IBGE.

As alternativas são definidas pelos municípios candidatos a serem sede da geração e pelas possibilidades de módulos geradores a serem empregados.

Os parâmetros técnicos e econômicos fornecidos neste bloco podem substituir diversos tipos de valores default presentes nas bases de dados, como por exemplo: custo de módulos gerador, taxa de atualização de capital e custo de insumos primários.

- Bloco II - Base de Dados - Este bloco possui todos os elementos, complementares aos fornecidos pelo usuário, necessários para a análise de cada caso em estudo, tais como: informações técnicas, econômicas e operacionais dos módulos geradores, dados sócio-econômicos e geográficos de micro-regiões, limites admissíveis de emissões de poluentes conforme legislação ambiental vigente, expectativa de tarifa em função das projeções do balanço geração/carga agregada.

- Bloco III - Cálculo dos Indicadores - Neste bloco são executados os procedimentos para a efetiva determinação dos valores dos indicadores econômicos, sociais e ambientais para as alternativas propostas, fundamentando-se nos elementos fornecidos pelo usuário e nas bases de dados, para todos os cenários previstos. O cálculo dos indicadores leva em consideração a intervenção do agente, quer seja investidor privado ou executor de políticas públicas, que arbitra pesos específicos a serem aplicados aos indicadores, conforme previsto no modelo.

- Bloco IV - Resultados Parciais e Priorização de Alternativas - Este bloco apresenta uma relação das alternativas estudadas com os respectivos indicadores, para todos os cenários, priorizadas conforme critérios préestabelecidos. 


\subsection{Descrição dos Blocos}

\subsubsection{Bloco I - Caracterização do Caso e das Alternativas}

Este bloco inicia o processo de análise de um caso por meio do recebimento das seguintes informações do usuário:

a) micro região a ser avaliada;

b) municípios, pertencentes a micro região, possíveis de sediar o módulo gerador;

c) módulos de geração a serem utilizados, identificados conforme código constante na base de dados de módulos de geração;

d) carga e por meio de curva de uma seqüência de diagramas de carga diária, por exemplo :

- diagrama do ano 0 ao ano 5 - primeiro contrato

\begin{tabular}{|l|l|l|l|l|l|l|l|l|l|l|l|l|l|l|l|l|l|l|l|l|l|l|l|l|}
\hline horas & $\mathbf{0 1}$ & $\mathbf{0 2}$ & $\mathbf{0 3}$ & $\mathbf{0 4}$ & $\mathbf{0 5}$ & $\mathbf{0 6}$ & $\mathbf{0 7}$ & $\mathbf{0 8}$ & $\mathbf{0 9}$ & $\mathbf{1 0}$ & $\mathbf{1 1}$ & $\mathbf{1 2}$ & $\mathbf{1 3}$ & $\mathbf{1 4}$ & $\mathbf{1 5}$ & $\mathbf{1 6}$ & $\mathbf{1 7}$ & $\mathbf{1 8}$ & $\mathbf{1 9}$ & $\mathbf{2 0}$ & $\mathbf{2 1}$ & $\mathbf{2 2}$ & $\mathbf{2 3}$ & $\mathbf{2 4}$ \\
\hline $\begin{array}{l}\text { carga } \\
\text { (MW) }\end{array}$ & 8 & 8 & 8 & 8 & 8 & 8 & 12 & 12 & 12 & 12 & 12 & 12 & 12 & 12 & 12 & 12 & 16 & 16 & 16 & 16 & 16 & 12 & 12 & 12 \\
\hline
\end{tabular}

- diagrama do ano 6 ao ano 10 - segundo contrato

\begin{tabular}{|l|l|l|l|l|l|l|l|l|l|l|l|l|l|l|l|l|l|l|l|l|l|l|l|l|}
\hline horas & 01 & 02 & 03 & 04 & 05 & 06 & 07 & 08 & 09 & 10 & 11 & 12 & 13 & 14 & 15 & 16 & 17 & 18 & 19 & 20 & 21 & 22 & 23 & 24 \\
\hline $\begin{array}{l}\text { carga } \\
\text { (MW) }\end{array}$ & 0 & 0 & 0 & 0 & 0 & 0 & 0 & 0 & 0 & 0 & 0 & 0 & 0 & 0 & 0 & 14 & 14 & 14 & 14 & 14 & 0 & 0 & 0 & 0 \\
\hline
\end{tabular}

e) modalidade e parâmetros de contratação: quando o módulo gerador não for operar no mercado livre ("spot"), isto é, a venda de energia é contratada no mercado regular, este item consiste no fornecimento do 
prazo, da disponibilidade (em horas por ano) e preço a ser pago pela produção do módulo gerador;

f) taxa de atualização de capital em \% ano;

g) período de amortização das instalações em anos;

h) distância da geração à conexão à rede elétrica: neste item são dadas as distâncias entre os locais de instalação do módulo gerador e os correspondentes pontos de conexão da rede elétrica e as correspondentes tensões de operação da rede elétrica;

i) dados para cálculo da colocação do insumo primário no local de geração: conforme o insumo primário seja gás natural neste item são dados a distância entre o local de instalação do módulo gerador e o ponto da rede de gasoduto onde será conectado e a pressão de operação do gasoduto ou, em se tratando de óleo ou biomassa, a distância entre o estoque mais próximo e o local de instalação do gerador;

j) pesos: neste item são fornecidos todos os pesos que ponderam os indicadores, ou seja, por exemplo a Tabela 16.

k) dados de cenários: são previstos 3 cenários, um otimista, um médio e um pessimista, com as correspondentes probabilidades de ocorrência $p_{\text {cot, }}$, $p_{c m e}$ e $p_{c p e}$, cada caracterizado por uma quadra de valores de custo do insumo primário, preço de venda da energia contratada e fator multiplicativo das curvas de carga, por exemplo, como ilustrado na Tabela 17. 
Tabela 16 - Exemplo de pesos para indicadores

\begin{tabular}{|c|c|c|c|c|}
\hline $\begin{array}{l}\text { Pesos } \\
\text { Conforme conceituação apresentadas no Bloco II }\end{array}$ & \multicolumn{4}{|c|}{$\begin{array}{c}\text { Valores dos Pesos } \\
\text { (em p.u.) }\end{array}$} \\
\hline \multicolumn{5}{|l|}{ Pesos gerais } \\
\hline $\begin{array}{lll}p_{e(i, j)} & p_{s(i, j)} & p_{a(i, j)}\end{array}$ & 0,3 & 0,4 & 0,3 & \\
\hline \multicolumn{5}{|l|}{ Pesos econômicos } \\
\hline$p_{e, r(i, j)} p_{e, m(i, j)}$ & 0,5 & 0,5 & & \\
\hline \multicolumn{5}{|l|}{ Pesos sociais } \\
\hline $\mathrm{p}_{\mathrm{s}, \mathrm{es}(\mathrm{i}, \mathrm{j})} \mathrm{p}_{\mathrm{s}, \mathrm{re}(\mathrm{i}, \mathrm{j})} \mathrm{p}_{\mathrm{s}, \mathrm{so}(\mathrm{i}, \mathrm{j})}, \mathrm{p}_{\mathrm{s}, \mathrm{emp}(\mathrm{i}, \mathrm{j})}$ & 0,3 & 0,2 & 0,3 & 0,2 \\
\hline$p_{s, e s, e d(i, j)} p_{s, e s, s a ~(i, j)}$ & 0,5 & 0,5 & & \\
\hline $\mathrm{p}_{\mathrm{s}, \mathrm{so}, \mathrm{lo}(\mathrm{i}, \mathrm{j})} \mathrm{p}_{\mathrm{s}, \mathrm{so}, \mathrm{en}(\mathrm{i}, \mathrm{j})} \mathrm{p}_{\mathrm{s}, \mathrm{so}, \mathrm{po}(\mathrm{i}, \mathrm{j})}$ & 0,2 & 0,3 & 0,5 & \\
\hline 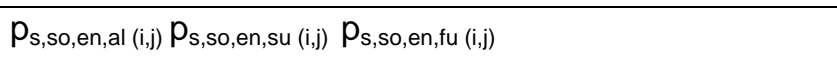 & 0,3 & 0,3 & 0,4 & \\
\hline $\mathrm{p}_{\mathrm{s}, \mathrm{so}, \mathrm{po}, \mathrm{gi}(\mathrm{i}, \mathrm{j})} \mathrm{p}_{\mathrm{s}, \mathrm{so}, \mathrm{po}, \mathrm{rc}(\mathrm{i}, \mathrm{j})} \mathrm{p}_{\mathrm{s}, \mathrm{so}, \mathrm{po}, \mathrm{em}(\mathrm{i}, \mathrm{j})} \mathrm{p}_{\mathrm{s}, \mathrm{so}, \mathrm{po}, \mathrm{po}(\mathrm{i}, \mathrm{j})}$ & 0,2 & 0,2 & 0,2 & 0,2 \\
\hline \multicolumn{5}{|l|}{ Pesos ambientais } \\
\hline$p_{\text {aco(i,j) }} p_{\text {ano(i,j) }} p_{\text {aso(i,j) }} p_{\text {amp(i,j) }}$ & 0,3 & 0,3 & 0,4 & 0 \\
\hline
\end{tabular}

Tabela 17 - Caracterização dos Cenários

\begin{tabular}{|c|c|c|c|c|c|}
\hline \multirow{2}{*}{ Cenários } & Probabilidade & \multicolumn{4}{|c|}{ Valor dos Parâmetros } \\
de & \begin{tabular}{c} 
Ocorrência \\
\cline { 2 - 6 }
\end{tabular} & $\begin{array}{c}\text { Custo do } \\
\text { insumo (p.u. } \\
\text { do valor } \\
\text { médio) }\end{array}$ & $\begin{array}{c}\text { Preço de venda da } \\
\text { Energia }(\mathrm{R} \$ / \mathrm{MWh})\end{array}$ & $\begin{array}{c}\text { Fator Multiplicativo } \\
\text { da Carga( p.u) }\end{array}$ & $\begin{array}{c}\text { Atraso de inicio } \\
\text { da operação } \\
\text { (anos) }\end{array}$ \\
\hline Otimista & Pcot=0,15 & 0,8 & 180 & 1,20 & 0 \\
\hline Médio & Pcme=0,60 & 1 & 150 & 1,00 & 0 \\
\hline pessimista & Pcpe=0,25 & 1,2 & 120 & 0,80 & 2 \\
\hline
\end{tabular}

I) dados gerais : qualquer dado disponível na base de dados por default pode ser substituído, no caso em estudo, por um dado fornecido neste 
bloco, por exemplo: limite da linha de pobreza substituição do valor default de $R \$ 151,00 /$ mês por $R \$ 75,50 /$ mês.

\subsubsection{Bloco II - Base de Dados}

O sistema de base de dados está estruturado conforme os seguintes módulos:

II.1 - Informações Técnicas das Máquinas

- Identificação da Máquina (tipo de tecnologia, fabricante e potencia);

- Tensão Nominal, em kV

- Potência nominal, em MW;

- Rendimento Global e/ou eficiência, em \%;

- Rate Heat, em kJ/kWh;

- Consumo especifico combustível, condição ISO ( $\mathrm{m}^{3} / \mathrm{kWh}$; ton/kWh)

- Disponibilidade, em horas /ano;

- Custo de O\&M fixo e variável, em R\$/ kWh;

- $\quad N^{\circ}$ de Empregos Gerados (quantidade de postos/MWh);

- Custo de Aquisição, Projeto e Implantação, em R\$/kWh;

- Emissões de $\mathrm{CO}$, de $\mathrm{SO}_{2}$, de $\mathrm{NO}_{x}$ e de particulado, em g/ MWh;

- Tecnologia empregada :

- Gerador acoplado a Turbina a Gás em Ciclo Combinado

- Gerador com a Turbina a Vapor com Caldeira de Biomassa

- Gerador com Motor Diesel

- Gerador com Motor à Gás Natural

- Gerador com Biodiesel

- Tonelada de $\mathrm{CO}_{2}$ evitada por MWh gerado

II.2 - Dados Sócio-Econômicos e Geográficos da Micro-Região

- Localização Geográfica das localidades, em coordenadas UTM;

- IDH-Médio ;

- Temperatura Média Anual em ${ }^{\circ} \mathrm{C}$;

- Umidade Média Anual em ${ }^{\circ} \mathrm{C}$;

- Renda per capita Média, em R\$/ano ; 
- Longevidade Média, em anos;

- Taxa de Alfabetização Média , em \%;

- Índice de Gini;

- Consumo per capita Médio;

- Distância estimada até o Ponto de Conexão à rede elétrica, em km;

- Nível de Tensão da Conexão Elétrica, em kV

- Distribuição da renda domiciliar acima da linha de pobreza, em \% da população

- Número de empregados formais;

II.3 -Caracterização dos Combustíveis

- Identificação do combustível;

- Poder calorífico, em kcal/ $\mathrm{Nm}^{3}$;

- Custo do combustível em $\mathrm{R} \$ / \mathrm{m}^{3}$ ou $\mathrm{R} \$ /$ ton;

- Custo do transporte do combustível, em R $\$ /$ ton/km;

II.4 - Limites de emissões ambientais

- Limite admissível de emissões de CO em g/ MWh;

- Limite máximo de emissões de $\mathrm{SO}_{2}$ projetadas em g/ MWh

- Limite máximo de emissões de $\mathrm{NO}_{x}$ em g/ MWh

- Limite Maximo de material particulado (MP) projetado em g/ MWh;

II.5 - Outros custos ou informações associadas

- Fator multiplicativo para aplicação de penalidade

- Projeção do custo de energia no mercado futuro associada a um determinado ano do período de estudo, por meio de um conjunto de pares de probabilidades e custos (em R $\$ / M W h$ )

- Custo do CRE, em R\$/ton de $\mathrm{CO}_{2}$ evitada;

- Disponibilidade de combustíveis na micro região;

- Custo de transporte do combustível até o local da CTE em (R\$/km);

- Custo de linha de conexão da central ao sistema existente $(R \$ / k m)$. 


\subsubsection{Bloco III - Cálculo dos Indicadores}

Considerando que todos os valores dos indicadores são normalizados e os valores dos pesos ou ponderações pertencem ao intervalo de 0 a 1 , formalmente, tem-se em linhas gerais que a figura de mérito $F(i)$ da alternativa (i) considerada é expressa por:

$$
F(i)=p_{\text {cot }} \cdot F(i, \cot )+p_{c m e} \cdot F(i, c m e)+p_{c p e} \cdot F(i, c p e)
$$

onde : $F(i, c o t), F(i, c e m)$ e $F(i, c p e)$ são as figuras de mérito da alternativa (i) quando ocorrem os cenários otimista, médio e pessimista, respectivamente, que apresentam as probabilidades de ocorrência $=p_{c o t}, p_{c m e}$ e $p_{c p e}$.

Em cada um dos cenários (j) com j= cot, cem ou cpe, conforme seja otimista, médio ou pessimista a figura de mérito é :

$$
F(i, j)=p_{e(i, j)} \cdot E(i, j)+p_{s(i, j)} \cdot S(i, j)+p_{a(i, j)} \cdot A(i, j)
$$

Onde $p_{e}(i, j), \quad p_{s}(i, j)$ e $p_{a}(i, j)$ são, respectivamente, os pesos dos aspectos econômico, social e ambiental e $E(i, j), S(i, j)$ e $A(i, j)$ são indicadores referentes aos aspectos econômico, social e ambiental. Note que esses 3 últimos indicadores são resultantes de uma serie de valores anuais de indicadores relativos ao período de estudo. O cálculo de cada um desses três indicadores resultantes é realizado por meio da média dos indicadores anuais, afetados de um fator que privilegia os valores mais próximos do ano inicial em detrimento dos mais distantes. Esse fator é fornecido pelo usuário é traduz a confiança nas projeções oferecendo uma espécie de "valor presente" do indicador resultante.

Se a análise desejada for no âmbito investidor, com maior interesse aos aspectos econômicos, este aspecto pode ser privilegiado por um peso maior. Sendo o usuário interessado em projetos para desenvolver políticas públicas ligadas a fatores ambientais, o maior peso deverá ser destinado aos indicadores relacionados a esta 
variável. Se o usuário se interessar por aspectos sociais e o uso de um novo projeto para um desenvolvimento regional sustentável, utilizando-se dos benefícios governamentais relacionados, os indicadores sociais devem receber maiores pesos.

O modelo ainda permite, mesclar interesses e soluções dentro dos cenários relacionados às três variáveis.

Na expressão da figura de mérito apresentada, tem-se que:

a) o Indicador Econômico $E(i, j)$ de uma alternativa (i,j) é a média ponderada do retorno do investimento $(R \quad(i, j))$ e da margem anual $(M \quad(i, j))$ do empreendimento conforme conceituados anteriormente, ou seja:

$$
E(i, j)=p_{e, r(i, j)} \cdot R(i, j)+p_{e, m(i, j)} \cdot M(i, j)
$$

onde

$p_{\text {er(i,j) e }}$ e $p_{\text {em(i,j) }}$ são os pesos atribuídos ao retorno de investimento e à margem, respectivamente e $R(i, j)$ e $M(i, j)$ são o retorno de investimento e a margem, respectivamente, expressos em valores normalizados.

b) o Indicador Social $S(i, j)$ de uma alternativa $(i, j)$ é a média ponderada de indicadores que expressam os benefícios advindos do empreendimento em termos de:

- educação e saúde por meio de recolhimentos legais de ISS (saúde), ICMS (saúde e educação) e IRPJ (saúde), (Ses (i,j) ) ;

- renda pelo aumento da receita de venda de energia (Sre (i,j));

- social, que representa a situação socioeconômica da localidade tratada na alternativa Sso(i,j) sendo tão maior, quanto menor seja o nível socioeconômico da localidade porquanto é função da distribuição de renda, da renda per capita, do nível de pobreza e de emprego.

- Semp (i,j) que caracteriza o incremento de postos de trabalho que a alternativa oferece, fundamentando-se na tecnologia empregada. 
- Sun (i,j) que indica a importância do impacto da implantação do projeto na universalização regional de energia.

É interessante notar que o indicador social, como os demais, se presta a comparação relativa entre alternativas propostas, de forma que quanto maior for, melhor será a aplicação da geração na alternativa que representa. Dessa forma está implícito $\mathrm{S}(\mathrm{i}, \mathrm{j})$ favorece a alternativa que com menor o nível socioeconômico e assim:

$S(i, j)=p_{s, e s(i, j)} \cdot \operatorname{Ses}(i, j)+p_{s, r e(i, j)} \cdot \operatorname{Sre}(i, j)+p_{s, s o} \cdot \operatorname{Sso}(i, j)+p_{s, e m p} \operatorname{Semp}(i, j)+p_{s, \text { un }} S_{u n}(i, j)$

Onde $p_{s, e s}(i, j), p_{s, r e}(i, j), p_{s, s o}(i, j), p_{s, e m p}$ e $p_{s, u n}$ são os pesos atribuídos aos indicadores Ses(i,j), Sre(i,j), Sso(i,j), Semp(i,j) e Sun(i,j) respectivamente e;

b1) $\operatorname{Ses}(i, j)=p_{s, e s, e d(i, j)} \cdot \operatorname{Sed}(i, j)+p_{s, e s, s a(i, j)} \cdot \operatorname{Ssa}(i, j)$

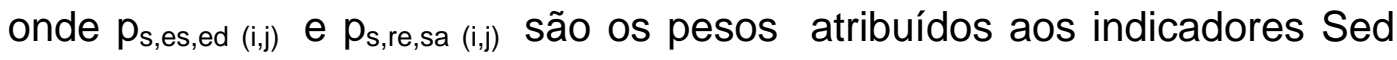
$(\mathrm{i}, \mathrm{j})$ e Ssa $(\mathrm{i}, \mathrm{j})$, respectivamente e;

- Ssa (i,j) é o percentual do imposto sobre a receita de venda de energia destinado à saúde da localidade sede do geração,

- Sed (i,j) é o percentual do imposto sobre a receita de venda de energia destinado à educação da localidade sede da geração,

b2) $\operatorname{Sre}(i, j)=\frac{R}{N_{\text {hab }}}$

onde $\mathrm{R}$ é receita anual da venda de energia produzida pelos módulos geradores da alternativa e $\mathrm{N}_{\text {hab }}$ é a população da localidade;

b3) $\operatorname{Sso}(i, j)=p_{s, s o, l o(i, j)} \cdot \operatorname{Slo}(i, j)+p_{s, s n, e n(i, j)} \cdot \operatorname{Sen}(i, j)+p_{s, s o, p o(i, j)} \cdot \operatorname{Spo}(i, j)$

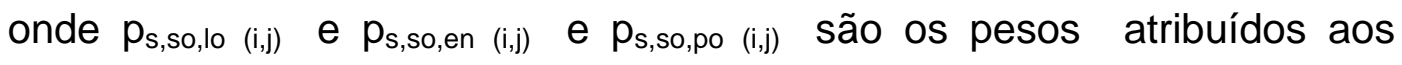
indicadores Slo $(i, j)$, Sem $(i, j)$ e Spo $(i, j)$ respectivamente, e: 
Slo $(i, j)$ é a expectativa de vida da população;

$$
\operatorname{Sen}(i, j)=p_{s, s o, e n, a l(i, j)} \cdot \operatorname{Sal}(i, j)+p_{s, s o, e n, s u(i, j)} \cdot \operatorname{Ssu}(i, j)+p_{s, s o, e n, f u(i, j)} \cdot \operatorname{Sfu}(i, j)
$$

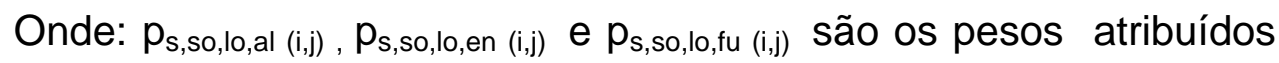
aos indicadores Sal (i,j), Ssu (i,j) e Sfu (i,j) respectivamente, onde: Sal é o porcentual da população alfabetizada, maior que 25 anos; Ssu (i, j) é o porcentual da população maior que 25 anos, cursando nível superior;

Sfu (i, j) é o porcentual da população com idade entre 7 e 14 anos cursando o ensino fundamental.

$$
\begin{aligned}
& \operatorname{Spo}(i, j)=p_{s, s 0, p o, g i(i, j)} \cdot \operatorname{Sgi}(i, j)+p_{s, s o, p o, r c(i, j)} \operatorname{Src}(i, j)+p_{s, s o, p o, e m} \operatorname{Sem}(i, j)+ \\
& p_{s, s o, p o, p o b} \cdot \operatorname{Spob}(i, j)
\end{aligned}
$$

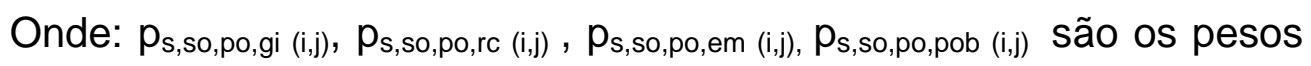
atribuídos aos indicadores Sgi(i,j), $\operatorname{Src}(i, j), \operatorname{Sem}(i, j)$ e $\operatorname{Spob}(i, j)$ respectivamente onde:

- Sgi(i,j) é o índice de Gini, que caracteriza a distribuição de renda, do município;

- Src(i,j) é a renda per capita do município;

- Sem(i,j) é o percentual da população com empregos formais em relação à população entre 18-60 anos, segundo dados do IBGE;

- Spob(i,j) é o porcentual da população acima da linha de pobreza do município;

b4) $\operatorname{Semp}(i, j)=Q P . E g$.

onde : Qp é a quantidade de novos postos por unidade de energia gerada (MWh) e Eg é a quantidade de energia gerada.

b5) $\operatorname{Sun}(i, j)=0 \quad$ ou $\quad 0<\operatorname{Sun}(i, j) \leq 1$ 
O indicador social Sun(i,j) referente à universalização é zero, quando avaliamse sistemas interligados e maiores do que zero, limitados a unidade, quando se referem a sistemas isolados. $O$ peso $p_{s, u n}$ será definido no estudo do projeto implantado em área com carência de suprimento de energia elétrica. Receberá maior peso quanto maior for seu impacto social, por exemplo: ampliar a taxa de universalização atendendo áreas rurais de baixa renda, escolas, creches, e outras atividades sociais e terá menor peso quando atender a objetivos econômicos, por exemplo: atender a agroindústria, comércio, e outras atividades relacionadas.

c) o Indicador Ambiental $A(i, j)$ de uma alternativa (i) é a média ponderada de indicadores que expressam os benefícios advindos do empreendimento, em termos de emissão de $\mathrm{CO}, \mathrm{SO}_{2}, \mathrm{NO}_{2}$ e particulados. A emissão de $\mathrm{CO}_{2}$, por não haver limitação regulada específica, é considerada como diminuição de receita integrada no indicador econômico. As emissões de $\mathrm{CO}, \mathrm{SO}_{2}, \mathrm{NO}_{2}$ e particulados devem ser inferiores aos níveis admissíveis adotados para que a alternativa não seja excluída. O indicador ambiental, formalmente, é :

$$
A(i, j)=p_{\text {aco }(i, j)} \cdot \operatorname{Aco}(i, j)+p_{\text {ano }(i, j)} \cdot A_{(n o}(i, j)+p_{\text {aso }(i, j)} \cdot \operatorname{Aso}(i, j)+p_{\text {amp }(i, j)} \cdot \operatorname{Amp}(i, j)
$$

onde

$p_{\text {aco(i,j), }} p_{\text {ano(i,j), }} p_{\text {aso(i,j) }}$ e $p_{a m p(i, j)}$ são os pesos atribuídos aos indicadores Aco(i,j), Ano (i,j), Aso(i,j) e Amp(i,j), respectivamente e;

- Aco(i,j) é a relação da diferença do limite máximo de emissão de CO permitido e o valor de emissão de $\mathrm{CO}$ da fonte, sobre o limite máximo de emissão de CO permitido;

- Aco(i,j) é a relação da diferença do limite máximo de emissão de $\mathrm{NO}_{2}$ permitido e o valor de emissão de $\mathrm{NO}_{2}$ da fonte, sobre o limite máximo de emissão de $\mathrm{NO}_{2}$ permitido;

- Aso(i,j) é a relação da diferença do limite máximo de emissão de $\mathrm{SO}_{2}$ permitido e o valor de emissão de $\mathrm{SO}_{2}$ da fonte, sobre o limite máximo de emissão de $\mathrm{SO}_{2}$ permitido; 
- Amp(i,j) é a relação da diferença do limite máximo de emissão de Particulados permitido e o valor de emissão de Particulados da fonte, sobre o limite máximo de emissão de Particulados permitido;

\subsubsection{Bloco IV - Resultados Parciais e Priorização de Alternativas}

Uma vez determinados os indicadores e as figuras de mérito das alternativas, são apresentados os resultados das análises realizadas sob os aspectos econômico, ambiental e social, bem como o mérito global de cada uma das alternativas.

Os vários resultados intermediários do processo são apresentados, oferecendo ao usuário informações complementares para apoio à decisão.

Estudos de sensibilidade podem ser realizados por meio da proposição de variações em parâmetros ou mesmo em ponderações, com o objetivo de se verificar a robustez das soluções e as correspondentes vulnerabilidades diante de possíveis variações de cenários, de limites e condições de contorno de modo geral. 


\section{ESTUDO DE CASO}

\subsection{Considerações Gerais}

Com o objetivo de ilustrar a aplicação do modelo proposto é apresentado neste capítulo um caso de referência focando alternativas com utilização de turbinas a gás, de motores a óleo com mistura B-5 (5\% de bioóleo) e turbina a vapor produzido por caldeira à bagaço de cana.

O estudo consiste em um caso base contemplando dois municípios da micro região baiana de Porto Seguro: Alcobaça e Porto Seguro e também em simulações para avaliar a sensibilidade dos pesos atribuídos para cada um dos aspectos: econômico, social e ambiental.

Os dados e informações socioeconômicas utilizadas nesse caso são fundamentalmente extraídos do Atlas Geográfico publicado pelo IBGE [23]. As características técnicas dos geradores são provenientes de fabricantes e as demais informações são de diferentes origens, como nos estudos do CENBIO [16], [17], a TRANSPETRO [22] e a GASPETRO [22]. As informações referentes ao Banco de Dados estão apresentadas no Anexo VI.

Em todos as análises realizadas neste estudo de caso, considerou-se que a central de geração está interligada ao sistema elétrico existente na região.

\subsection{Bloco I - Caracterização do Caso e das Alternativas}
a) micro região : Porto Seguro
b) municípios : Alcobaça e Porto Seguro
c) módulos de geração : GE-5; MCI-5 e TVBM; 


\section{d) carga}

- primeiro contrato: diagrama do ano 0 ao ano 5 -

\begin{tabular}{|l|l|l|l|l|l|l|l|l|l|l|l|l|l|l|l|l|l|l|l|l|l|l|l|l|}
\hline Horas & $\mathbf{0 1}$ & $\mathbf{0 2}$ & $\mathbf{0 3}$ & $\mathbf{0 4}$ & $\mathbf{0 5}$ & $\mathbf{0 6}$ & $\mathbf{0 7}$ & $\mathbf{0 8}$ & $\mathbf{0 9}$ & $\mathbf{1 0}$ & $\mathbf{1 1}$ & $\mathbf{1 2}$ & $\mathbf{1 3}$ & $\mathbf{1 4}$ & $\mathbf{1 5}$ & $\mathbf{1 6}$ & $\mathbf{1 7}$ & $\mathbf{1 8}$ & $\mathbf{1 9}$ & $\mathbf{2 0}$ & $\mathbf{2 1}$ & $\mathbf{2 2}$ & $\mathbf{2 3}$ & $\mathbf{2 4}$ \\
\hline $\begin{array}{c}\text { Carga } \\
\mathbf{( M W}\end{array}$ & 12 & 12 & 12 & 12 & 12 & 12 & 15 & 15 & 15 & 15 & 15 & 15 & 18 & 18 & 18 & 18 & 18 & 18 & 18 & 18 & 18 & 18 & 18 & 18 \\
\hline
\end{tabular}

- diagrama do ano 6 ao ano 10 - segundo contrato

\begin{tabular}{|l|l|l|l|l|l|l|l|l|l|l|l|l|l|l|l|l|l|l|l|l|l|l|l|l|}
\hline Horas & $\mathbf{0 1}$ & $\mathbf{0 2}$ & $\mathbf{0 3}$ & $\mathbf{0 4}$ & $\mathbf{0 5}$ & $\mathbf{0 6}$ & $\mathbf{0 7}$ & $\mathbf{0 8}$ & $\mathbf{0 9}$ & $\mathbf{1 0}$ & $\mathbf{1 1}$ & $\mathbf{1 2}$ & $\mathbf{1 3}$ & $\mathbf{1 4}$ & $\mathbf{1 5}$ & $\mathbf{1 6}$ & $\mathbf{1 7}$ & $\mathbf{1 8}$ & $\mathbf{1 9}$ & $\mathbf{2 0}$ & $\mathbf{2 1}$ & $\mathbf{2 2}$ & $\mathbf{2 3}$ & $\mathbf{2 4}$ \\
\hline $\begin{array}{c}\text { Carga } \\
\mathbf{( M W}\end{array}$ & 18 & 18 & 18 & 18 & 18 & 18 & 18 & 18 & 18 & 18 & 18 & 18 & 18 & 18 & 18 & 18 & 18 & 18 & 18 & 18 & 14 & 14 & 14 & 14 \\
\hline
\end{tabular}

e) modalidade e parâmetros de contratação: mercado regulado, operação continua durante o período de estudo, disponibilidade de 8600 horas por ano durante o período de estudo e preço a ser pago pela produção é $R \$$ 5000/ MW.ano para demanda e R\$ 180 / MWh.ano para energia no primeiro período e no segundo, $R \$ 2500$ / MW.ano e $R \$ 260$ / MWh.ano para demanda e energia, respectivamente.

f) taxa de atualização de capital $6 \%$ por ano

g) período de amortização das instalações 10 anos

h) distância da geração à conexão à rede elétrica:

- distância entre o local de instalação do módulo gerador no município Alcobaça e o ponto de conexão da rede elétrica de 13,8 $\mathrm{kV}: 5 \mathrm{~km}$

- distância entre o local de instalação do módulo gerador no município Porto Seguro o ponto de conexão da rede elétrica de $13,8 \mathrm{kV}: 4 \mathrm{~km}$

i) dados para cálculo da colocação do insumo primário no local de geração: 
- Distância entre o local de instalação do módulo gerador no município Alcobaça e a rede de gasoduto de alta pressão: 14 km

- Distância entre o local de instalação do módulo gerador no município Porto Seguro e a rede de gasoduto de alta pressão: 8 km

- Distância entre o local de instalação do módulo gerador no município Alcobaça e o estoque de óleo: 440 km (em Vitória)

- Distância entre o local de instalação do módulo gerador no município Porto Seguro e o estoque de óleo: 600 km (em Vitória)

- Distância entre o local de instalação do módulo gerador no município Alcobaça e o estoque de bioóleo: 15 km em média

- Distância entre o local de instalação do módulo gerador no município Porto Seguro e o estoque de bioóleo: 15 km em média

j) pesos: A definição dos pesos no caso base para cada um dos aspectos econômico, social e ambiental - foi realizada atribuindo um equilíbrio entre os diversos fatores, mediante a atribuição de peso de 1/3 a cada um dos 3 aspectos. A Tabela 18 apresenta a distribuição destes pesos.

Por sua vez aos componentes do fator "econômico", que são margem e TIR, foram atribuídos pesos iguais (0,5 para cada um) e aos componentes do fator "ambiental", que são os níveis relativos de emissão de $\mathrm{CO}, \mathrm{NO}_{2}$, $\mathrm{SO}_{2}$ e Particulados, também foram atribuídos pesos iguais $(0,25$ para cada um).

Os diversos componentes do fator "social" tiveram as seguintes participações:
a) recursos para educação
$15 \%$
b) recursos para saúde
$15 \%$
c) renda para o município
$20 \%$
d) situação sócio econômica do município
$30 \%$
e) novos postos de trabalho
$20 \%$

A participação de $30 \%$ da situação sócio econômica do município foi caracterizada por: 
- longevidade

$6 \%$

- alfabetização > 25 anos

$2,7 \%$

- nível superior $>25$ anos

$2,7 \%$

- educ. fund. de 7 e 25 anos

$3,6 \%$

- índice de gini

$3,8 \%$

- renda per capita

$3,8 \%$

- empregos formais

$3,8 \%$

- pop. acima linha da pobreza 3,8\%

Tabela 18 - Distribuição de pesos para o caso base

\begin{tabular}{|c|c|c|c|c|}
\hline $\begin{array}{l}\text { Pesos } \\
\text { Conforme conceituação apresentadas no Bloco II }\end{array}$ & \multicolumn{4}{|c|}{$\begin{array}{l}\text { Valores dos Pesos } \\
\text { (em p.u.) }\end{array}$} \\
\hline \multicolumn{5}{|l|}{ Pesos gerais } \\
\hline $\begin{array}{lll}p_{e(i, j)} & p_{s(i, j)} & p_{a(i, j)}\end{array}$ & 0,33 & 0,33 & 0,33 & \\
\hline \multicolumn{5}{|l|}{ Pesos econômicos } \\
\hline$p_{e, r(i, j)} p_{e, m(i, j)}$ & 0,5 & 0,5 & & \\
\hline \multicolumn{5}{|l|}{ Pesos sociais } \\
\hline$p_{s, e s(i, j)} p_{s, r e(i, j)} p_{s, s o(i, j)} p_{s, e m p(i, j)}$ & 0,3 & 0,2 & 0,3 & 0,2 \\
\hline$p_{s, e s, e d ~(i, j)} p_{s, e s, s a(i, j)}$ & 0,5 & 0,5 & & \\
\hline$p_{s, s o, l o ~(i, j)} p_{s, s o, e n(i, j)} p_{s, s o, p o(i, j)}$ & 0,2 & 0,3 & 0,5 & \\
\hline 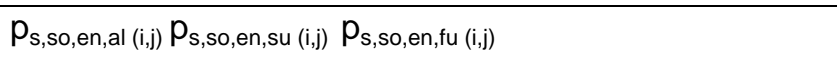 & 0,3 & 0,3 & 0,4 & \\
\hline$p_{s, s o, p o, g i(i, j)} p_{s, s o, p o, r c(i, j)} p_{s, s o, p o, e m(i, j)} p_{s, s o, p o, p o(i, j)}$ & 0,25 & 0,25 & 0,25 & 0,25 \\
\hline \multicolumn{5}{|l|}{ Pesos ambientais } \\
\hline$p_{\text {aco(i,j) }} p_{\text {ano(i,j) }} p_{\text {aso(i,j) }} p_{\text {amp(i,j) }}$ & 0,25 & 0,25 & 0,25 & 0,25 \\
\hline
\end{tabular}

Lembrando que:

$\mathrm{p}_{\mathrm{e}}(\mathrm{i}, \mathrm{j}), \quad \mathrm{p}_{\mathrm{s}}(\mathrm{i}, \mathrm{j})$ e $\mathrm{p}_{\mathrm{a}}(\mathrm{i}, \mathrm{j})$ são, respectivamente, os pesos gerais dos aspectos econômico, social e ambiental;

$p_{\text {er(i,j) e }} p_{\text {em(i,j) }}$ são os pesos atribuídos ao retorno de investimento e à margem, respectivamente;

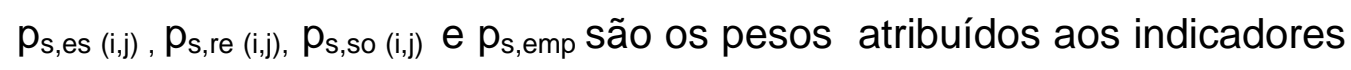
Ses(i,j), Sre(i,j),Sso(i,j), Semp(i,j) respectivamente; 


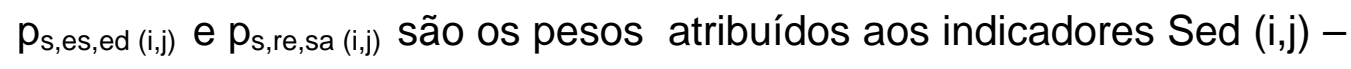
foco receita para educação e Ssa $(i, j)$ - foco receita para saúde, respectivamente;

$\mathrm{p}_{\mathrm{s}, \mathrm{so}, \mathrm{lo}}(\mathrm{i}, \mathrm{j})$ e $\mathrm{p}_{\mathrm{s}, \mathrm{so}, \mathrm{en}}(\mathrm{i}, \mathrm{j})$ e $\mathrm{p}_{\mathrm{s}, \mathrm{so}, \mathrm{po}}(\mathrm{i}, \mathrm{j})$ são os pesos atribuídos aos indicadores Slo $(i, j)$, Sen (i,j) e Spo (i,j) respectivamente;

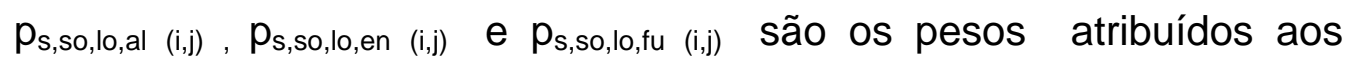
indicadores Sal (i,j), Ssu (i,j) e Sfu (i,j) - foco na alfabetização da população respectivamente;

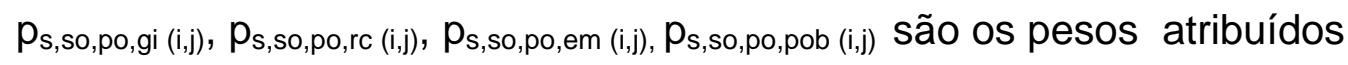
aos indicadores Sgi(i,j), Src(i,j), Sem(i,j) e $\operatorname{Spob}(i, j)$ - foco na distribuição de renda, emprego e linha de pobreza respectivamente;

$p_{a c o(i, j),} p_{a n o(i, j),} p_{a s o(i, j)}$ e $p_{a m p(i, j)}$ são os pesos atribuídos aos indicadores Aco(i,j), Ano $(i, j)$, Aso(i,j) e Amp(i,j) - foco nos limites de emissões de CO, $\mathrm{NO}_{2}, \mathrm{SO}_{2}$ e materiais particulados respectivamente;

Estudos de sensibilidade foram realizados, considerando apenas cada um dos aspectos individualmente: econômico, social e ambiental, denominados CE-Caso Econômico, CS-Caso Social e CA-Caso Ambiental. Também foi simulado um caso desprezando cada um dos aspectos, que foram denominados por CES, CEA e CSA, correspondentes aos casos sem os aspectos ambiental, social e econômico, respectivamente.

k) dados de cenários: cada uma das alternativas, pertencentes a cada caso, foram analisadas considerando os cenários, com as devidas probabilidades de ocorrência, definidos conforme os fatores multiplicativos dos parâmetros da Tabela 19. 
Tabela 19 - Caracterização de Cenários

\begin{tabular}{|c|c|c|c|c|c|}
\hline \multirow{2}{*}{ Cenários } & \multirow{2}{*}{$\begin{array}{l}\text { Probabilidade } \\
\text { de Ocorrência }\end{array}$} & \multicolumn{4}{|c|}{ Valor dos Fatores Multiplicativos ( $p . u$ ) } \\
\hline & & Venda da Energia & \begin{tabular}{|c|} 
Venda \\
Demanda
\end{tabular} & $\begin{array}{l}\text { Custo do } \\
\text { Insumo }\end{array}$ & Carga \\
\hline Otimista & Pcot $=0,15$ & 1,50 & 1,50 & 1,20 & 1,20 \\
\hline Médio & Pcme $=0,60$ & 1,00 & 1,00 & 1,00 & 1,00 \\
\hline pessimista & Pcpe $=0,25$ & 0,95 & 0,95 & 1,00 & 0,95 \\
\hline
\end{tabular}

I) informação geral: limite da linha de pobreza $R \$ 75,50$ / mês.

\subsection{Bloco II - Base de Dados}

\subsubsection{Informações Técnicas das Máquinas}

No anexo VI estão apresentados os dados referentes as informações técnicas dos módulos de geração: GE5 (TGCC de 5,5 MW), GE10 (TGCC de 13,73 MW) e MCI5 (Motor de Combustão Interna funcionando com Biodiesel B-5).

\subsubsection{Dados Sócio-Econômicos e Geográficos da Micro-Região}

Na micro região de Porto Seguro, analisa-se as alternativas de implantação de CTE's nos municípios de Alcobaça e Porto Seguro. As informações que caracterizam estes municípios estão no Anexo VI.

7.3.3 Caracterização dos Combustíveis 
No caso em estudo os combustíveis avaliados são: Gás Natural e o Bioóleo. As informações destes combustíveis estão apresentadas no Anexo VI.

\subsubsection{Limites de emissões ambientais}

Os limites de emissões utilizadas neste estudo de caso estão baseados no Padrão de Qualidade do Ar conforme Resolução CONAMA 3 [33] e estão apresentados no Anexo VI, devidamente adaptados aos itens de interesse nesta análise.

\subsubsection{Outros custos ou informações associadas}

Outros custos necessários a caracterização do caso e informações associadas como: disponibilidade de insumos energéticos e custo da tonelada de $\mathrm{CO}_{2}$ evitada para utilização do cálculo das vantagens advindas da venda de CER's estão no Anexo VI .

\subsection{Bloco III - Cálculo dos Indicadores}

Os indicadores são calculados, a partir dos dados apresentados, utilizando a seqüência descrita no Ítem 6.5.3., para cada uma das alternativas listadas a seguir. São dezoito cenários avaliados dentro da concepção da aplicação de uma das três tecnologias, em um dos dois locais de estudo e com três cenários distintos, para uma perspectiva de 10 anos (tempo de amortização considerado). Apresenta-se nos quadros a seguir os resultados obtidos para $01^{\circ}$ ano e ao final da análise considerando o horizonte de 10 anos.

\subsubsection{Alternativas}

São três cenários em estudo (otimista, médio e pessimista), avaliados com três diferentes módulos geradores e em dois municípios da micro região de Porto Seguro.

A identificação destas alternativas está apresentada na Tabela 20. 
Tabela 20 - Caracterização das Alternativas para o caso Porto Seguro

\begin{tabular}{|c|c|c|c|c|}
\hline \multicolumn{2}{|c|}{ Identificação } & \multirow{2}{*}{ Cenário } & \multirow{2}{*}{ Município } & \multirow{2}{*}{ Módulo de Geraçãc } \\
\hline Cenário j & Alternativa $\mathrm{i}$ & & & \\
\hline 1 & 1 & \multirow{6}{*}{ otimista } & \multirow{3}{*}{ Alcobaça } & 4 x GE 5 MVA \\
\hline 1 & 2 & & & $4 \times \mathrm{MCl} 5 \mathrm{MVA}$ \\
\hline 1 & 3 & & & $1 \times$ TVBM20 MVA \\
\hline 1 & 4 & & \multirow{3}{*}{ Porto Seguro } & $4 \times$ GE 5 MVA \\
\hline 1 & 5 & & & $4 \times \mathrm{MCl} 5 \mathrm{MVA}$ \\
\hline 1 & 6 & & & $1 \times$ TVBM20 MVA \\
\hline 2 & 1 & \multirow{6}{*}{ médio } & \multirow{3}{*}{ Alcobaça } & $4 \times$ GE 5 MVA \\
\hline 2 & 2 & & & $4 \times \mathrm{MCl} 5 \mathrm{MVA}$ \\
\hline 2 & 3 & & & $1 \times$ TVBM20 MVA \\
\hline 2 & 4 & & \multirow{3}{*}{ Porto Seguro } & $4 \times$ GE 5 MVA \\
\hline 2 & 5 & & & $4 \times \mathrm{MCl} 5 \mathrm{MVA}$ \\
\hline 2 & 6 & & & $1 \times$ TVBM20 MVA \\
\hline 3 & 1 & \multirow{6}{*}{ pessimista } & \multirow{3}{*}{ Alcobaça } & $4 \times$ GE 5 MVA \\
\hline 3 & 2 & & & $4 \times \mathrm{MCl} 5 \mathrm{MVA}$ \\
\hline 3 & 3 & & & $1 \times$ TVBM20 MVA \\
\hline 3 & 4 & & \multirow{3}{*}{ Porto Seguro } & 4 x GE 5 MVA \\
\hline 3 & 5 & & & $4 \times \mathrm{MCl} 5 \mathrm{MVA}$ \\
\hline 3 & 6 & & & $1 \times$ TVBM20 MVA \\
\hline
\end{tabular}

\subsubsection{Indicador Econômico E(i,j)}

Os parâmetros são calculados conforme a metodologia descrita anteriormente e os resultados para o Cenário Otimista no primeiro ano de operação estão apresentados na Tabela 21. 
Tabela 21 - Resultados do Indicador Econômico - Cenário Otimista

\begin{tabular}{|c|c|c|c|c|c|c|}
\hline \multicolumn{7}{|c|}{ INDICADORES ECONÔMICOS - CENÁRIO OTIMISTA } \\
\hline \multirow[t]{2}{*}{ Parâmetro } & \multicolumn{6}{|c|}{ Alternativa } \\
\hline & Alt $(1,1)$ & Alt $(1,2)$ & Alt $(1,3)$ & Alt $(1,4)$ & Alt $(1,5)$ & Alt $(1,6)$ \\
\hline $\mathrm{ROL}$ & $8.805 .170,00$ & $9.208 .031,00$ & $15.000 .090,00$ & $4.024 .513,00$ & $5.086 .273,00$ & $15.000 .090,00$ \\
\hline Ea (MWh) & 165.564 & 165.564 & 165.564 & 165.564 & 165.564 & 165.564 \\
\hline Dmax MW & 18 & 18 & 18 & 18 & 18 & 18 \\
\hline RBR & $46.322 .280,00$ & $46.322 .280,00$ & $46.322 .280,00$ & $46.322 .280,00$ & $46.322 .280,00$ & $46.322 .280,00$ \\
\hline TRB & $10.436 .410,00$ & $10.436 .410,00$ & $10.436 .410,00$ & $10.436 .410,00$ & $10.436 .410,00$ & $10.436 .410,00$ \\
\hline CKY & $115.024,00$ & $3.044 .722,00$ & $2.001 .669,00$ & $115.024,00$ & $3.044 .722,00$ & $2.001 .669,00$ \\
\hline DOA & $27.195 .724,00$ & $29.722 .561,00$ & 22.886 .549 & $31.976 .382,00$ & $30.914 .622,00$ & $22.886 .549,00$ \\
\hline $\mathrm{C}_{\text {amor }}$ & $2.510 .328,73$ & $3.613 .351,96$ & $5.715 .307,14$ & $2.510 .328,73$ & $3.613 .351,96$ & $5.715 .307,14$ \\
\hline $\mathrm{CGe}_{\text {amor }}$ & $2.503 .642,62$ & $3.603 .728,02$ & $5.700 .111,44$ & $2.503 .642,62$ & $3.603 .728,02$ & $5.700 .111,44$ \\
\hline $\mathrm{CG}_{\text {instal }}(\mathrm{R} \$)$ & $26.400 .000,00$ & $38.000 .000,00$ & $60.000 .000,00$ & $26.400 .000,00$ & $38.000 .000,00$ & $60.000 .000,00$ \\
\hline $\mathrm{C}_{\mathrm{obc}} \quad \mathrm{R} \$$ & $4.224 .000,00$ & $6.080 .000,00$ & $3.732 .000,00$ & $4.224 .000,00$ & $6.080 .000,00$ & $3.732 .000,00$ \\
\hline JDC(\%/ano) & 9 & 9 & 9 & 9 & 9 & 9 \\
\hline jur (\%/ano) & 6 & 6 & 6 & 6 & 6 & 6 \\
\hline $\mathrm{n}_{\text {vida }}$ anos & 10 & 10 & 10 & 10 & 10 & 10 \\
\hline$f_{a c}$ & 0,0759 & 0,0759 & 0,0759 & 0,0759 & 0,0759 & 0,0759 \\
\hline $\mathrm{CCX}_{\mathrm{amor}}$ & $88.128,22$ & $126.851,22$ & $200.291,40$ & $88.128,22$ & $126.851,22$ & $200.291,40$ \\
\hline$C C x_{\text {instal }}$ & $1.161 .600,00$ & $1.672 .000,00$ & $2.640 .000,00$ & $1.161 .600,00$ & $1.672 .000,00$ & $2.640 .000,00$ \\
\hline Cust linha & $350.000,00$ & $350.000,00$ & $350.000,00$ & $350.000,00$ & $350.000,00$ & $350.000,00$ \\
\hline $\begin{array}{l}\text { Cfix } \\
\text { R\$/MWano; }\end{array}$ & $15.600 .000,00$ & $15.480 .000,00$ & $9.600 .000,00$ & $15.600 .000,00$ & $151.480 .000,00$ & $9.600 .000,00$ \\
\hline $\begin{array}{l}\text { Cvar }_{\text {O\&M }} \\
\mathrm{R} \$ \text { /MWhano }\end{array}$ & $3.178 .829,00$ & $1.386 .768,00$ & $1.986 .768,000$ & $3.178 .829,00$ & $1.386 .768,00$ & $1.986 .768,000$ \\
\hline $\mathrm{k}_{\mathrm{mul}}$ & 10 & 10 & 10 & 10 & 10 & 10 \\
\hline$M(i, j)$ & $19.126 .556,00$ & $16.599 .719,00$ & $23.435 .731,00$ & $14.345 .898,00$ & $15.407 .658,00$ & $23.435 .731,00$ \\
\hline$E(i, j)$ & 0,80 & 0,70 & 0,69 & 0,76 & 0,67 & 0,63 \\
\hline
\end{tabular}

\subsubsection{Indicador Social S(i,j)}

Os parâmetros são calculados conforme a metodologia descrita anteriormente e os resultados para o Cenário Otimista estão apresentados na Tabela 22. 
Tabela 22 - Resultados do Indicador Social - Cenário Otimista

\begin{tabular}{|l|c|c|c|c|c|c|}
\hline \multicolumn{7}{|c|}{ INDICADORES SOCIAIS - CENÁRIO OTIMISTA } \\
\hline Parâmetro & \multicolumn{7}{|c|}{ Alternativas } \\
\hline & Alt(1,1) & Alt(1,2) & Alt(1,3) & Alt(1,4) & Alt(1,5) & Alt(1,6) \\
\hline Ssa $(i, j)$ & 2.779 & 2.779 & 2.779 & 2.779 & 2.779 & 2.779 \\
\hline Sed $(i, j)$ & 41.231 & 41.037 & 41.037 & 41.037 & 41.037 & 41.037 \\
\hline Ses(i,j) & 0,34 & 0,34 & 0,34 & 0,34 & 0,34 & 0,34 \\
\hline Sre (i,j) & 0,64 & 0,64 & 0,64 & 0,14 & 0,14 & 0,14 \\
\hline Slo (i,j) & 0,95 & 0,95 & 0,95 & 1,00 & 1,00 & 1,00 \\
\hline Sal & 63,65 & 63,65 & 63,65 & 76,43 & 76,43 & 76,43 \\
\hline Ssu & 0,90 & 0,90 & 0,90 & 0,16 & 0,16 & 0,16 \\
\hline Sfu $(i, j)$ & 88,50 & 88,50 & 88,50 & 84,77 & 84,77 & 84,77 \\
\hline Sen (i,j) & 55 & 55 & 55 & 57 & 57 & 57 \\
\hline Sgi(i,j) & 0,57 & 0,57 & 0,57 & 0,64 & 0,64 & 0,64 \\
\hline Src(i,j) & 0,03 & 0,03 & 0,03 & 0,06 & 0,06 & 0,06 \\
\hline Sem(i,j) & 0,05 & 0,05 & 0,05 & 0,33 & 0,33 & 0,33 \\
\hline Spo(i,j) & 0,27 & 0,27 & 0,27 & 0,40 & 0,40 & 0,40 \\
\hline Sso (i,j) & 0,49 & 0,49 & 0,49 & 0,57 & 0,57 & 0,57 \\
\hline Semp(i,j) & 37,80 & 60,71 & 122,63 & 37,80 & 60,71 & 122,63 \\
\hline S(i,j) & 0,43 & 0,47 & 0,56 & 0,36 & 0,39 & 0,48 \\
\hline
\end{tabular}

\subsubsection{Indicador Ambiental $\mathrm{A}(\mathrm{i}, \mathrm{j})$}

Os parâmetros são calculados conforme a metodologia descrita anteriormente e os resultados para o Cenário Otimista estão apresentados na Tabela 23. 
Tabela 23 - Resultados do Indicador Ambiental - Cenário Otimista

\begin{tabular}{|c|c|c|c|c|c|c|}
\hline \multicolumn{7}{|c|}{ INDICADORES AMBIENTAIS - CENÁRIO OTIMISTA } \\
\hline parâmetro & \multicolumn{7}{|c|}{ alternativas } \\
\hline & Alt(1,1) & Alt(1,2) & Alt(1,3) & Alt(1,4) & Alt(1,5) & Alt(1,6) \\
\hline Aco(i,j); & 0,865 & 0,400 & 0,999 & 0,865 & 0,400 & 0,999 \\
\hline Ano(i,j) & 0,195 & 0,947 & 0,579 & 0,195 & 0,947 & 0,579 \\
\hline Aso(i,j) & 1,000 & 0,915 & 1,000 & 1,000 & 0,915 & 1,000 \\
\hline Amp(i,j) & 0,554 & 0,025 & 0,367 & 0,554 & 0,025 & 0,367 \\
\hline A(i,j) & 0,64 & 0,59 & 0,73 & 0,64 & 0,59 & 0,73 \\
\hline
\end{tabular}

\subsection{Resultados Parciais e Priorização de Alternativas}

Os resultados parciais dos indicadores $E(i, j), S(i, j)$ e $A(i, j)$ em cada cenário, considerando os pesos gerais simulados descritos na Tabela 24, bem como, 0 resultado do cálculo da figura de mérito da alternativa, estão apresentados nas figuras 3, 4, 5, 6, 7, 8 e 9, para cada caso avaliado, sendo:

OAGN - Cenário Otimista em Alcobaça com Gás Natural

OABIO - Cenário Otimista em Alcobaça com Bioóleo

OACN - Cenário Otimista em Alcobaça com Cana de Açúcar

OPGN - Cenário Otimista em Porto Seguro com Gás Natural

OPBIO - Cenário Otimista em Porto Seguro com Bioóleo

OPCN - Cenário Otimista em Porto Seguro com Cana de Açúcar

MAGN - Cenário Médio em Alcobaça com Gás Natural

MABIO - Cenário Médio em Alcobaça com Bioóleo

MACN - Cenário Médio em Alcobaça com Cana de Açúcar

MPGN - Cenário Médio em Porto Seguro com Gás Natural

MPBIO - Cenário Médio em Porto Seguro com Bioóleo

MPCN - Cenário Médio em Porto Seguro com Cana de Açúcar

PAGN - Cenário Pessimista em Alcobaça com Gás Natural

PABIO - Cenário Pessimista em Alcobaça com Bioóleo

PACN - Cenário Pessimista em Alcobaça com Cana de Açúcar 
PPGN - Cenário Pessimista em Porto Seguro com Gás Natural PPBIO - Cenário Pessimista em Porto Seguro com Bioóleo PPCN - Cenário Pessimista em Porto Seguro com Cana de Açúcar

Tabela 24 - Pesos gerais considerados nas simulações do caso

\begin{tabular}{|l|c|c|c|}
\hline \multirow{2}{*}{\multicolumn{1}{|c|}{ Caso }} & \multicolumn{3}{c|}{ Pesos Gerais } \\
\cline { 2 - 4 } & $p_{\mathrm{e}(i, j)}$ & $\mathrm{p}_{\mathrm{s}(\mathrm{i}, \mathrm{j})}$ & $\mathrm{p}_{\mathrm{a}(\mathrm{i}, \mathrm{j})}$ \\
\hline CB - Caso Base & 0,33 & 0,33 & 0,33 \\
\hline CE - Caso Econômico & 1 & 0 & 0 \\
\hline CS - Caso Social & 0 & 1 & 0 \\
\hline CA -Caso Ambiental & 0 & 0 & 1 \\
\hline CSE - Caso Econômico Social & 0,5 & 0,5 & 0 \\
\hline CSA - Caso Social Ambiental & 0 & 0,5 & 0,5 \\
\hline CEA - Caso Econômico Ambiental & 0,5 & 0 & 0,5 \\
\hline
\end{tabular}

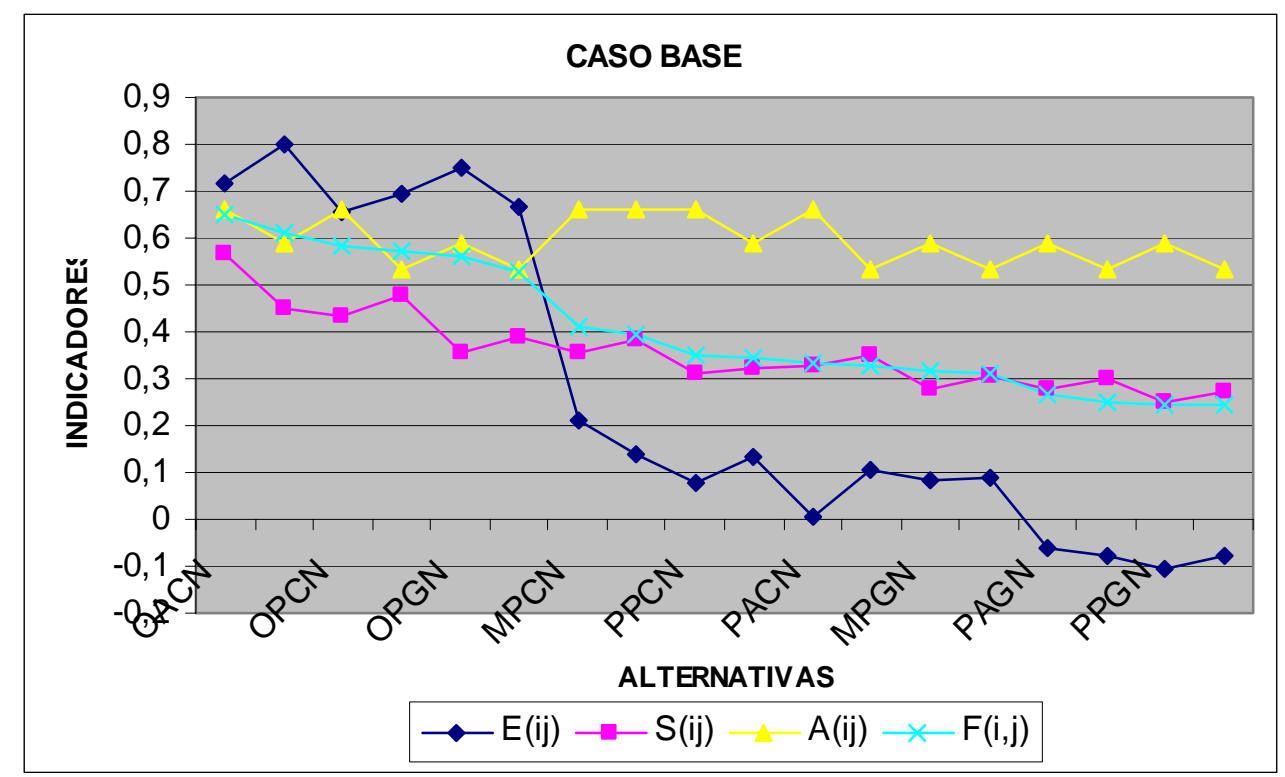

Figura 3 - Resultados Caso Base 


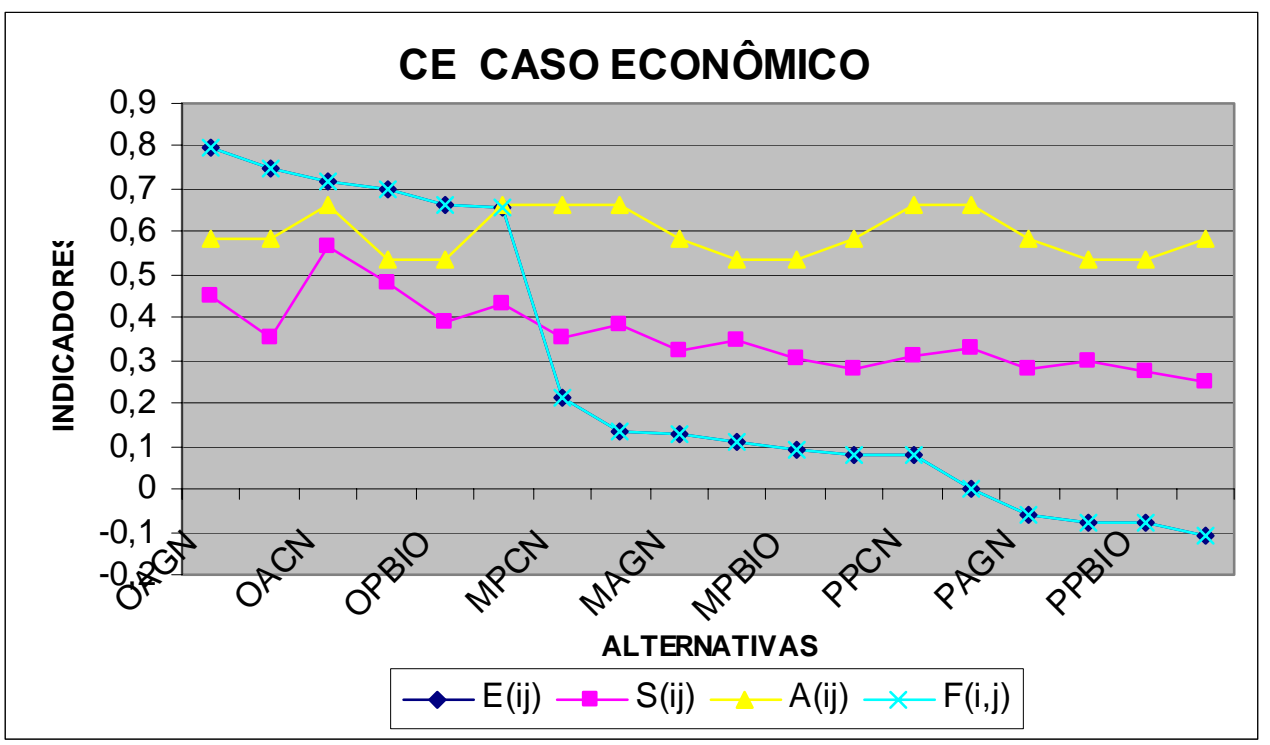

Figura 4 - Resultados CE - Caso Econômico

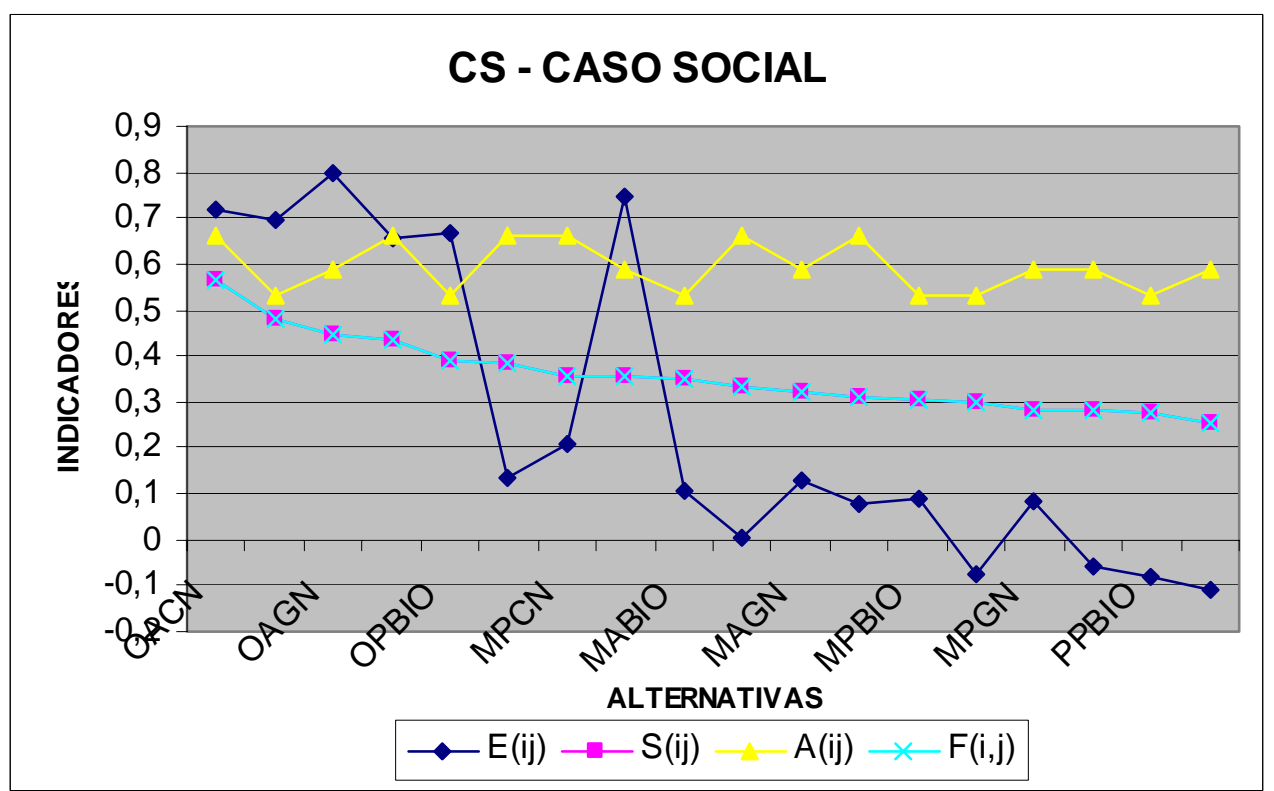

Figura 5 - Resultados CS - Caso Social 


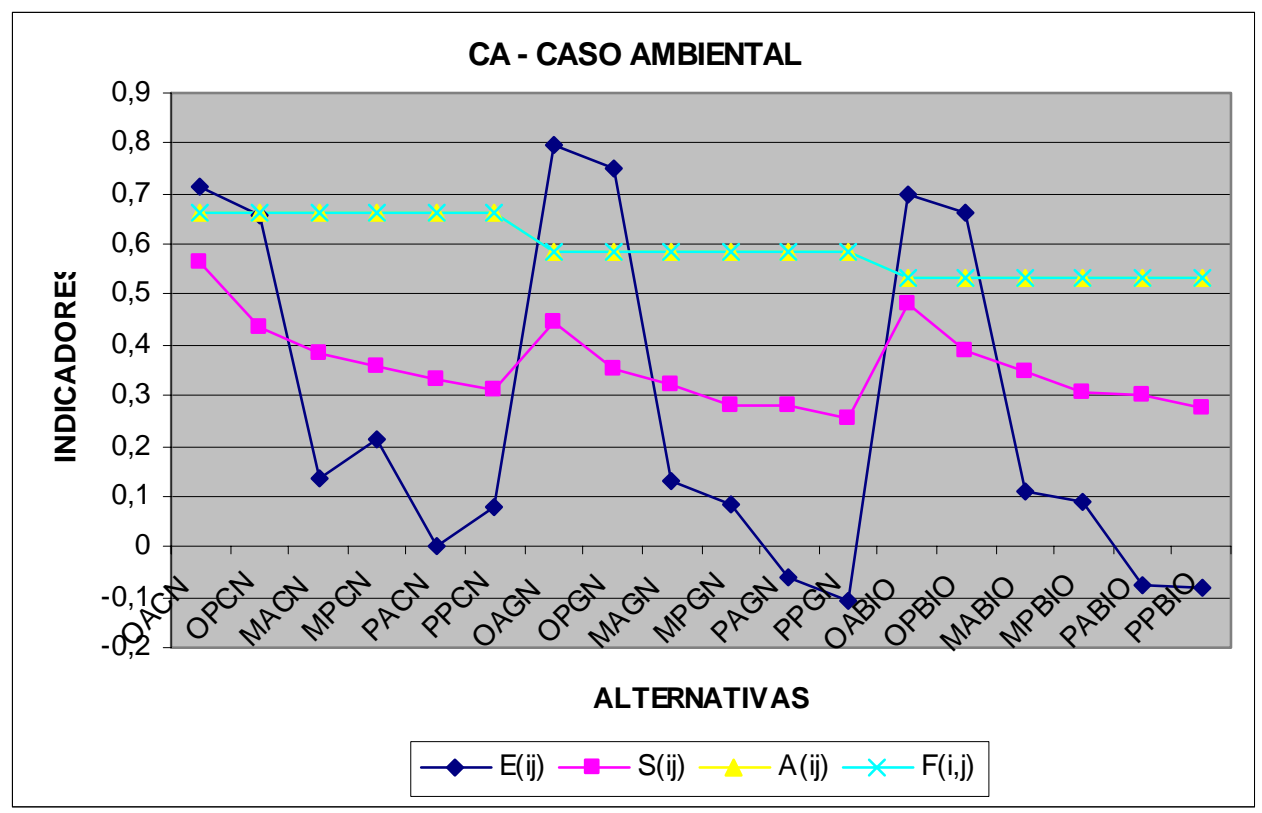

Figura 6 - Resultados CA - Caso Ambiental

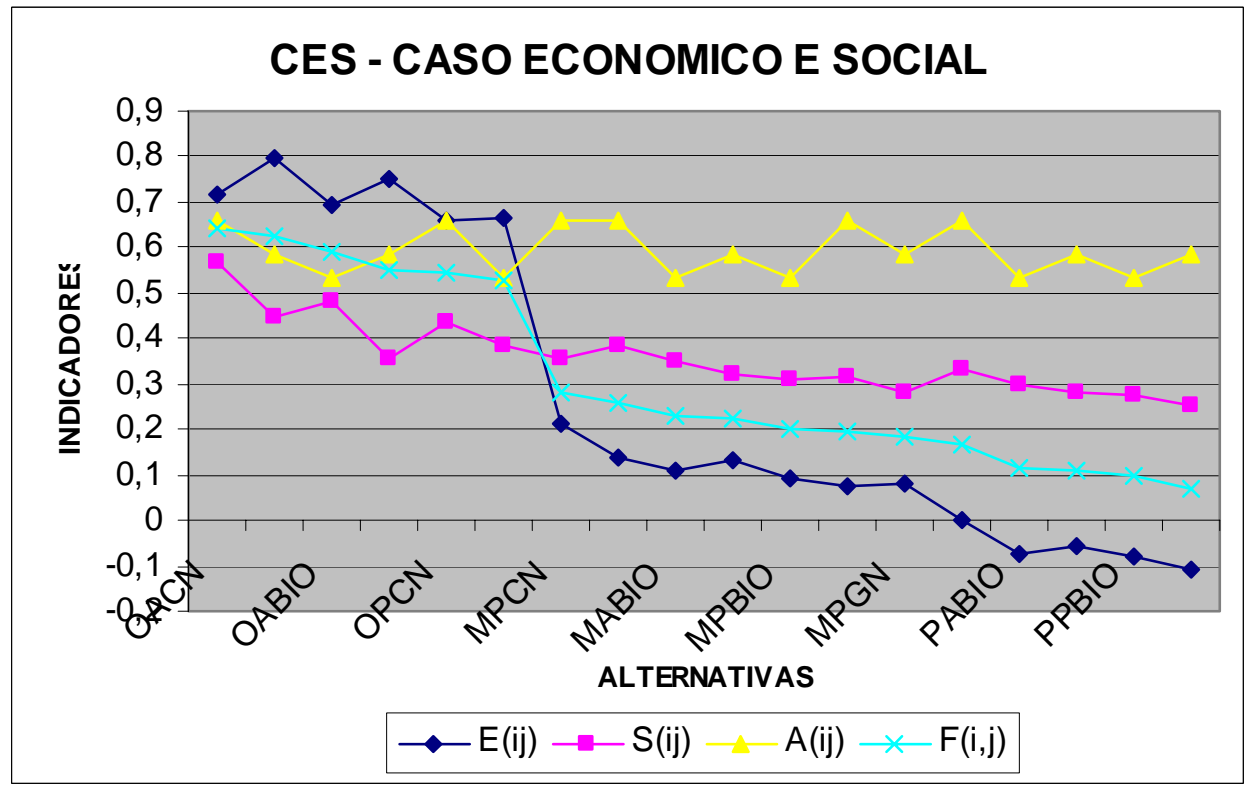

Figura 7 - Resultado CES - Caso Econômico Social 


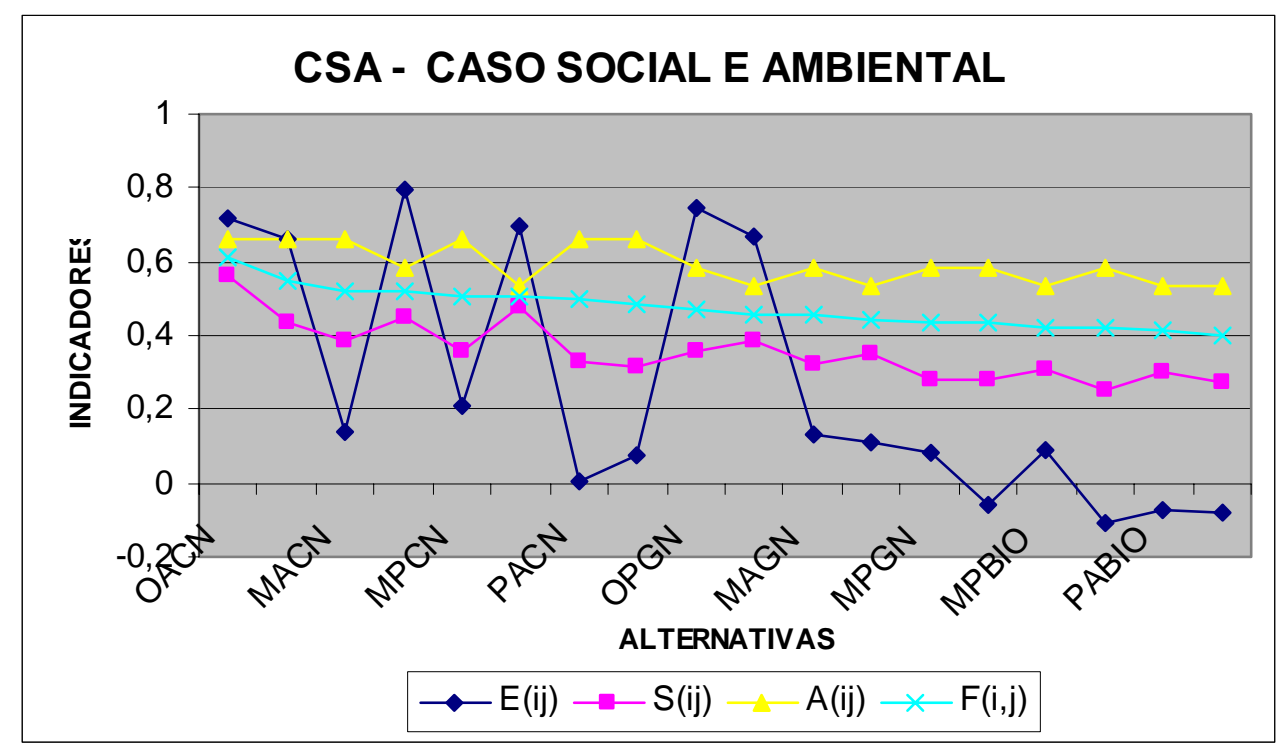

Figura 8 - Resultados Caso CSA - Caso Social Ambiental

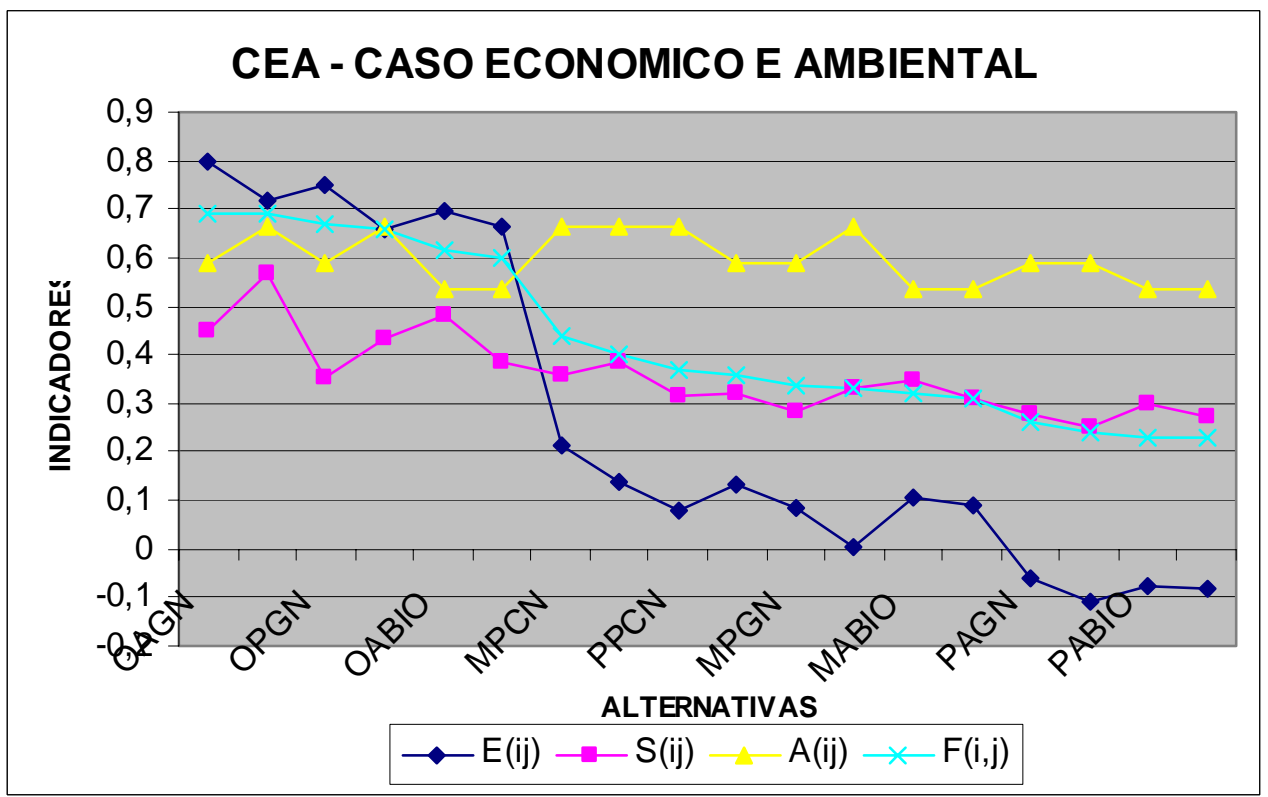

Figura 9 - Resultados Caso CEA - Caso Econômico Ambiental

A Figura 10 apresenta uma avaliação dos indicadores para cada alternativa, após a aplicação dos pesos dos cenários em cada caso simulado, onde:

AGN - Alternativa Turbina a Gás Natural em Alcobaça ABIO - Alternativa $\mathrm{MCl}$ com Óleo Combustível B-5 (Biodiesel) em Alcobaça ACN - Alternativa de Turbina a Vapor com Bagaço de Cana em Alcobaça PGN - Alternativa Turbina a Gás Natural em Porto Seguro 
PBIO - Alternativa MCl com Óleo Combustível B-5 (Biodiesel) em Porto Seguro

PCN - Alternativa de Turbina a Vapor com Bagaço de Cana em Porto Seguro

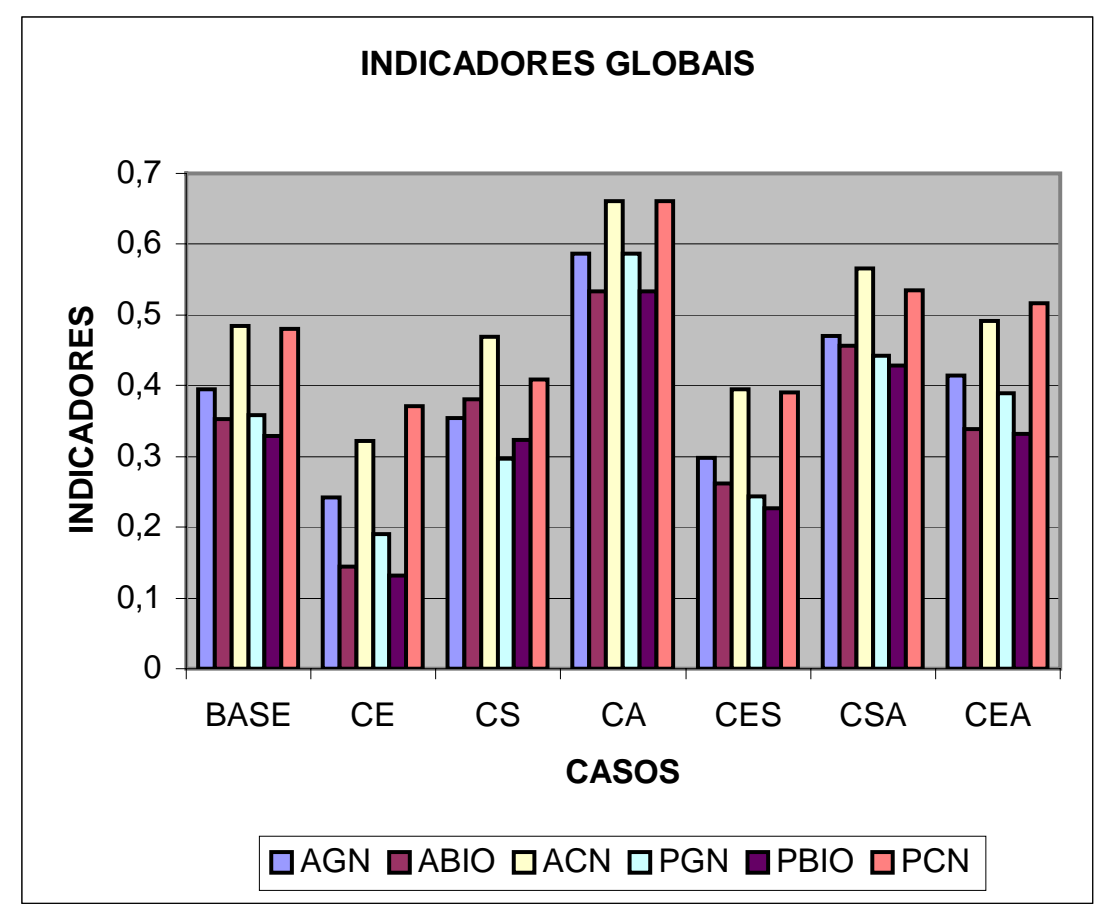

Figura 10 - Indicadores Globais para as Alternativas

\subsection{Comentários dos Resultados e Análise de Sensibilidade}

Da análise das simulações realizadas observa-se que:

- O caso base indica que a solução mais adequada, considerando as ponderações adotadas, foi a aplicação de Turbina a Vapor com queima de bagaço de cana em Porto Seguro, exprimindo um equilíbrio entre os benefícios econômicos, sociais e ambientais;

- O aspecto social pode alterar a ordem de priorização das soluções, quando classificadas apenas pelo critério econômico, como se pode observar na instalação 
de geração por queima de bagaço de cana em Alcobaça no caso base e na aplicação de turbina a Gás Natural no Caso Econômico;

- O impacto social positivo de uma geração em um município, diante de suas características sócio econômicas podem direcionar a solução para uma localidade, independentemente dos benefícios econômicos, como é observado no caso da preferência pelo município de Alcobaça preterindo Porto Seguro em qualquer uma das tecnologias consideradas;

- Embora todas as alternativas consideradas atendam as restrições ambientais, nota-se que as alternativas que aplicam a tecnologia de queima de bagaço de cana são priorizadas diante das demais;

- Os casos analisados consideram a venda de energia e de demanda, o que pode ser visto como o fornecimento a um consumidor que contrata uma geração para substituir uma parcela da energia fornecida pela concessionária. Por outro lado, os casos analisados podem representar o suprimento de cargas isoladas ou a contribuição a uma concessionária que substitui investimentos em instalações para garantia de oferta pela contratação de um gerador distribuído.

- Na proposta de identificar o projeto com melhores características sociais, a alternativa com Turbina a Vapor em Alcobaça com Bagaço de Cana de Açúcar como insumo é a que apresenta melhor resposta nos casos Base, CS, CA, CES, CSA e CEA, sendo candidata ao Certificado Beneficio Social. 


\section{CONCLUSÃO, CONTRIBUIÇÕES E PROSSEGUIMENTO DA PESQUISA}

\subsection{Conclusão}

As recentes transformações que vem se processando no setor elétrico brasileiro, desestatizando os segmentos de geração e de distribuição, ao lado da crescente necessidade de investimentos para expansão da oferta de energia elétrica, tem oferecido interessantes oportunidades para implementação de geração distribuída.

Por outro lado, a crescente importância da responsabilidade social e ambiental exigida de empreendimentos, especialmente daqueles de infra-estrutura, tem exigido uma visão multidisciplinar dos estudos de viabilidade, que outrora era elaborada fundamentalmente sob a ótica econômica.

Assim, atualmente o aspecto puramente econômico do investidor deve ser mesclado pelo seu interesse na responsabilidade social, sob o pano de fundo das exigências regulatórias, incluindo as ambientais.

O modelo desenvolvido nesta pesquisa é uma solução para avaliar o mérito de um empreendimento de geração distribuída, considerando os aspectos econômico, social e ambiental.

Fundamentado em várias informações disponíveis em bases de dados constituídas por várias instituições, como o IBGE - Instituto Brasileiro de Geografia e Estatística, Fabricantes de Geradores, Municipalidades, dentre outras, o modelo proposto foi concebido para calcular diferentes indicadores de mérito que quantifica, objetivamente, aspectos econômicos como a taxa de retorno de capital e a margem liquida, bem como fatores sociais como o impacto na educação, na saúde, na renda e no emprego e ainda, restrições ambientais.

A intensidade da responsabilidade social subjetiva do investidor pode ser manifesta a partir de vários indicadores sociais concebidos, de forma hierárquica, os quais se compõem e expressam a importância relativa de vários aspectos que podem impactar a comunidade onde a geração é instalada. 
A solução apresentada, sem prejuízo da avaliação dos aspectos pragmáticos relativos à viabilidade econômica e respeito à regulamentação ambiental, traz uma forma simples e clara de atribuir um grau de mérito agregado às alternativas de implementação de geração distribuída, considerando o impacto social positivo que representa.

A análise de cenários e de sensibilidade, considerando a aplicação de pesos ponderados, diante da variação de parâmetros diversos, permite aferir o grau de robustez e de importância da precisão de variáveis específicas.

O estudo de caso analisado permite ilustrar a importância de aplicação da metodologia, que ressalta os aspectos sociais, ambientais e locacionais, muitas vezes não considerados na priorização de investimentos em Geração Distribuída.

A idéia de atribuir um Certificado Beneficio Social ao empreendimento, embora não seja inédita, foi integrada ao modelo que propõe um procedimento inovador e objetivo para graduar a implementação de uma geração distribuída, podendo eventualmente se prestar como indicador de financiamentos privilegiados ou outros incentivos do gênero.

Do exposto, entende-se que o modelo apresentado, embora não esgote o tema, é uma importante contribuição para incentivar a forma de avaliar um empreendimento de geração distribuída.

\subsection{Contribuições}

O modelo de solução para quantificação integrada de aspectos econômicos, sociais e ambientais de uma implementação de geração distribuída é a principal contribuição deste trabalho. Com este modelo é possível avaliar os benefícios que um empreendimento dessa natureza possa trazer, considerando aspectos de responsabilidade social, sem prejuízo da avaliação econômica e o atendimento às regulamentações ambientais, destacando-se contribuições em: 
- Concepção e procedimento da avaliação de indicadores de cunho social, fundamentados em bases de dados e em informações objetivas, disponíveis e aberta;

- Possibilidade de expressão do beneficio social de um empreendimento por meio de indicadores;

- Integrar resultados do mérito econômico e ambiental ao impacto social do empreendimento;

- Possibilitar a verificação da robustez e sensibilidade de uma solução, diante de cenários possíveis, envolvendo aspectos de oferta e de demanda de energia;

- Apoiar investidores a identificar projetos que atendam as políticas publicas de Geração de Energia Elétrica;

- Permitir avaliar os benefícios sociais decorrentes da implantação de uma geração distribuída associados a diferentes municípios;

- Proposição de emissões de Certificados de Benefícios Sociais associados a um empreendimento de geração distribuída, que poderiam, a semelhança dos Certificados de Redução de Emissões, ser comercializados, promovendo e incentivando empreendimentos que resultam em melhorias sociais.

- Disponibilizar uma metodologia para avaliação do impacto social de Geração Distribuída, que possa ser utilizada no planejamento da expansão da oferta de energia.

\subsection{Temas para o prosseguimento da pesquisa}

Durante o desenvolvimento deste trabalho surgiram vários temas que não foram detalhados por serem exógenos ao objeto central desta pesquisa, mas representam importantes tópicos que poderiam ser explorados futuramente, dando prosseguimento ao aperfeiçoamento do modelo proposto ou contribuindo com a linha de pesquisa desta tese. Dentre esses estão: 
- Aperfeiçoamento de modelos de avaliação do impacto social da energia elétrica em comunidades, analisando condições sociais antes e após a implantação do projeto;

- Diretrizes para Programas de Incentivo a geração distribuída, fundamentados no mérito de responsabilidade social que apresentam;

- Refinamento do modelo para o cálculo de custos de transporte de insumos primários e de conexão da geração distribuída à rede de distribuição de energia;

- Integração do modelo proposto ao processo de Planejamento Integrado de Recursos;

- Introdução de procedimentos de comercialização mais elaborados no modelo proposto, considerando aspectos probabilísticos.

- Introdução de álgebra Fuzzy para avaliação dos indicadores

- Estudos com mérito em Decisões Participativas, incluindo novos pesos e indicadores, avaliados por cenários externos, utilizando Analise Hierárquica (AHP) e programação em Delphi.

- Estudo dos riscos de investimentos nos projetos escolhidos aplicando métodos estatísticos objetivos como o Value at Risk.

- Utilização de modelos geo-referenciados como por exemplo, o ARC GIS, para suporte a metodologia.

- Integrar a metodologia outros pesos para análise, como por exemplo, um peso tecnológico baseado no índice de nacionalização dos equipamentos a serem instalados. 


\section{REFERÊNCIAS BIBLIOGRÁFICAS}

[1] ABREU, P.L.; MARTINEZ,J.A. Gás Natural: O Combustível do novo Milênio. Porto Alegre: Plural Comunicação, 1999. 92 p.

[2] AGÊNCIA NACIONAL DE ENERGIA ELÉTRICA. Nota Técnica Revisão Tarifária no 30/2003. In: <http://www.aneel.gov.br>. Acesso em 12 nov 2006.

[3] AGÊNCIA NACIONAL DE ENERGIA ELÉTRICA. PRODIST - Módulos do PRODIST. In: <http://www.aneel.gov.br/visualizar texto.cfm?idxt=939> . Acesso em 15 jun 2007.

[4] ARAUJO, M.S.M. Relatório de Análise do Mecanismo de Desenvolvimento Limpo - MDL - Estudo de Caso ANEEL/MCT/PNUD, Brasilia, 2000.

[5] BALESTIERE, J.A.P. Cogeração: Geração Combinada de Eletricidade e Calor. Florianópolis: Ed. UFSC, 2002.

[6] BIODIESEL Palestras / Documentos. Disponível em <http://www.biodiesel.gov.br/redearquivos/rede documentos.htm>. Acesso em: 12 abr 2007.

[7] BIODIESELBR: Mapa do Biodiesel, 2007.

[8] BLASQUES, L.C.M. Estudo da Viabilidade Técnico-Econômica de Sistemas Híbridos para Geração de Eletricidade. 2005. Dissertação de Mestrado, UFPA, Belém, 2005.

[9] BLASQUES,L.C.M.; TUPIASSU,A.F. ; PINHO,J.T. Análise Econômica de Tecnologias para Eletrificação de uma Pequena Comunidade Isolada na Amazônia. SNPTEE, Curitiba, out. 2005.

[10] BOSE, A.; CASAVANT, K.; et al. Modeling the Interaction between the technical, Social, Economical and Environmental Components of Large Scale Electric Power Systems. EPNES Workshop, Orlando, out. 2003.

[11] CADDET/IEA/OECD. A Centralized Thermophilic Biogas Plant in Dennamark. Technical Brochure CADDET/IEA/OECD, nº 43, 1996.

[12] CADDET/IEA/OECD Combined Heat and Power Plant Burns Woodchip and Biogas. Technical Brochure CADDET/IEA/OECD, nº 149, mar. 2001.

[13] CAMPOS, C.P. A Conservação de Florestas no Brasil, Mudança de Clima e o Mecanismo de Desenvolvimento Limpo do Protocolo de Kyoto. 2001. Dissertação de Mestrado - COPPE, UFRJ, Rio de Janeiro, 2001. 
[14] CENTROCLIMA: Geração de Energia Elétrica por meio de uma Usina Termelétrica movida a Biomassa para operar acoplada a uma Pequena Central Hidrelétrica em Rondônia. Relatório Técnico CENTROCLUMA, Projeto MMA, 2003.

[15] COELHO,S.T. Mecanismos para Implementação da Cogeração de Eletricidade a partir da Biomassa - Um Modelo para o Estado de São Paulo. 1999. Tese de Doutoramento - EPUSP, Universidade de São Paulo, São Paulo, 1999.

[16] COELHO,S.T.; PALETTA, C.E.M.; FREITAS, M.A.V. Medidas Mitigadoras para a Redução de Emissões de Gases de Efeito Estufa na Geração Termelétrica Projeto BRA/00/29, ANEEL, Brasília 2000.

[17] COELHO,S.T.; SILVA,O.C.; CONSIGLIO,M.; PISETTA,M; MONTEIRO,M.B.C.A. Panorama do Potencial de Biomassa no Brasil - Projeto BRA/00/29. ANEEL, Brasília, 2002.

[18] COELHO,S.T.; ZYLBERSZTAIN, D. Barreiras e Mecanismos de Implementação à Cogeração de Eletricidade a partir de Biomassa. III Congresso Brasileiro de Planejamento Energético, São Paulo, 1998.

[19] COElho,S.T.; BOlOGNINI, M.F; PAletTA, C.E.; GUARDABASSI, P.M. Evaluation of Externalities in Sugarcane-Origin Cogenertation Process in Brazil. 1 World Conference and Exhibition for Energy and Industry, Sevilha, 2000.

[20] CORREIA, J.C. Atendimento Energético a Pequenas Comunidades Isoladas: Barreiras e Possibilidades. Revista T\&C Amazônia, Ano III, n6, jan. 2005.

[21] CREA/RJ: CONSELHO REGIONAL DE ENGENHARIA E ARQUITETURA/RJ Pagando pra Ver. Revista CREA/RJ, Rio de Janeiro: CREA/RJ, nº 50. 2005. p.3033.

[22] GASPETRO: banco de dados. In: GASPETRO. Disponível em: < www.gaspetro.com.br>. Acesso em 14 abr 2007.

[23] IBGE: banco de dados. In: INSTITUTO BRASILEIRO DE GEOGRAFIA E ESTATISTICA. Disponível em < http://www.ibge.gov.br/cidadesat/default.php>. Acesso em 14 fev 2007.

[24] INEE: Instituto Nacional de Eficiência Energética. Avaliação Econômica Financeira para Serraria. Relatório Técnico, 2004. 
[25] INSTITUTO ETHOS: Home. In: ETHOS. Disponível em $<$ http://www.ethos.org.br/DesktopDefault.aspx?TabID=3344\&Alias=ethos\&Lang=ptBR>. Acesso em 15 mai 2007.

[26] JOCKYMAN,A. Lucro Verde, Revista Eco21, Ano XIII, ed. 81, 2003.

[27] KIRCHSTEIGER,C.; TEICHMANN,J.; BALLING,L. Probabilistic Outage Analysis of a combined-cycle power plant. Fuel and Energy Abstracts, Amsterdan, v.36, p. 452, nov.1995.

[28] LORA,E.S.L. Prevenção e Controle da Poluição nos Setores Energético, Industrial e de Transporte. 2. ed. Rio de Janeiro: Ed. Interciência, 2002. 503 p.

[29] MACEDO, W.M.; OLIVEIRA, L.G.M.; BRITO, A.U.; ZILLES, R.; PINHO, J.T. Metodologia de Avaliação do Problema de Suprimentos de Energia Elétrica em Comunidades não Atendidas: O Caso da Comunidade de Maruja. Congresso Brasileiro de Energia, Rio de Janeiro, 2004.

[30] MACIEL, D.M.H. Internalização de Variáveis Ambientais na Análise da Viabilidade de Projetos: O caso do Setor Elétrico. 2001. Dissertação de Mestrado, UFSC, Florianópolis, 2001.

[31] MAGALHÃES SOBRINO, P. Oportunidade de Negócios através da Obtenção de Créditos de Carbono e Cogeração. Palestra CPFL In: <http://www.cpfl.com.br/new/brasil/>. Acesso em 15 abr 2007.

[32] MINISTÉRIO DO MEIO-AMBIENTE. RESOLUÇÃO/CONAMA/N. ${ }^{\circ} 005$ de 15 jun 1989. In: <http://www.mma.gov.br/port/conama/res/res89/res0589.html> . Acesso em 22 mar 2006.

[33] MMA: MINISTÉRIO DO MEIO-AMBIENTE. RESOLUÇÃOICONAMA/N. ${ }^{\circ} 003$ de 28 jun 1990. In: <http://www.mma.gov.br/port/conama/res/res90/res0390.html >. Acesso em 22 mar 2006.

[34] MMA: MINISTÉRIO DO MEIO-AMBIENTE. RESOLUÇÃOICONAMA/N. ${ }^{\circ} 008$ de 06 dez 1990. In: <http://www.mma.gov.br/port/conama/res/res90/res0890.html >. Acesso em 22 mar 2006.

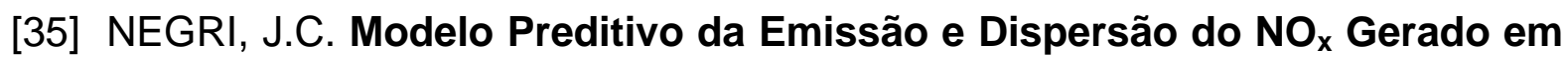
Usinas Termoelétricas como Instrumento de Análise de Inserção e Capacidade de Suporte Regional da Qualidade do Ar. 2002. Tese (Doutorado em Engenharia Mecânica), Universidade de São Paulo, São Paulo, 2002. 
[36] OLIVEIRA, L.B.; COSTA, A.O. Biodiesel - Uma Experiência de Desenvolvimento Sustentável. In: <http://www.ivig.coppe.ufrj.br/doc/biodiesel.pdf>. Acesso em 15 fev 2007.

[37] PEREIRA, A.S. Do fundo ao Mecanismo: Gênese, Características e Perspectivas para o Mecanismo de Desenvolvimento Limpo; Ao encontro ou de Encontro à Equidade?. 2002. Dissertação de Mestrado - COPPE, UFRJ, Rio de Janeiro, 2002.

[38] PETROBRAS: PORTAL BR, In: <http://www.br.com.br/portalbr/calandra.nsf/ first/0036default> . Acesso em 16 fev 2007.

[39] PEUGEOT: Poço de Carbono. In: <http://www.peugeot.com.br/ecologia/ poco.htm> . Acesso em 15 mai 2007.

[40] PNUD: Programa das Nações Unidas para o Desenvolvimento. Atlas do Desenvolvimento Humano no Brasil . In: < http://www.pnud.org.br/atlas/, 2000> . Acesso em 12 jan 2007.

[41] QUAAK, P.; KNOEF, H.; STASSEN, H. Energy from Biomass - A Review of Combustion and Gasification Technologies. World Bank Technical Paper 422 , Washington, 1999.

[42] ROCHA, M.T. Aquecimento Global e o Mercado de Carbono - Uma Aplicação do Modelo CERT. 2003. Tese (Doutorado em Economia Aplicada) Escola Superior de Agricultura Luiz de Queiroz, Universidade de São Paulo, Piracicaba, 2003.

[43] RUBIN,E.S.;RAO,A.B.;CHEN,C. Comparative Assessments of Fossil Fuel Power Plants with $\mathrm{CO} 2$ Capture and Storage. Proceedings of 7th International Conference on Greenhouse Gas Control Technologies, Vancouver, set. 2004.

[44] SÁ JUNIOR, G.N.; AZEVEDO, R.O. Análise Econômico-Financeira para Implantação de Centrais Termelétricas a Gás no Brasil. 2002. Trabalho de Conclusão (Engenharia Mecânica) UNIFEI, Itajubá, 2002,

[45] SANTOS, N.O. Termodinâmica Aplica às Centrais Termelétricas - Teoria e Prática . Rio de Janeiro: Ed. Interciência, 2000. 118 p.

[46] SIMS,R.E.H; ROGNER,H.H.; GREGORY,K. Carbon emission and mitigation cost comparisons between fossil fuel, nuclear and renewable energy resources for electricity generation. Energy Police, Amsterdan, v.31, p.1312-1325, 2003.

[47] SOUZA, S.M.N; PEREIRA,W.C.; NOGUEIRA,C.E.C; PAVAN,A.A.; SORDI,A. Custo da eletricidade gerada em conjunto motor gerador utilizando biogás da 
Suinocultura. Revista Acta Scientariun Technology, Maringá, v.26, n², p.127-134, 2004.

[48] STEMAC: Tabela de Potência para Grupos Geradores à Gás Natural. In: $<$ http://www.stemac.com.br/content/produtos/prod_gasnatural_tabela.asp?Feature_i $d=27 \&$ line_id=224>. Acesso em 22 nov 2006.

[49] TOLMASQUIM, M.T. (Coord.) Geração de Energia Elétrica no Brasil. Rio de Janeiro: Ed. Interciência/COPPE-CENERGIA, 2005. 198 p.

[50] TORTORELLO, L.M. O Impacto da Oferta de Energia Elétrica no Desenvolvimento Social - Uma Contribuição ao Modelo de Planejamento da Expansão. 2003. Dissertação (Mestrado em Engenharia Elétrica), Universidade de São Paulo, São Paulo, 2003.

[51] UDAETA, M.E.M. Planejamento Integrado de Recursos Energéticos - PIR para o Setor Elétrico (pensando o Desenvolvimento Sustentável). 1997. Tese (Doutorado em Engenharia Elétrica), Universidade de São Paulo, São Paulo, 1997.

[52] VALOR ECONÔMICO Tractebel vende crédito de carbono ao Japão, São Paulo, 12 jan 2007. 


\section{ANEXO I}

\section{POTENCIALIDADES REGIONAIS DE GERAÇÃO DE ENERGIA COM CANA DE AÇUCAR E ÓLEOS VEGETAIS SEGUNDO COELHO [17]}

Oportunidades de Aproveitamento de Biomassa encontradas na Região Norte para Geração de Energia Elétrica (MW).

\begin{tabular}{|c|c|c|}
\hline MESORREGIÃO & 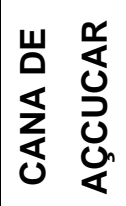 & 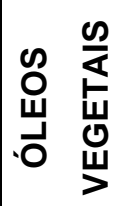 \\
\hline Centro Amazonense & 2.83 & \\
\hline Sudoeste Paraense & 2,19 & \\
\hline Sudeste Paraense & 5,15 & \\
\hline Nordeste Paraense & & 155,5 \\
\hline
\end{tabular}

Oportunidades de Aproveitamento de Biomassa encontradas na Região Nordeste para Geração de Energia Elétrica (MW)

\begin{tabular}{|c|c|c|}
\hline MESORREGIÃO & 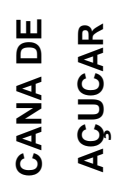 & 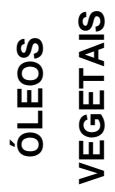 \\
\hline Centro Maranhense & 5 & \\
\hline Sul Maranhense & 5 & \\
\hline Leste Maranhense & 5 & \\
\hline Centro-Norte Piauiense & 5 & \\
\hline Sul Cearense & 5 & \\
\hline Leste Potiguar & 22 & \\
\hline Mata Paraibana & 45 & \\
\hline Metropolitana de Recife & 45 & \\
\hline Mata Pernambucana & 165,93 & \\
\hline Leste Alagoano & 369,31 & \\
\hline Leste Sergipano & 22 & \\
\hline Vale São Francisco Bahia & 22 & \\
\hline Metropolitana de Salvador & 5 & 40 \\
\hline Sul Baiano & 5 & 4,28 \\
\hline
\end{tabular}


Oportunidades de Aproveitamento de Biomassa encontradas na Região CentroOeste para Geração de Energia Elétrica (MW)

\begin{tabular}{|c|c|}
\hline MESORREGIÃO & 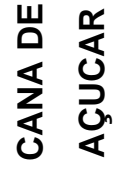 \\
\hline Norte Mato-Grossense & 23 \\
\hline Nordeste Mato-Grossense & 5 \\
\hline Sudoeste Mato-Grossense & 73,98 \\
\hline Centro Sul Mato-Grossense & 5 \\
\hline Sudeste Mato-Grossense & 23 \\
\hline Centro Norte do M. Grosso do Sul & 23 \\
\hline Sudoeste de Mato Grosso do Sul & 46 \\
\hline Leste de Mato Grosso do Sul & 23 \\
\hline Centro Goiano & 46 \\
\hline Sul Goiano & 61,79 \\
\hline
\end{tabular}

Oportunidades de Aproveitamento de Biomassa encontradas na Região Sul para Geração de Energia Elétrica (MW)

\begin{tabular}{|c|c|c|}
\hline MICRORREGIÃO & 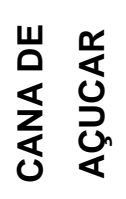 & 足 \\
\hline Noroeste Paranaense & 117,76 & \\
\hline Norte Central Paranaense & 97,84 & \\
\hline Norte Pioneiro Paranaense & 47,45 & \\
\hline Centro Ocidental Paranaense & 19,77 & \\
\hline
\end{tabular}


Oportunidades de Aproveitamento de Biomassa encontradas na Região Sudeste para Geração de Energia Elétrica (MW)

\begin{tabular}{|c|c|}
\hline MESORREGIÃO & 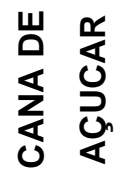 \\
\hline Presidente Prudente & 25 \\
\hline Araçatuba & 130 \\
\hline Assis & 130 \\
\hline Bauru & 270 \\
\hline São Jose do Rio Preto & 270 \\
\hline Ribeirão Preto & 849,86 \\
\hline Central Mineira & 25 \\
\hline Vale do Mucuri & 25 \\
\hline Zona da Mata & 25 \\
\hline Sul/Sudoeste de Minas & 25 \\
\hline Araraquara & 130 \\
\hline Campinas & 130 \\
\hline Piracicaba & 270 \\
\hline Itapetininga & 25 \\
\hline Baixada Fluminense & 25 \\
\hline Norte Fluminense & 25 \\
\hline Sul Espírito-Santense & 25 \\
\hline Litoral Norte Espírito-Santense & 25 \\
\hline
\end{tabular}




\section{ANEXO II}

\section{LOCALIZAÇÃO DE CITY-GATES E MAPA SISTEMA GASODUTOS BRASIL Localização City - Gates Brasileiros (1/2)}

\begin{tabular}{|c|c|}
\hline DESCRIÇÃO & LOCALIZAÇÃO \\
\hline Petrobrás Transporte SA - TRANSPETRO & City-gate Mossoró (PB) (Gasoduto Guamaré - Pecém) \\
\hline Petróleo Brasileiro S.A - PETROBRAS & City-gate UTE Macaé Merchant \\
\hline Petróleo Brasileiro S.A - PETROBRAS & City-gate UTE Juiz de Fora \\
\hline Petróleo Brasileiro S.A - PETROBRAS & City-gate UTE RioGen Merchant - Japeri (RJ) \\
\hline Petróleo Brasileiro S.A - PETROBRAS & City-gate de Guapimirim (Gasoduto Cabiúnas - Reduc / GASDUC) \\
\hline Petróleo Brasileiro S.A - PETROBRAS & City-gate de São Bernardo do Campo (Gasoduto GASAN) \\
\hline Petróleo Brasileiro S.A - PETROBRAS & City-gate de Duque de Caxias TERMORIO (Gasodutos GASDUC I e II e GASVOL) \\
\hline Petróleo Brasileiro S.A - PETROBRAS & City-gate de Barbacena (MG) (Gasoduto GASBEL) \\
\hline Petróleo Brasileiro S.A - PETROBRAS & City-gate de Paracambi (RJ) (Gasoduto GASVOL) \\
\hline Petróleo Brasileiro S.A - PETROBRAS & City-gate de Macaé (RJ) (Norte Fluminense) (Gasoduto GASDUC I e II) \\
\hline Petróleo Brasileiro S.A - PETROBRAS & City-gate de Macaé (RJ) (Macaé Merchant)(Gasoduto GASDUC I e II) \\
\hline Petrobrás Transporte SA - TRANSPETRO & City-gate de Aracati (CE) e ramal (Gasoduto GASFOR) \\
\hline Petrobrás Transporte SA - TRANSPETRO & City-gate de Caucaia (CE) (Gasoduto GASFOR) \\
\hline Petrobrás Transporte SA - TRANSPETRO & City-gate e ramal (Termofortaleza) (Gasoduto GASFOR) \\
\hline Petrobrás Transporte SA - TRANSPETRO & City-gate e ramal (Termopernambuco) (Gasoduto GASALP) \\
\hline Consórcio Malhas Sudeste Nordeste & City-Gate em Pedras de Fogo (PB) (Gasoduto Guamaré-Cabo "Nordestão") \\
\hline Consórcio Malhas Sudeste Nordeste & City-Gate em São Brás do Suaçuí (MG) (Gasoduto GASBEL) \\
\hline Petrobrás Transporte SA - TRANSPETRO & City-Gate em Aracruz (ES) (Gasoduto Lagoa Parda - Vitória) \\
\hline Transportadora Brasileira Gasoduto Bolívia-Brasil - TBG & City-Gate Corumbá / MS (Gasoduto Bolívia-Brasil) \\
\hline Transportadora Brasileira Gasoduto Bolívia-Brasil - TBG & City-Gate Campo Grande / MS (Gasoduto Bolívia-Brasil) \\
\hline Transportadora Brasileira Gasoduto Bolívia-Brasil - TBG & City-Gate Três Lagoas / MS (Gasoduto Bolívia-Brasil) \\
\hline Transportadora Brasileira Gasoduto Bolívia-Brasil - TBG & City-Gate Valparaíso / SP (Futura) (Gasoduto Bolívia-Brasil)* \\
\hline Transportadora Brasileira Gasoduto Bolívia-Brasil - TBG & City-Gate Bilac / SP (Gasoduto Bolívia-Brasil) \\
\hline Transportadora Brasileira Gasoduto Bolívia-Brasil - TBG & City-Gate Boa Esperança do Sul / SP (Gasoduto Bolívia-Brasil) \\
\hline Transportadora Brasileira Gasoduto Bolívia-Brasil - TBG & City-Gate São Carlos / SP (Gasoduto Bolívia-Brasil) \\
\hline Transportadora Brasileira Gasoduto Bolívia-Brasil - TBG & City-Gate Rio Claro / SP (Gasoduto Bolívia-Brasil) \\
\hline Transportadora Brasileira Gasoduto Bolívia-Brasil - TBG & City-Gate Limeira / SP (Gasoduto Bolívia-Brasil) \\
\hline Transportadora Brasileira Gasoduto Bolívia-Brasil - TBG & City-Gate Americana / SP (Gasoduto Bolívia-Brasil) \\
\hline Transportadora Brasileira Gasoduto Bolívia-Brasil - TBG & City-Gate Replan / SP (Gasoduto Bolívia-Brasil) \\
\hline Transportadora Brasileira Gasoduto Bolívia-Brasil - TBG & City-Gate Jaguariúna / SP (Gasoduto Bolívia-Brasil) \\
\hline Transportadora Brasileira Gasoduto Bolívia-Brasil - TBG & City-Gate Itatiba / SP (Gasoduto Bolívia-Brasil) \\
\hline Transportadora Brasileira Gasoduto Bolívia-Brasil - TBG & City-Gate Guararema /SP (Gasoduto Bolívia-Brasil) \\
\hline Transportadora Brasileira Gasoduto Bolívia-Brasil - TBG & City-Gate Sumaré / SP (Gasoduto Bolívia-Brasil) \\
\hline Transportadora Brasileira Gasoduto Bolívia-Brasil - TBG & City-Gate Campinas / SP (Gasoduto Bolívia-Brasil) \\
\hline Transportadora Brasileira Gasoduto Bolívia-Brasil - TBG & City-Gate Indaiatuba / SP (Gasoduto Bolívia-Brasil) \\
\hline Transportadora Brasileira Gasoduto Bolívia-Brasil - TBG & City-Gate Itu / SP (Gasoduto Bolívia-Brasil) \\
\hline Transportadora Brasileira Gasoduto Bolívia-Brasil - TBG & City-Gate Porto Feliz / SP (Gasoduto Bolívia-Brasil)* \\
\hline Transportadora Brasileira Gasoduto Bolívia-Brasil - TBG & City-Gate Araçoiaba da Serra / SP (Gasoduto Bolívia-Brasil) \\
\hline Transportadora Brasileira Gasoduto Bolívia-Brasil - TBG & City-Gate Campo Largo / PR (Gasoduto Bolívia-Brasil)* \\
\hline Transportadora Brasileira Gasoduto Bolívia-Brasil - TBG & City-Gate Araucária CIC / PR (Gasoduto Bolívia-Brasil) \\
\hline
\end{tabular}




\section{LOCALIZAÇÃO DE CITY-GATES E MAPA SISTEMA GASODUTOS BRASIL}

\section{Localização City - Gates Brasileiros (2/2)}

\begin{tabular}{|c|c|}
\hline DESCRIÇÃO & LOCALIZAÇÃO \\
\hline Transportadora Brasileira Gasoduto Bolívia-Brasil - TBG & City-Gate REPAR / PR (Gasoduto Bolívia-Brasil) \\
\hline Transportadora Brasileira Gasoduto Bolívia-Brasil - TBG & City-Gate Araucária UTE / PR (Gasoduto Bolívia-Brasil) \\
\hline Transportadora Brasileira Gasoduto Bolívia-Brasil - TBG & City-Gate Joinville / SC (Gasoduto Bolívia-Brasil) \\
\hline Transportadora Brasileira Gasoduto Bolívia-Brasil - TBG & City-Gate Guaramirim / SC (Gasoduto Bolívia-Brasil) \\
\hline Transportadora Brasileira Gasoduto Bolívia-Brasil - TBG & City-Gate Gaspar / SC (Gasoduto Bolívia-Brasil) \\
\hline Transportadora Brasileira Gasoduto Bolívia-Brasil - TBG & City-Gate Brusque / SC (Gasoduto Bolívia-Brasil) \\
\hline Transportadora Brasileira Gasoduto Bolívia-Brasil - TBG & City-Gate Tijucas / SC (Gasoduto Bolívia-Brasil) \\
\hline Transportadora Brasileira Gasoduto Bolívia-Brasil - TBG & City-Gate São Pedro de Alcântara / SC (Gasoduto Bolívia-Brasil) \\
\hline Transportadora Brasileira Gasoduto Bolívia-Brasil - TBG & City-Gate Tubarão / SC (Gasoduto Bolívia-Brasil) \\
\hline Transportadora Brasileira Gasoduto Bolívia-Brasil - TBG & City-Gate Urussanga / SC (Gasoduto Bolívia-Brasil) \\
\hline Transportadora Brasileira Gasoduto Bolívia-Brasil - TBG & City-Gate Nova Veneza / SC (Gasoduto Bolívia-Brasil) \\
\hline Transportadora Brasileira Gasoduto Bolívia-Brasil - TBG & City-Gate Várzea do Cedro / RS (Gasoduto Bolívia-Brasil) \\
\hline Transportadora Brasileira Gasoduto Bolívia-Brasil - TBG & City-Gate Igrejinha / RS (Gasoduto Bolívia-Brasil)* \\
\hline Transportadora Brasileira Gasoduto Bolívia-Brasil - TBG & City-Gate Araricá / RS (Gasoduto Bolívia-Brasil) \\
\hline Transportadora Brasileira Gasoduto Bolívia-Brasil - TBG & City-Gate Cachoeirinhas / RS (Gasoduto Bolívia-Brasil) \\
\hline Transportadora Brasileira Gasoduto Bolívia-Brasil - TBG & City-Gate Canoas / RS (Gasoduto Bolívia-Brasil) \\
\hline Transportadora Brasileira Gasoduto Bolívia-Brasil - TBG & City-Gate REFAP/ RS (Gasoduto Bolívia-Brasil) \\
\hline Transportadora Brasileira Gasoduto Bolívia-Brasil - TBG & City-Gate UTE Canoas / RS (Gasoduto Bolívia-Brasil) \\
\hline
\end{tabular}

- Instalações Futuras

\section{Mapa de Gasodutos}

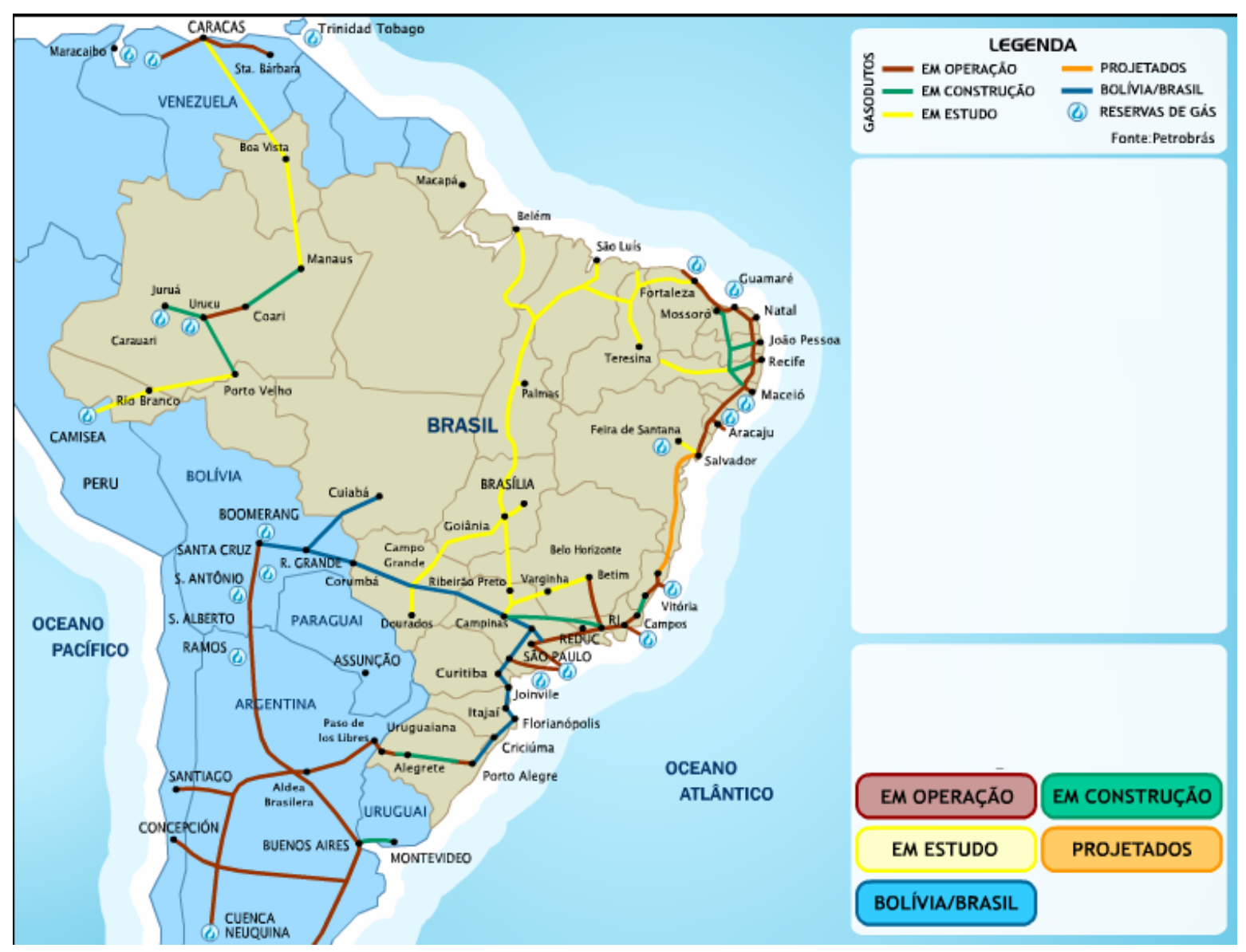




\section{ANEXO III \\ ESTOQUE DE ÓLEO DIESEL E SIMILARES}

\section{Tabela XXX - Estoque de Diesel e Similares $\left(\mathrm{m}^{3}\right)$ [TRANSPETRO]}

\begin{tabular}{|c|c|c|c|c|c|c|}
\hline DESCRIÇÃO & $\begin{array}{l}\text { Óleo Diesel } \\
\text { Tipo B / D }\end{array}$ & $\begin{array}{c}\text { Óleo Diesel } \\
\text { Marítimo }\end{array}$ & $\begin{array}{c}\text { Óleo combustível } \\
\text { A-1 e/ou A-2 }\end{array}$ & GN & GLP & Característica \\
\hline Utinga-São Caetano (SP) & 47516 & 6792 & 60919 & & & Terrestre \\
\hline Uberlândia (MG) & 35935 & & & & 9546 & Terrestre \\
\hline Uberaba (MG) & 21605 & & & & & Terrestre \\
\hline São Gonçalo (RJ) & 4480 & & & & & Terrestre \\
\hline Ribeirão Preto (SP) & 30528 & & & & 6367 & Terrestre \\
\hline Juiz de Fora (MG) & 5725 & & & & & Terrestre \\
\hline Joinville/Guaramirim (SC) & 8506 & & & & & Terrestre \\
\hline Jequié (BA) & 12136 & & & & 4817 & Terrestre \\
\hline Japeri (RJ) & 25500 & & & & & Terrestre \\
\hline Itajaí (SC) & 15474 & 9496 & & & 6364 & Terrestre \\
\hline Itabuna (BA) & 14830 & & & & 4816 & Terrestre \\
\hline Guarulhos (RJ) & 41304 & & & & & Terrestre \\
\hline Guararema (SP) & 84025 & & & & & Terrestre \\
\hline Goiânia (GO) & 84963 & & & & 20312 & Terrestre \\
\hline Cubatão (SP) & 20106 & & & & & Terrestre \\
\hline Celi-Duque de Caxias (RJ) & 68356 & & & & & Terrestre \\
\hline Candeias (BA) & 3070 & & 3066 & & & Terrestre \\
\hline Cabiunas-Macaé (RJ) & & & & 4868 & & Terrestre \\
\hline Brasília (DF) & 31436 & & & & 9520 & Terrestre \\
\hline Biguaçu (SC) & 15644 & & & & & Terrestre \\
\hline Barueri (SP) & 76842 & & 16400 & & 6570 & Terrestre \\
\hline Volta Redonda (RJ) & 3829 & & & & & Terrestre \\
\hline Soares Dutra (RS) & 47339 & & & & & Terrestre \\
\hline Madre de Deus (BA) & 106878 & & 105662 & & 52928 & Marítimo \\
\hline Tefé (AM) & 798 & & & & 1092 & Fluvial \\
\hline Suape-Ipojuca (PE) & 5717 & & 84546 & & & Marítimo \\
\hline São Sebastião (SP) & 212297 & & 40421 & & & Marítimo \\
\hline Solimões-Coari (AM) & & & & & 16000 & Fluvial \\
\hline Itaqui-São Luis (MA) & 43688 & & 27128 & & 4829 & Marítimo \\
\hline São Francisco do Sul (SC) & & & & & & Marítimo \\
\hline Rio grande (RS) & 17900 & & 16714 & & & Lacustre \\
\hline Reman-Manaus (AM) & & & & & & Fluvial \\
\hline Regência-Linhares (ES) & & & & & 90 & Marítimo \\
\hline Paranaguá (PR) & 52458 & & 34800 & & 9600 & Marítimo \\
\hline Niterói-Canoas (RS) & 10417 & & 5981 & & & Fluvial \\
\hline Dunas-Natal (RN) & 9132 & & & & & Fluvial \\
\hline Mucuripe-Fortaleza (CE) & & & & & & Marítimo \\
\hline Miramar-Belém (PA) & 17701 & & & & 6362 & Marítimo \\
\hline
\end{tabular}




\begin{tabular}{|c|c|c|c|c|c|c|}
\hline DESCRIÇÃO & $\begin{array}{c}\text { Óleo Diesel } \\
\text { Tipo B / D }\end{array}$ & $\begin{array}{c}\text { Óleo Diese } \\
\text { Marítimo }\end{array}$ & $\begin{array}{c}\text { Óleo combustível } \\
\text { A-1 e/ou A-2 }\end{array}$ & GN & GLP & Característica \\
\hline Maceio (AL) & & & & & & Marítimo \\
\hline Ilha Redonda (RJ) & & & & & 47243 & Marítimo \\
\hline Ilha Dágua (RJ) & 50914 & & 68329 & & & Marítimo \\
\hline Guamaré (RN) & & & & & 3000 & Marítimo \\
\hline Florianópolis-Biguaçu (SC) & 15644 & & & & & Terrestre \\
\hline Carmopolis-Aracaju (SE) & & & & & 6000 & Marítimo \\
\hline Cabedelo (PB) & & & & & & Marítimo \\
\hline Angra (RJ) & 21200 & & 67500 & & & Marítimo \\
\hline Alemoa-Santos (SP) & 47778 & & 130168 & & 91332 & Marítimo \\
\hline Vitória (ES) & 39300 & & 74000 & & & Marítimo \\
\hline Total (m3) & 1350971 & 16288 & 735634 & 4868 & 306788 & \\
\hline
\end{tabular}

Tabela - Estoque de Diesel e Similares $\left(\mathrm{m}^{3}\right)$

\begin{tabular}{|c|c|c|c|c|c|}
\hline DESCRIÇÃO & $\begin{array}{l}\text { Óleo Diesel } \\
\text { Tipo B }\end{array}$ & $\begin{array}{c}\text { Óleo Diesel } \\
\text { Tipo D }\end{array}$ & $\begin{array}{c}\text { Óleo Diesel } \\
\text { Marítimo }\end{array}$ & $\begin{array}{c}\text { Óleo combus- } \\
\text { tível A-1 }\end{array}$ & $\begin{array}{c}\text { Óleo Combus- } \\
\text { tível A-2 }\end{array}$ \\
\hline Vitória (ES) & 25354 & & 8233 & 37491 & 31454 \\
\hline Porto Velho (RO) & 11377 & & & & \\
\hline Belém (PA) & 8223 & 6248 & & 12635 & \\
\hline Manaus (AM) & 21485 & & & & \\
\hline SUAPE (PE) & 11501 & 22995 & & & \\
\hline São Luis (MA) & 16283 & & & 13857 & \\
\hline Fortaleza (CE) & 16429 & 8159 & & 8005 & \\
\hline Natal (RN) & & 11097 & & & \\
\hline Cruzeiro do Sul (AC) & & & 1364 & & \\
\hline Belo Monte (PA) & & & 1555 & & \\
\hline Oriximina (PA) & & & 1375 & 3629 & \\
\hline Vila do Conde (PA) & & & & 20106 & \\
\hline Caracarai (RR) & & & 6759 & & \\
\hline Maceio (AL) & 10218 & & & & \\
\hline Recife (RE) & & & 2492 & & \\
\hline Cabedelo (PB) & 6096 & & & & \\
\hline Total (m3) & 126966 & 48499 & 21778 & 95723 & 31454 \\
\hline
\end{tabular}




\section{ANEXO IV - EMISSÕES COM GERAÇÃO A TV [15]}

Emissões de particulados em caldeiras a bagaço de cana

\begin{tabular}{|l|c|c|}
\hline \multicolumn{1}{|c|}{ Condições de Operação } & $\begin{array}{c}\text { Emissões de } \\
\text { Particulados } \\
\left(\mathbf{m g} / \mathbf{N m}^{3}\right)\end{array}$ & $\begin{array}{c}\text { Quantidade de } \\
\text { particulados emitida } \\
\text { por tonelada de } \\
\text { bagaço queimado } \\
\mathbf{( 5 0 \%} \text { umidade) }\end{array}$ \\
\hline Recomendações da CETESB & 120 & 0,5 \\
\hline Caldeiras monitoradas pela CETESB & 150 & 0,6 \\
\hline Caldeiras com multiciclone & 500 & 2 \\
\hline Caldeiras sem retentor de fuligem & $4000-6000$ & $15-25$ \\
\hline
\end{tabular}

Emissões de poluentes em caldeiras a bagaço de cana (50\% de umidade)

\begin{tabular}{|c|c|}
\hline Poluente & $\mathrm{kg} /$ ton bagaço \\
\hline $\mathrm{SO}_{2}$ & 0 \\
\hline $\mathrm{NO}_{\mathrm{x}}$ & 0,6 \\
\hline $\mathrm{CH}_{4}$ & 0 \\
\hline $\mathrm{CO}$ & 0 \\
\hline Particulados & 0,6 \\
\hline
\end{tabular}

Emissões de poluentes a partir de óleo Diesel

\begin{tabular}{|c|c|c|c|c|}
\hline \multicolumn{5}{|c|}{ Óleo Diesel } \\
\hline Poluente & $\mathrm{kg} /$ litro OD & $\mathrm{kg} / 1000$ litros & $\mathrm{g} / \mathrm{MJ}$ & $\mathrm{kg} / \mathrm{I} \mathrm{OD}$ \\
\hline $\mathrm{CO}_{2}$ & 2,6501 & - & 80 & 3,077 \\
\hline $\mathrm{SO}_{2}$ & 0,0037 & 3,74 & 0,09 & 0,0035 \\
\hline $\mathrm{NO}_{\mathrm{x}}$ & 0,0402 & 40,2 & 0,99 & 0,0381 \\
\hline $\mathrm{CH}_{4}$ & 0 & 0 & 0,22 & 0,0085 \\
\hline $\mathrm{CO}$ & 0,0143 & 14,3 & 0,99 & 0,0381 \\
\hline Particulados & 0,0055 & 5,48 & 0,104 & 0,004 \\
\hline
\end{tabular}




\section{ANEXO V - CUSTO DE CONEXÃO DE GERAÇÃO COM O SISTEMA DE DISTRIBUIÇÃO}

\section{1 Objetivo}

O objetivo deste Anexo é estabelecer um modelo simplificado para o cálculo do custo de conexão de uma geração distribuída a um sistema de distribuição.

\section{V .2 Hipóteses de trabalho}

São assumidas as seguintes hipóteses de trabalho:

- A subestação de geração de energia é constituída por um transformador elevador cuja tensão secundária é igual à tensão de operação do sistema de distribuição, ao qual da linha de transporte de energia que se conectará;

- A conexão da linha de transporte da geração até o sistema de distribuição é realizada sem subestação de conexão ou chaveamento;

- A linha de transporte da geração é dedicada a esse fim;

- A tensão de operação da linha de transporte é de 13,8 kV ou de 69 kV;

- As linhas são montadas sobre postes de concreto;

- O custo da faixa de passagem é desprezado (servidão);

- São consideradas 3 bitolas de cabos, de alumínio, a serem utilizados: 336MCM, 477MCM, 556MCM;

- A máxima queda de tensão na linha de transporte deve ser inferior a 4\%;

- A linha de transporte pode ser de circuito simples ou duplo, conforme a potencia a ser transmitida seja:

- 1 circuito simples para transporte de até $5 \mathrm{MW}$, em 13,8 kV;

- 1 circuito simples para transporte de até $30 \mathrm{MW}$, ou $69 \mathrm{kV}$;

- 1 circuito duplo para transporte de até $5 \mathrm{MW}$ a $10 \mathrm{MW}$, em 13,8 kV;

- 2 circuitos duplos para transporte de até $10 \mathrm{MW}$ a $20 \mathrm{MW}$, em 13,8 kV; 
- 3 circuitos duplos para transporte de até $10 \mathrm{MW}$ a $20 \mathrm{MW}$, em 13,8 kV;

\section{V.3 Metodologia}

Considerando que o custo operacional de uma linha é a soma do custo de amortização e o custo das perdas, o condutor escolhido é aquele que apresenta menor custo operacional.

Por meio das curvas de custo operacional dos condutores considerados versus a corrente equivalente de perdas (aquela que se percorrer continuamente o condutor provoca a mesma perda do que a resultante do ciclo de carga, ou seja o produto do fator de perdas pela perda máxima) é possível obter as intersecções que determinam os intervalos de utilização econômica dos cabos, conforme ilustra a figura abaixo, por exemplo, para os seguintes parâmetros :

$$
\begin{gathered}
\text { Custo.da.linha }\left(\frac{R \$}{\mathrm{~km}}\right)=\text { Custo.do.cabo }\left(\frac{R \$}{\mathrm{~km}}\right)+\text { Custo.da.posteação }\left(\frac{R \$}{\mathrm{~km}}\right) \\
C_{\text {oper }}=f_{\text {amor }} \cdot C_{\text {cabo }}+C_{\text {poste }}+3 . f_{\text {per }} \cdot R \cdot I_{\text {max }^{2}} \cdot\left(\left(\frac{8760}{f_{\text {carga }}} \cdot C_{e n}\right)+C_{\text {dem }}\right) \text { em } \mathrm{R} \$ / \mathrm{km},
\end{gathered}
$$

Onde:

$C_{\text {oper }}=f_{\text {amor }} \times C_{\text {cabo }}+C_{\text {poste }}+3 f_{\text {per }}$ R leq max $^{2}\left(8760 / f_{\text {carga }} \times C_{\text {en }}+C_{\text {dem }}\right)$

$\mathrm{C}_{\text {oper }}=$ custo operacional $(\mathrm{R} \$ / \mathrm{km})$

$f_{a m o r}=$ fator de amortização de capital

$\mathrm{C}_{\text {cabo }}=$ custo do cabo $(\mathrm{R} \$ / \mathrm{km})$

$C_{\text {poste }}=$ custo da posteação $(R \$ / k m)$

$f_{\text {per }}=$ fator de perdas

$\mathrm{R}$ leq $_{\max }^{2}=$ perdas máxima $(\mathrm{kW})$

$\mathrm{f}_{\text {carga }}=$ fator de carga

$\mathrm{C}_{\text {en }}=$ custo da energia $\mathrm{R} \$ / \mathrm{kWh}$ )

$\mathrm{C}_{\mathrm{dem}}=$ custo da energia $\mathrm{R} \$ / \mathrm{kW}$ ) 


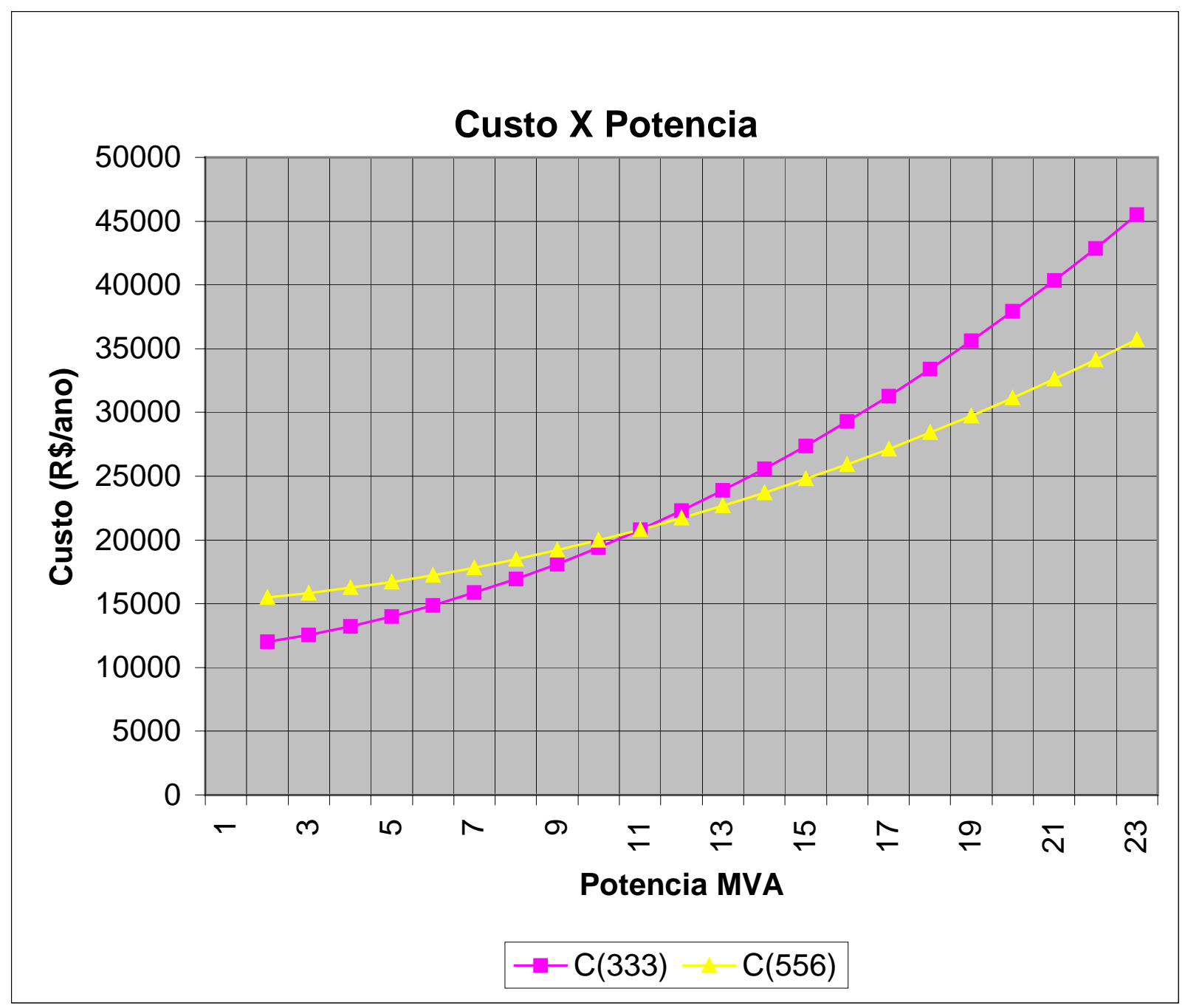




\section{ANEXO VI - ESTUDO DE CASO - MICRO REGIÃO PORTO SEGURO}

Informações Técnicas da Tecnologia

\begin{tabular}{|c|c|c|c|}
\hline Descrição do dado & Altern. 1 & Altern. 2 & Altern. 3 \\
\hline Identificação da Máquina & GE5 & MCI5 & TVBM20 \\
\hline Tensão Nominal, em kV & 13,8 & 13,8 & 13,8 \\
\hline Potência nominal, em MW; & $4 \times 5,5$ & $4 \times 5$ & 20 \\
\hline Rendimento Global , em \%; & 30,7 & 38,0 & 35,0 \\
\hline Rate Heat, em kJ/kWh; & 9730 & 9477 & 8000 \\
\hline Consumo espec. ISO I/ MWh & & 330 & \\
\hline Consumo espec. ISO m ${ }^{3} / \mathrm{MWh}$ & 4.500 & & \\
\hline Disponibilidade, em horas /ano; & 8100 & 8600 & 8600 \\
\hline Custo de O\&M Fixo, em R\$/ kW; & 65 & 35 & 100 \\
\hline Custo de O\&M Variável, em R\$/ kWh; & 0,016 & 0,010 & 0,010 \\
\hline $\mathrm{N}^{0}$. de Empregos Gerados/MWh & 0,000228831 & 0,00733 & 0,00741 \\
\hline Custo de Instalação $\mathrm{R} \$ / \mathrm{kW}^{\text {Tecnologia empregada : }}$ & 1200 & 1900 & 3000 \\
\hline $\mathrm{CO}_{2}$ evitado ton $/ \mathrm{MWh}$ em & 0,0232 & 0,613 & 0,403 \\
\hline substituição a combustível fóssil & & & \\
\hline Emissão de CO & 1350 & 6000 & 10 \\
\hline Emissão de SO ${ }_{2}$ & - & 8,52 & 0 \\
\hline Emissão de $\mathrm{NO}_{2}$ & 153 & 10 & 80 \\
\hline Emissão de MP $\left(\mu \mathrm{Mg} / \mathrm{m}^{3}\right)$ & 107 & 234 & 230 \\
\hline
\end{tabular}

Características dos Combustíveis

\begin{tabular}{|l|c|c|c|}
\hline & GN & Bioóleo & $\begin{array}{c}\text { Bagaço de } \\
\text { cana }\end{array}$ \\
\hline Poder Calorífico Inferior $\left(\mathrm{kcal} / \mathrm{Nm}^{3}\right)$ ou $(\mathrm{kJ} / \mathrm{kg})^{\star}$ & 8500 & 8700 & $7530^{\star}$ \\
\hline Custo do combustível em $\mathrm{R} \$ / \mathrm{MWh}$ & 75 & 540 & 33,73 \\
\hline
\end{tabular}


Caracterização do Municípios

\begin{tabular}{|l|c|c|}
\hline \multirow{2}{*}{} & \multicolumn{2}{|l|}{} \\
\cline { 2 - 3 } & Alcobaça & Porto Seguro \\
\hline Localização Geográfica - Altitude Sede (m) & 9 & 49 \\
\hline Longitude & $-39,20$ & $-39,07$ \\
\hline Latitude & $-17,52$ & $-16,45$ \\
\hline IDH-Municipal (2000) & 0,637 & 0,699 \\
\hline População Total (2000) & 20.900 & 95.721 \\
\hline Temperatura Média Anual em ${ }^{\circ} \mathrm{C} ;$ & 24,2 & 24,4 \\
\hline Umidade Média Anual em ${ }^{\circ}$ C; & 76 & 75 \\
\hline Renda per capita Média, em R\$/ano (2000) & 116,63 & 192,78 \\
\hline Esperança de vida ao nascer,em anos (2000) & 61,15 & 64,7 \\
\hline Taxa de Alfabetização Média , em \%; & 69,69 & 81,42 \\
\hline Índice de Gini (2000) & 0,57 & 0,64 \\
\hline PIB per capita (2003) & $4.056,09$ & $2.911,00$ \\
\hline Consumo per capita Médio residencial em kWh & 14,99 & 26,44 \\
\hline Distância da CTE até a conexão rede elétrica km; & 5 & 5 \\
\hline Tensão da conexão elétrica,em kV & 13,8 & 13,8 \\
\hline \% população com renda acima de R\$ 75,50 & 44,4 & 56,64 \\
\hline No empregados formais IBGE 2000 & 490 & 17.131 \\
\hline População Ativa entre 18-60 anos IBGE 2000 & 10.141 & 51.669 \\
\hline
\end{tabular}

Padrões Nacionais de Qualidade do Ar - adaptado [33]

\begin{tabular}{|c|c|c|}
\hline & Válido para Alco & baça e Porto Segurd \\
\hline & Padrão Primário & Padrão Secundáric \\
\hline Partículas Totais em suspensão (24 horas) ${ }^{(1)} \mathrm{em} \mu \mathrm{g} / \mathrm{m}^{3}$ & 240 & 240 \\
\hline Partículas Totais em suspensão MGA ${ }^{(2)} \mathrm{em} \mu \mathrm{g} / \mathrm{m}^{3}$ & 150 & 150 \\
\hline Dióxido de Enxofre (24 horas) ${ }^{(1)} \mathrm{em} \mu \mathrm{g} / \mathrm{m}^{3}$ & 365 & 100 \\
\hline Dióxido de Enxofre MAA ${ }^{(3)} \mathrm{em} \mu \mathrm{g} / \mathrm{m}^{3}$ & 80 & 40 \\
\hline Monóxido de Carbono em 1 hora ${ }^{(1)} \mathrm{em} \mu \mathrm{g} / \mathrm{m}^{3}$ & 40.000 & 40.000 \\
\hline Monóxido de Carbono em 8 horas ${ }^{(1)} \mathrm{em} \mu \mathrm{g} / \mathrm{m}^{3}$ & 10.000 & 10.000 \\
\hline Dióxido de Nitrogênio em 1 hora ${ }^{(1)} \mathrm{em} \mu \mathrm{g} / \mathrm{m}^{3}$ & 320 & 190 \\
\hline Dióxido de Nitrogênio MAA ${ }^{(3)} \mathrm{em} \mu \mathrm{g} / \mathrm{m}^{3}$ & 100 & 100 \\
\hline
\end{tabular}




\section{Outros dados relevantes ao caso}

\begin{tabular}{|l|c|c|}
\hline $\begin{array}{l}\text { Multas e penalidades por falha de suprimento na barra de } \\
\text { geração por motivos intempestivos em \% fatura }\end{array}$ & $\begin{array}{c}\text { Alcobaça } \\
\text { vezes o preço } \\
\text { de venda }\end{array}$ & $\begin{array}{c}10 \text { vezes o preço } \\
\text { de venda }\end{array}$ \\
\hline $\begin{array}{l}\text { Custo atribuído à emissão de uma tonelada de } \mathrm{CO}_{2} \text {, em } \\
\mathrm{R} \$ / \text { ton de } \mathrm{CO}_{2}\end{array}$ & 30,00 & 40,00 \\
\hline $\begin{array}{l}\text { Disponibilidade de dendê e bagaço mamona em ton na micro } \\
\text { região }\end{array}$ & 1788 & 1788 \\
\hline Custo do transporte do combustível, em $\mathrm{R} \$ /$ ton/km & 8 & 8 \\
\hline
\end{tabular}

(1) Dendê em Caravelas - 1300 ton e em Alcobaça - 450 ton. Bagaço Mamona em Medeiros Neto - 38 ton 